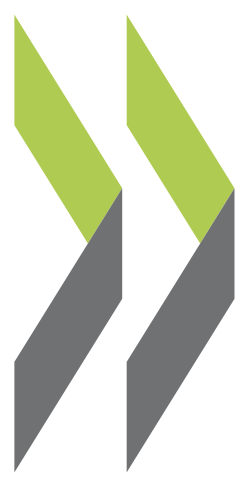

SIGMA Papers No. 48

\title{
Civil Service in the Western Balkans
} Professionalisation Jan-Hinrik Meyer-Sahling 

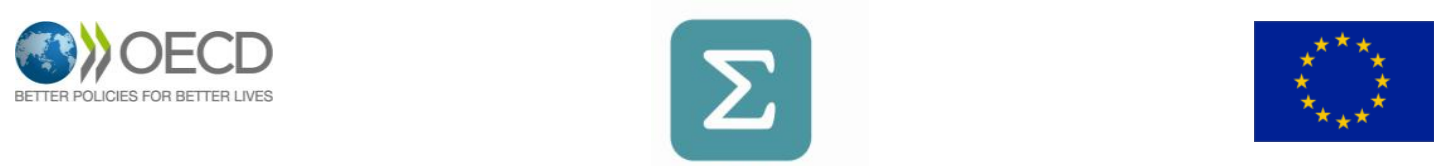

\section{SIGMA}

Support for Improvement in Governance and Management

A joint initiative of the $O E C D$ and the EU, principally financed by the EU

\section{Civil Service Professionalisation in the Western Balkans Jan-Hinrik Meyer-Sahling}

SIGMA PAPER No. 48

This document has been produced with the financial assistance of the European Union. The views expressed herein can in no way be taken to reflect the official opinion of the European Union, and do not necessarily reflect the views of the OECD and its member countries or of the beneficiary countries participating in the SIGMA Programme.

This document and any map included herein are without prejudice to the status of or sovereignty over any territory, to the delimitation of international frontiers and boundaries and to the name of any territory, city or area. 


\section{THE SIGMA PROGRAMME}

The SIGMA Programme - Support for Improvement in Governance and Management - is a joint initiative of the OECD and the EU, principally financed by the EU.

In 2012, SIGMA supports the public governance reform efforts of the following countries:

- EU Candidates and Potential Candidates - Albania, Bosnia and Herzegovina, Croatia, the former Yugoslav Republic of Macedonia, Kosovo*, Montenegro, Serbia and Turkey.

- European Neighbours - Algeria, Armenia, Azerbaijan, Egypt, Georgia, Jordan, Lebanon, Moldova, Morocco, Tunisia and Ukraine.

SIGMA provides assistance in the following areas:

- Legal Framework and Civil Service Management: Civil service and human resources management; Administrative law and justice; Regulatory policy.

- Public Finance Management: Public expenditure management; Public internal financial control; External audit.

- Public Procurement.

- Policy-making and Co-ordination: Policy development, co-ordination and implementation.

- Strategy and Reform.

SIGMA uses a variety of support mechanisms:

- Advice on reforms, design and implementation of strategies and strategic development plans;

- Analysis and assessment of legal frameworks, methodologies, systems and institutions;

- Peer reviews and assistance;

- Drafting of studies, handbooks and other reference material;

- Methodological, technical and strategic input to optimise other Commission assistance;

- Training;

- Support to networks of policy-makers and practitioners.

Further information on SIGMA: www.sigmaweb.org

\section{OECD 2012}

All requests for permission to reproduce or translate this publication for commercial or non-commercial purposes should be submitted to rights@oecd.org

* This designation is without prejudice to positions on status, and is in line with UNSCR 1244/99 and the ICJ Opinion on the Kosovo Declaration of Independence. 


\section{TABLE OF CONTENTS}

THE SIGMA PROGRAMME $\quad 2$

ACKNOWLEDGEMENT $\quad 4$

EXECUTIVE SUMMARY $\quad 5$

Approach 5

Findings $\quad 6$

Recommendations $\quad 8$

1. INTRODUCTION

2. ANALYTIC STRATEGY 12

3. TEN DOMAINS OF CIVIL SERVICE MANAGEMENT

3.1. Reform programmes 17

Declining support for European principles of administration 18

3.2. Civil service laws $r$

Wide acceptance of civil service laws $\quad 22$

3.3. Central management 25

Contested central civil service management $\quad 26$

3.4. Recruitment 32

Ineffectiveness of merit recruitment procedures $\quad 33$

3.5. Tenure 40

Towards the de-regulation of civil service tenure rules 40

3.6. Senior civil service 44

Persisting politicisation of the senior civil service $\quad 44$

3.7. Performance management $\quad 50$

Towards performance management as a disciplinary tool 50

3.8. Salary management $\quad 54$

Salary management between transparency and a lack of incentives $\quad 54$

3.9. Training $\quad 60$

Limited capacity of civil service training systems 60

3.10. Integrity management in the civil service $\quad 65$

$\begin{array}{ll}\text { Limited effectiveness of civil service integrity management } & 66\end{array}$

4. DISCUSSION AND CONCLUSION

$\begin{array}{ll}\text { Comparison across levels of institutionalisation } & 71\end{array}$

Reform trajectories $\quad 77$

Credibility of the European perspective $\quad 77$

Conditional effectiveness of international assistance including SIGMA

Clarification and update of the European principles of administration $\quad 81$ 


\section{ACKNOWLEDGEMENT}

This paper has benefited from the help and support of many people. In particular, I would like to thank the country experts from the Western Balkan states: Ansi Shundi (Albania, Kosovo), Damir Ahmetovic (Bosnia and Herzegovina), Dubravka Prelec (Croatia), Aleksandra Tanja Trendafilova (the former Yugoslav Republic of Macedonia), Ivica Ivanovic and Marija Cimbaljevic (Montenegro), and Aleksandra Rabrenovic (Serbia). I am also indebted to Marija Zurnic and Tim Veen from the University of Nottingham for research assistance and collaboration on the project. Special thanks, finally, go to Christian van Stolk, Barbara Janta and Janice Pedersen from RAND Europe for being excellent partners on this project.

Jan-Hinrik Meyer-Sahling 


\section{EXECUTIVE SUMMARY}

This report examines the professionalisation of the civil service in seven Western Balkan states: Albania, Bosnia and Herzegovina, Croatia, the former Yugoslav Republic of Macedonia ${ }^{1}$, Kosovo, Montenegro and Serbia. In the case of Bosnia and Herzegovina, the civil service is analysed separately for the state level (henceforth $\mathrm{BiH}$ ), the Federation level (FBiH) and the Republika Srpska (henceforth RS).

The report builds on SIGMA Paper No. 44 (2009), which assessed the sustainability of civil service reforms in the new EU member states of Central and Eastern Europe after their accession to the European Union (henceforth EU) in 2004. SIGMA Paper No. 44 found that Central and Eastern European states had made significant progress towards the establishment of professional and impartial civil service systems before joining the EU. Yet after accession only a minority of countries, namely the Baltic States, continued to invest in the professionalisation of the civil service.

Accordingly, the paper examines, first, the degree to which civil service systems 'fit' the European principles of administration and, second, the drivers of civil service professionalisation, in order to gain insights with regard to the sustainability of reforms in the Western Balkans.

\section{Approach}

The report analyses civil service professionalisation in the Western Balkans against the European principles of administration as the guiding concept employed by the European Commission and SIGMA for the reform of the civil service in pre-accession states. The degree of fit with European principles is assessed along ten domains of civil service management ('width of institutionalisation') and three levels of institutionalisation ('depth of institutionalisation').

The domains of civil service management are:

(i) the adoption and implementation of civil service reform programmes that fit the European principles of administration;

(ii) the adoption and implementation of civil service laws;

(iii) the establishment of central civil service management institutions with sufficient capacity for effective cross-governmental management of the civil service;

(iv) the establishment of merit recruitment systems including open competition for entry, professional examination and independence from political interference;

(v) the establishment of civil service tenure rules that stabilise public administration and protect employment in the civil service;

(vi) the development of a professional and de-politicised senior civil service system including prospects of merit promotion to management positions;

1 The term 'Macedonia' is used in the figures for formatting purposes only. 
(vii) the establishment of fair and effective performance management systems for civil servants;

(viii) the establishment of predictable and transparent salary systems as well as adequate salary levels;

(ix) the establishment of training systems that provide for regular and effective training and development of civil servants;

(x) the establishment of integrity management systems that provide guidance for ethical behaviour in the civil service and regulate, monitor and sanction conflict of interest in the civil service.

The three levels of institutionalisation are:

(i) formal rules;

(ii) rule implementation (cf. management practices);

(iii) rule internalisation (cf. attitudes of civil servants towards European principles of administration).

For the analysis, the report relies on three types of empirical evidence. First, legal material and both governmental and non-governmental reports on civil service developments in the Western Balkan states were screened and analysed. Second, personal interviews were conducted in the winter of 2010/2011 with senior civil servants, members of parliament and outside observers of the civil service in the Western Balkan states.

Third, a web-based survey was conducted in the Western Balkan states. The survey targeted both managing and non-managing civil servants of the ministerial bureaucracy. It sought to uncover their attitudes towards the European principles of administration in order to tap into the value basis of civil servants in the Western Balkans. The survey was conducted in local languages. It was distributed by the central civil service management structures across all ministries of the central government apparatus. Based on the empirical evidence, the report reflects the state of civil service management in the Western Balkan at the end of 2011.

\section{Findings}

The paper shows that the civil service in the Western Balkans provides a mixed picture of achievements and persisting weaknesses. The main weakness of civil service systems is the low degree of rule effectiveness combined with a low degree of reform sustainability. These weaknesses run through the entire region. Prospects of achieving sustainable civil service professionalisation are low for Western Balkan states.

Specifically, civil service systems in the Western Balkans have achieved a medium to high degree of fit with European principles with regard to the formal-legal level of institutionalisation. At the formal-legal level they outperform the new EU member states from Central and Eastern Europe except Lithuania. None of the civil service systems in the Western Balkans is in need of radical change. Major reorganisations are likely to create more costs than benefits especially in the short and medium term. Yet all formal-legal frameworks have weaknesses that call for an incremental upgrade.

Second, at the level of rule implementation, the analysis identifies an intermediate fit with European principles at best. Formal rules of civil service management are widely applied in the Western Balkans. 
Minor implementation gaps can be identified for most countries but there is no evidence of systematic evasion of formal civil service rules.

The main weakness of civil services in the Western Balkans is the lack of rule effectiveness. Even if formal civil service rules exist and even if they are routinely implemented, they often fail to achieve the outcomes that they are meant to achieve. The lack of rule effectiveness is particularly pertinent in the domains of senior civil service management, integrity management and performance management. The same weaknesses apply to the areas of recruitment and civil service training, albeit to a lesser extent.

Civil service systems perform better with regard to employment protection, salary management and central civil service management. However, the recent trend in the area of civil service tenure clearly points away from the European principles of administration and towards a de-regulated, private sectorbased model of employment. Salary systems achieve a considerable degree of transparency and predictability but at the expense of providing performance incentives for civil servants.

Central civil service management institutions have achieved a considerable degree of institutionalisation, especially when considering the state of affairs a decade ago. Yet central institutions lack enforcement powers and, above all, they remain contested. Their position must be considered as uncertain, which is particularly worrying as proactive reform supporters and entrepreneurs are mainly found in central management institutions rather than anywhere else in the politico-administrative system. Strengthening their position will be vital for the future professionalisation of the civil service in the Western Balkans.

The two domains with the relatively highest degree of fit include the presence and implementation of civil service laws and the presence and continuous renewal of civil service reform programmes. These are the two domains of civil service professionalisation with the lowest thresholds for achieving success. Civil service laws are indeed widely accepted in the region. By contrast, recent civil service reform programmes indicate a gradual shift away from the European principles of administration as applied by the European Commission and SIGMA towards a more discretionary approach to civil service management.

Third, the analysis shows that civil servants are, by and large, supportive of the principles of professional civil service management. The attitudes are very positive with regard to the principles of de-politicisation and meritocracy. The main mismatch concerns the persisting reluctance to accept a partial centralisation of civil service management functions and the growing attraction of de-regulated, discretionary approaches to salary management and civil service tenure. In the domain of integrity management there is clearly a lack of awareness of the nature of conflict of interest in the public sector.

While the analysis identifies important differences across domains of civil service management and levels of institutionalisation, it shows that cross-national differences are remarkably small. In the overall assessment, the civil service of most countries reaches an intermediate degree of fit with European principles of administration. This finding takes into account considerable progress in the area of formallegal institutionalisation but a low quality of implementation.

Kosovo's civil service is the only case that retains an overall medium to low degree of fit. However, Kosovo has recently started to implement a new formal-legal framework and can be expected to catch up with the other Western Balkan states shortly. In contrast to the new EU member states of Central and Eastern Europe, civil service systems in the Western Balkans are generally characterised by a high degree of similarity in terms of formal institutions, the quality of implementation and the attitudes of civil servants towards European principles of administration. 
The trajectories of civil service reform in the Western Balkans can be traced to the interplay of international and domestic factors. Both the international and domestic contexts provide opportunity structures that create incentives for politicians and domestic administrative policy-makers to invest in the professionalisation of the civil service.

The paper argues that the domestic conditions are by and large unfavourable for civil service professionalisation. However, the international context, in particular signals and assistance provided by the EU, has the capacity - under specific conditions - to alter the opportunity structure of domestic politicians and administrative policy-makers. The sustainability of reforms is therefore considered as low unless the international community remains actively involved in civil service reform. Civil service professionalisation in the Western Balkans is hence by and large externally dependent.

The impressive progress in civil service professionalisation in the Western Balkans between the late 1990s and mid 2000s is strongly related to the positive European perspective that governments, administrative reformers and citizens perceived at the time. The weakening of a European perspective for the Western Balkan states since the mid 2000s has reinforced the negative political incentives that originate in the domestic political, economic and social context.

The influence of international aid and assistance, including support from SIGMA, has been largely conditional on the presence of a European perspective. The effectiveness of international assistance has hence declined since the mid 2000s. During the first half of the 2000s, the European principles of administration were largely uncontested as the main paradigm for civil service reform.

However, over the last few years, they have been increasingly challenged by managerial approaches to civil service management that entail a larger degree of discretion for civil service managers. The contestation of the European principles as the most desired concept to guide civil service reform and the lack of specific guidelines for institutional reform have increasingly undermined the capacity of the international community to direct and monitor reform efforts in the Western Balkans. Further reform slippage is likely unless the European principles are reviewed, clarified and re-fashioned in the area of civil service reform.

The prospects of civil service professionalisation differ only marginally between Western Balkan states. However, in Montenegro, the prospects of successful civil service professionalisation are slightly more promising thanks to a higher degree of political continuity and the revival of a credible European perspective in 2010.

\section{Recommendations}

Recommendations are specifically drawn for the role of the European Commission and SIGMA rather than for individual countries. Country-specific recommendations will be formulated at a later stage on the basis of the report. The Western Balkan states are a difficult terrain for a proactive approach to civil service professionalisation. While international support can claim considerable achievements during the first half of the 2000s, limited progress has been made since then in all Western Balkan states except Kosovo. A future EU approach to civil service reform will have to take this trajectory into account.

1. Clarification: It will be necessary to update, review and clarify the very content of the European principles of administration insofar as civil service reform in pre-accession states is concerned. The growing contestation of the European principles in recent reform programmes and by civil servants themselves calls for a clarification of the reform principles. Indeed, it is worth 
considering the re-launch of the European principles as a wider initiative for better governance in Europe.

2. Operationalisation: Any clarification of the European principles will have to be followed by an operationalisation, that is, the specification of guidelines for institutional reform and for the observation of management practices in the civil service. It will be necessary to derive 'minimum standards' that are applicable across borders, together with 'menus' that provide options for context-sensitive reform and development. Without clearer guidelines for operationalising European principles in the area of civil service reform, it will be difficult for the European Commission and SIGMA to effectively direct future civil service developments in the Western Balkans.

3. Communication: Once the reform principles have been reviewed, clarified and operationalised, it will be necessary to invest in the communication of the content, purpose and benefits of the principles advocated by the European Commission and SIGMA. It is evident that the European principles of administration tend to remain poorly understood and not widely known among civil servants. The lack of understanding applies both to the nature of the European principles and to the benefits of the development of professional, de-politicised and impartial civil service systems in the Western Balkans in general and for EU accession in particular.

4. Monitoring: The European Commission and SIGMA will have to strengthen their efforts to monitor public administration reform developments, including civil service reform. Monitoring involves both legal developments as well as the quality of implementation. In particular, it might be necessary to develop new instruments for the continuous assessment of the quality of rule implementation.

5. Coordination: The European Commission and SIGMA will have to consider a closer coordination of their activities in order to enhance their ability to direct civil service reform developments in the Western Balkans. While the European Commission has the authority to criticise and potentially sanction the behaviour of candidate and potential candidate states, SIGMA has the expertise to provide advice and to conduct well-informed oversight. SIGMA might become more of an 'arm of the Commission' that advises the Commission and monitors on its behalf. Yet the effectiveness of closer coordination will also depend on the willingness of DG Enlargement country desks to take advantage of SIGMA's expertise.

6. Credibility: Successful interventions from abroad will ultimately depend on the ability of the European Commission and SIGMA to credibly signal to Western Balkan states that civil service professionalisation matters. Due to the absence of an acquis communautaire for public administration and the lack of a negotiation chapter on public administration reform, civil service issues generally suffer from a problem of credible conditionality. In particular, the European Commission will have to consider new instruments to raise the importance of civil service reform in the accession process. Tying civil service reform measures to specific rewards that can be handed out during the accession process is one option. A second option involves mechanisms for structured dialogue on public administration reform between the European Commission and SIGMA on the one hand and the governments of Western Balkan states on the other.

7. Domestic management capacity: Special attention will have to be paid to the capacity of central civil service management structures in the Western Balkan states. Unless central civil service 
offices are able to rely on strong prime ministerial support, ministries of public administration provide a more promising opportunity structure for effective management and for acting as a bridge between the domestic level and the European Commission and SIGMA.

8. Constitutional entrenchment: Given the lack of natural domestic political incentives for civil service professionalisation, it will be necessary to consider alternative mechanisms for the entrenchment of institutions and practices. Civil service unions have rarely acted as modernising forces in the Western Balkans. The role of business has been ambiguous in countries with under-developed market economies. Hence, the European Commission and SIGMA will have to rely primarily on institutional mechanisms to lock in current and future levels of civil service professionalisation. Constitutional entrenchment of the civil service and rigid amendment rules are the most promising instruments, and are consistent with the aim of strengthening the rule of law in the Western Balkans. 


\section{INTRODUCTION}

This paper examines the professionalisation of the civil service in seven Western Balkan states: Albania, Bosnia and Herzegovina, Croatia, the former Yugoslav Republic of Macedonia, Kosovo, Montenegro and Serbia. In the case of Bosnia and Herzegovina, the civil service is analysed separately for the state level (henceforth $\mathrm{BiH}$ ), the Federation of Bosnia and Herzegovina (FBiH) and the Republika Srpska (henceforth RS). The District of Brcko is not considered in this report. Specifically, the paper examines, first, the degree to which civil service systems 'fit' the European principles of administration and, second, the drivers of civil service reform and professionalisation in order to gain a better understanding of the sustainability of reforms and the options for a future EU civil service policy.

The report builds on SIGMA Paper No. 44 which assessed the sustainability of civil service reforms in the new EU member states of Central and Eastern Europe after their accession in 2004. SIGMA Paper No. 44 found that Central and Eastern European states had made significant progress towards the establishment of professional and impartial civil service systems before joining the EU. Yet after accession only a minority of countries, namely the Baltic States, continued to invest in the professionalisation of the civil service. Therefore, for the Western Balkan states, concerns over the degree and sustainability of civil service professionalisation have emerged at an early stage.

The paper is divided into three parts. The first part presents the analytical framework and the empirical data used to prepare the paper. The second part is the main part of the report. It is divided into ten sections, each of which examines one domain of civil service management. The third part summarises the main findings and discusses the drivers of and obstacles to reform trajectories, with a view on the sustainability of the civil service professionalisation in the Western Balkans. 


\section{ANALYTIC STRATEGY}

This section first outlines the analytical framework used for the study of civil service professionalisation in the Western Balkans in the context of EU integration and goes on to describes the empirical research strategy chosen to generate data for assessing civil service professionalisation.

The European Commission's approach to public administration reform, including civil service professionalisation, is based on the application of the European principles of administration. The concept of the European Administrative Space was developed in the late 1990s by SIGMA on behalf of the European Commission (see SIGMA Papers No. 23 and 27). It considers that public administration at all levels of the European Union system of multi-level governance embodies basic principles such as the rule of law and therefore legal certainty and predictability, openness and transparency, legal accountability, efficiency and effectiveness. Each principle includes secondary principles of administration, for instance political neutrality, impartiality, professional integrity and fair and equal treatment of public administration staff.

The European principles are derived from the Treaties of the European Union, case law of the European Court of Justice, and administrative law codes of EU member states. It is assumed that, at least in theory, they are shared in the legal frameworks, daily practices and cultures of public administration in the EU and its member states. In practice, the European principles become a benchmark for the assessment of the quality of public administration. The European principles do not assume that all member states converge towards an identical institutional framework. Rather, the diversity of institutional frameworks among EU member states indicates that different institutional solutions are assumed to embody the same kind of legal principles, as long as minimum institutional standards are met.

The European principles of administration have not been formulated explicitly in a charter for European governance or as a code for good administrative practice for the EU and candidate countries in order to derive a clear model for civil service reform. ${ }^{2}$ Yet a closer reading of the European Commission's Progress Reports and of the annual civil service and administrative framework assessments that SIGMA conducts for the European Commission provides a list of minimum standards for the reform of the civil service and their relation to the European principles of administration. The minimum standards have remained remarkably stable since the formulation of these principles in the late 1990s.

For analytical reasons, they can be divided between ten domains of civil service management and three levels of institutionalisation (see also Meyer-Sahling $2009^{3}, 2011^{4}$ ).

The ten domains capture the width of institutionalisation, that is, how widely the European principles of administration are incorporated in civil service management.

\footnotetext{
2 The European Code on Good Administrative Behaviour published by the European Ombudsman and adopted by the European Parliament in 2001 provides an additional important reference point but it does not provide guidelines for the reform of the civil service.

3 "The Sustainability of Civil Service Reforms in Central and Eastern Europe Five years After Accession", SIGMA Paper 44, 2009.

$4 \quad$ "The Durability of EU Civil Service Policy in Central and Eastern Europe after Accession", Governance, Volume 24, Issue 2, April 2011.
} 
They are:

1. The adoption and implementation of civil service reform programmes in the context of wider public administration reform programmes compatible with the European principles of administration. Reform programmes indicate government commitment to civil service reform in accordance with the European principles.

2. The adoption and implementation of a civil service law, including a clearly defined scope of the civil service, in order to promote the rule of law in public administration as well as principles of legal predictability and accountability.

3. The establishment of central institutions responsible for the cross-governmental management of the civil service with sufficient capacity to ensure civil service management in accordance with the European principles across the public administration.

4. The establishment of civil service recruitment systems, including open competition for access, standardised examination mechanisms and de- politicised selection and appeal, in order to promote principles of openness, merit recruitment, and fair and equal treatment, as opposed to informality, incompetence, favouritism and political patronage.

5. The establishment of civil service tenure rules and practices that promote stability in the civil service and ensure management in accordance with principles of political neutrality and fair and equal treatment of civil servants.

6. The existence of senior civil service systems that ensure merit selection and promotion to management ranks of the civil service as opposed to politicisation, in order to ensure principles of effectiveness and political neutrality of the civil service.

7. The development of performance management in the civil service, in particular by means of establishing performance evaluation systems that promote principles of effectiveness in the civil service while ensuring the fair and equal treatment of civil servants.

8. The establishment of civil service salary systems that ensure principles of predictability, transparency and fairness while promoting the effectiveness of the civil service by means of setting adequate salary levels and providing incentives for performance.

9. The establishment of civil service training systems, including civil service training institutions, training programmes and training participation to support principles of effectiveness and professional competence in the civil service.

10. The establishment of integrity management systems that induce ethical behavior in the civil service, in particular by means of regulating political and professional conflicts of interest, and that develop monitoring and sanctioning mechanisms in order to ensure principles of impartiality, political neutrality and professional integrity in the civil service.

The three levels of institutionalisation refer to the depth of institutionalisation. They are:

1. Formal rules, which refers to formal-legal structures governing civil service management. 
2. Rule implementation, which refers to the effective application of formal rules in the daily practice of civil service management.

3. Rule internalisation, which refers to the attitudes of civil servants towards European principles of administration.

The three levels of institutionalisation are not entirely independent from each other. It is conceivable that formal rules, rule implementation and rule internalisation are congruent. Alternatively, it is conceivable to find incongruence between levels of institutionalisation. For instance, if formal rules and rule implementation are incongruent, some formal rules are typically ignored in practice. Similarly, when the levels of rule implementation and rule internalisation are incongruent, it can be assumed that civil servants disapprove of current management practices and possibly rules.

The degree of (in)congruence of the levels of institutionalisation has implications for the sustainability of civil service professionalisation. When formal rules, rule implementation and rule internalisation are congruent, it can be expected that institutional regimes are stable and, by and large, uncontested. By contrast, it can be expected that a regime is less stable the larger the degree of incongruence across the three levels of institutionalisation. Incongruence is likely to be a greater problem if practices and attitudes deviate from the European principles of administration. If civil servants' attitudes are largely supportive of European principles, conditions for professionalisation are better.

However, general congruence and/or constructive incongruence across levels of institutionalisation are no more than one dimension of civil service reform sustainability. Sustainability might be best understood as a combination of ideas, interests, institutions and environmental conditions that maintain a high degree of fit with European principles of administration, prevent a decline from a high degree of fit, and promote change towards a high degree of fit in settings that do not (yet) meet standards of civil service professionalisation as conceptualised by the European Commission and SIGMA. Hence, sustainability does not equal durability of reforms but rather a dynamic concept that, ideally, implies learning from and adaptation to changing circumstances.

In order to identify combinations that promote, or fail to promote, civil service professionalisation, this paper concentrates on the interplay of international and domestic factors. In particular, it examines the opportunity structures for politicians and administrative policy-makers that are created by international and domestic contexts. The interplay of both contexts is especially important when considering international conditions that have the capacity to influence the opportunity structures resulting from the domestic context.

In a context with domestic conditions that support civil service professionalisation, these kinds of international conditions might supplement, reinforce and possibly accelerate reforms. In a context with unfavourable domestic conditions for professionalisation, these international conditions might develop the capacity to transform the incentives of domestic politicians and administrative policy-makers and hence change the course of civil service reform. Therefore, these international transformative conditions have a very important role for the future orientation of the European Commission's civil service policy towards the Western Balkans.

The next sections of this paper examine the degree to which civil service systems in the Western Balkans have institutionalised European principles of administration in both width and depth. Questions of sustainability will be addressed in each section to the extent that they are applicable. The conclusions of 
this paper will return to the interplay of domestic and international factors and their impact on civil service reform sustainability in the Western Balkans.

The analysis of the fit of civil service systems with the European principles of administration is based on three types of empirical evidence. First, legal material and both governmental and non-governmental reports on civil service developments in the Western Balkan states were examined in order to assess the formal legal institutionalisation of the European principles of administration.

Second, approximately $20-25$ personal interviews were conducted in each country during the winter of 2010/2011 with senior civil servants, members of parliament and outside observers of the civil service such as academics and NGO representatives. Interviewees were selected in order to gather as many viewpoints as possible and to generate a balanced picture of the state of civil service professionalisation. The personal interviews have been relevant for the assessment of all three levels of institutionalisation and all domains of civil service management.

Third, two web-based surveys were conducted in the Western Balkan states. One survey was designed as a so-called 'expert survey' of internal and external observers of the senior civil service in the region. The survey explicitly targeted the domain of senior civil service management and included additional questions on the role of the European Commission and SIGMA in civil service development.

The second survey targeted managing and non-managing civil servants of the ministerial bureaucracy. It sought to uncover their attitudes towards the European principles of administration and represents a key tool for assessing the level of rule internalisation in the Western Balkan states. Knowledge of civil servants' attitudes also provides important cues with regard to their support for current and future reform initiatives. A lack of support for the European principles among civil servants seriously undermines the prospects of successfully institutionalising them in the near future. The survey was conducted in local languages. It was distributed by the central civil service management structures across all ministries of the central government apparatus.

Civil servants were asked to assess basic statements on a five point Likert scale that ranges from 'strongly disagree' to 'strongly agree'. These statements aim to capture individual European principles of administration as well as institutions that are associated with the European principles.

In order to obtain a valid representation of the results, the paper shows the mean response for individual items on a scale of 1 (strongly disagree) to 5 (strongly agree). Where appropriate (i.e. when items scale together and hence measure the same underlying concept), specific indices that combine answers to several questions were constructed. In general, the construction of indices is preferable because it increases the reliability of the results.

Generally speaking, a score of 4 and above is considered as a positive and desirable measurement to identify a good fit with European principles of administration. It means that at least 50 per cent of the respondents supported a European principle of administration.

Any score below 4 indicates an insufficient fit with the European principles of administration. For instance, a mean score of 3 indicates 'neutral' support but it indicates that well under 50 per cent of the respondents agree with the statement in relation to a European principle. Finally, a score around 2 indicates a clear disagreement with the European principle. This is clearly the least desirable outcome when assessing the quality of civil services in the Western Balkans. 
For the purpose of this paper, we consider a score of 4 and above to indicate a high degree of fit with European principles, a score of 3 to 4 a moderate degree of fit and a score below 3 as a low degree of fit.

Overall, the survey generated 3838 responses that were used for the analysis. The large variation in response rates between countries implies that the reliability of the results differs across them. Data reliability is much higher for Croatia, Serbia and Albania than for RS. The number of responses for Kosovo, the former Yugoslav Republic of Macedonia, Montenegro, BiH and FBiH is sufficiently high to assume a reasonable degree of data reliability. Despite potential reliability problems in RS, the decision was taken to include the results as there is for the time being virtually no data available. Future research will have to be undertaken in order to gain a more reliable picture of civil service management.

Table 1.1. Survey Responses

\begin{tabular}{|c|c|}
\hline Albania & 705 \\
\hline Croatia & 1316 \\
\hline Kosovo & 129 \\
\hline The former Yugoslav Republic of Macedonia & 220 \\
\hline Montenegro & 256 \\
\hline Serbia & 805 \\
\hline FBiH & 230 \\
\hline RS & 54 \\
\hline BiH & 343 \\
\hline Total & 3838 \\
\hline
\end{tabular}




\section{TEN DOMAINS OF CIVIL SERVICE MANAGEMENT}

\subsection{Reform programmes}

This section examines the domain of civil service reform programmes. It concentrates on whether civil service reform programmes have been adopted and are being implemented, the extent to which they are related to wider public administration reform programmes, and the extent to which the objectives of the reform fit the European principles of administration. Reform programmes do not directly address a particular European principle of administration but their status indicates government commitment to civil service reform in general and the European principles of administration in particular. In this regard, reform programmes provide important signals for politicians, civil servants and the public, as well as the international community, with regard to their importance and the ideas that underlie civil service reform.

An important caveat should be raised at this stage. Reform programmes belong to the world of declarative if not symbolic politics. There is usually no guarantee that the (good) intentions of a reform programme make their way into the statute book. Even if they do, it takes time for legislative changes to have a lasting effect on civil service management practices.

Moreover, the development of a reform programme is typically the most predictable and least complex part of the process of civil service professionalisation. Small change teams prepare reform programmes within a short and predictable (i.e. plannable) period of time. By contrast, the implementation of civil service reform programmes is more complex. It takes a long time and involves a multitude of actors often with diverging interests.

Using reform programmes as an indicator for gauging progress made towards the alignment of the civil service with the European principles of administration might therefore be highly misleading. In particular, reform programmes that are based on the logic of 'the more change, the better' run the risk of undermining the professionalisation of public administration rather than improving it. Reformism, understood here as the rapid succession of reforms that aim at major structural, behavioural and attitudinal change in public administration, tends to create uncertainty, instability and unpredictability both among civil servants and in the environment of public administration. Administrative capacity is reduced rather than strengthened.

Reform programmes should therefore aim at lengthening time horizons of politicians and civil servants rather than shortening them. There should be space for the analysis of the situation and the development of a strategy that explicitly addresses the European principles of administration and their operationalisation into institutional choices.

Consensus-building measures in the process of reform preparation are also essential. They may require time but are a necessary condition for the prospects of implementation in a context of multiple actors. Without adequate attention to implementation, reform programmes are unlikely to generate positive results.

The overall record of Western Balkan states in the area of civil service reform programmes remains positive. All countries have a civil service reform programme in place, which is, to varying degrees, connected to a wider public administration reform programme. This positive finding indicates general government commitment to civil service reform. However, the recent trend points towards a declining 
compatibility of civil service programmes with the European principles of administration. The normative basis for the future of civil service professionalisation is increasingly contested, undermining successful Europeanisation in accordance with the policy template advocated by the European Commission and SIGMA.

\section{Declining support for European principles of administration}

All Western Balkan states have adopted and are implementing civil service reform programmes. However, they differ with regard to the stage they are at in the reform cycle, the reform ambition, the ideas underlying the reforms, and the process of reform development including the role of international organisations.

First, the former Yugoslav Republic of Macedonia and Montenegro have very recently adopted new reform programmes. The former Yugoslav Republic of Macedonia passed the new 'Public Administration Reform Programme' at the end of 2010. Montenegro passed the reform programme called 'AURUM' in March 2011. In both cases, civil service reform is an essential part of the reform programmes.

The two civil service reform programmes share a wide scope. For instance, in the former Yugoslav Republic of Macedonia, the programme affects all areas of civil service management except the salary system. The radical approach to reform is best symbolised by the establishment of a new Ministry of Information Society and Administration. The former Ministry of Information Society took over functions from the former Civil Service Agency (CSA), the Government Secretariat and the Ministry of Justice. The CSA has not been abolished but has lost most of its functions. It has been renamed the Agency for Administration (AA) and has retained its status as an autonomous agency accountable to Parliament.

In addition, the reform programme proposes a shift towards managerial approaches of civil service management. For instance, the de-regulation of procedures for the dismissal of civil servants in accordance with private sector methods was envisaged. Even if the official reform programme nominally refers to the European principles of administration, many proposed reform measures clearly imply a shift away from these principles.

The most recent reform programme in Montenegro is less radical than in the former Yugoslav Republic of Macedonia. Even if all areas of civil service management are affected, the focus of the programme is on upgrading the existing system. The Human Resource Management Authority under the Ministry of Interior is supposed to be strengthened, the merit principle is supposed to be strengthened in the areas of recruitment and promotion and the implementation of the appraisal system is supposed to be improved. Yet, as is the case in the former Yugoslav Republic of Macedonia, Montenegro's reform programme envisages a de-regulation of dismissals from the civil service and hence a partial shift away from the European principles of administration.

The other countries differ in that they tend to be at the other end of the reform cycle. Serbia, for instance, updated the 2004 Public Administration Reform Strategy in 2009. Several aspects of the reform update had already been addressed by the 2009 amendment of the Civil Service Law, for example by giving the central Human Resource Management Service (HRMS) a smaller role in the area of recruiting civil servants. The declining capacity of the central civil service management institution, made worse by staff cuts taken in response to the economic crisis, challenges the progress towards the European principles. The Ministry of Public Administration, which is in charge of reform development, is currently focusing on the preparation of a new training strategy. 
In Bosnia and Herzegovina, the 2006 Public Administration Reform Strategy has recently entered a third stage that will guide activities between 2011 until 2014. The focus is on the improvement of implementation and the upgrading of the civil service's legal basis.

In Kosovo, the 2007 Public Administration Reform Strategy was updated in the autumn of 2010 to cover the period until 2013. Following the adoption of the Civil Service Law and the Salary Law in the spring of 2010 , the focus is naturally on the implementation of these new laws.

Albania passed a new Inter-Sectoral Public Administration Reform programme in 2009. It was prepared in the context of the National Strategy for Development and Integration which covers all areas of public policy and was adopted by the Albanian Government in 2008. The reform programme concentrates on the reform of the civil service and in particular on the revision and adoption of a new civil service law. Even if a new reform programme has formally been passed, the contents are not new. They reflect the failed attempts to revise the Civil Service Law in 2005 and 2008. The 2009 reform programme makes a new attempt to revise the civil service system. A new amendment of the Law had been prepared at the time of writing but it remains to be seen whether the political stalemate in the country can be overcome this time round.

Croatia is in an intermediate position. The 2008 State Administration Reform Strategy (SARS) expired in 2011 but, according to the Ministry of Administration, the preparation of a new strategy has already begun. In parallel, the Croatian Government passed in 2009 the Civil Service - Human Resource Development Strategy 2010-2013. The programme was prepared with assistance from Denmark. It covers a wide range of civil service management issues and in particular training and development, including the establishment of a school of public administration. The existence of two reform programmes indicates problems of temporal coordination of reform matters in Croatia. It remains to be seen to what extent the civil service reform programme can be implemented without renewing the public administration reform strategy.

The Croatian example points to the role of the international community in civil service reform programme development in Western Balkan states. International organisations, in particular the European Commission, have generally played an instrumental role in public administration reform in the Western Balkans over the last decade. The EU has mobilised governments in the region to prepare reform programmes. The ambitious reform programme in the former Yugoslav Republic of Macedonia is directly related to the criticism raised in EC Progress Reports. The growing political importance of the issue generated prime ministerial support for public administration reform. The programme was prepared by the Government Secretariat in the context of an EU IPA project. In other words, the EU even co-financed the development of a reform programme whose outcome of which is only partially compatible with the European principles of administration.

In Montenegro, the preparation of the reform programme was strongly influenced by the prospects of gaining candidate status in the autumn of 2010. As in the former Yugoslav Republic of Macedonia, it generated high-level political support. A Government Council for Public Administration Reform headed by a Deputy Prime Minister was established. Montenegro received support from various international organisations such as the UNDP, the World Bank, the Council of Europe and SIGMA.

The EU has also played an important role in keeping civil service reform on the agenda in the other countries. Persistent criticism in the annual Progress Reports of Albania, Croatia, BiH and Kosovo regularly directed government attention back to problems of civil service professionalisation. 
Serbia differs from the other countries in that it has received much less criticism from the European Commission in terms of civil service development. While reform initiatives in the mid 2000s were strongly influenced by World Bank and SIGMA advice, the current reform initiatives have to some extent been a bottom-up initiative taken by the Ministry of Public Administration. Faced with the need to update the reform programme, the Ministry conducted an internal needs analysis and inter-ministerial consultation processes. As a result, the reform initiative may be less ambitious, but as a home grown initiative it is likely to be more effective and sustainable.

Finally, the countries differ with regard to the paradigms underlying the current reform programmes. In general, the reform programmes clearly refer to the European principles of administration and good governance principles as the normative basis of reform. Yet the recent programmes developed in Montenegro and the former Yugoslav Republic of Macedonia have incorporated a large portion of New Public Management (NPM) thinking, which is based on the assumption that private sector methods can be transferred to the public sector. In particular, the former Yugoslav Republic of Macedonia's programme makes prominent references to performance management, 'competency management' and 'dismissal like in the private sector'. In fact, several of these measures have already been included in the new Civil Service Law.

NPM approaches to civil service management are not unknown in the region. Yet so far civil service reform has been dominated by a continental European Rechtsstaat ${ }^{5}$ model that reflects the EC's interpretation of the European principles of administration.

The emerging NPM turn implies that the Western Balkan states are catching up with the new EU member states of Central and Eastern Europe. In these states, NPM has gained prominence since the early 2000s and in particular EU accession. The diffusion of NPM ideas is reinforced when Western Balkan states receive direct advice from new member states that have experimented with NPM ideas. This is the case, for example, of the former Yugoslav Republic of Macedonia.

The growing popularity of NPM approach reflects the rise of a young generation of political leaders, who often have experience in the private sector. Indeed, key decision-makers in the areas of administrative reform and implementation in the former Yugoslav Republic of Macedonia and Montenegro belong to this group.

At the same time, the incorporation of NPM ideas reflects a sense of dissatisfaction and disappointment with reform progress over the last five to six years. All Western Balkan states except Kosovo made considerable investments in public administration institution-building in the first half of the 2000s. The lack of progress and the perception of a persistently ineffective public administration have reduced the appeal of the European principles as the dominant paradigm for guiding civil service reform.

In effect, some reformers advocate a change of paradigm because they hold the model of civil service reform that was adopted in the early 2000s responsible for the persistent ineffectiveness of public administration. As the remainder of this report will show, this interpretation fails to acknowledge the

Rechtsstaat is a concept in continental European legal thinking, originally borrowed from German jurisprudence, which can be translated as "legal state", "state of law", "state of justice", or "state of rights". It is a "constitutional state" in which the exercise of governmental power is constrained by the law, and is often tied to the Anglo-American concept of the rule of law. In a Rechtsstaat, the power of the state is limited in order to protect citizens from the arbitrary exercise of authority. In a Rechtsstaat the citizens share legally based civil liberties and they can use the courts. A country cannot be a liberal democracy without first being a Rechtsstaat. 
failure to properly implement a civil service reform model that is based on the European principles of administration.

The terms of the civil service reform discourse have clearly changed in the Western Balkans. The European principles of administration continue to figure prominently in reform programmes, not least because they constitute an official EU stance towards pre-accession states. However, the lack of conceptual clarity provides enough room for the re-interpretation of the European principles by candidate and potential candidate states. Explicitly or implicitly, NPM-inspired reform initiatives are likely to play a growing role in the Western Balkans. The increasing contestation of the normative basis of EUdriven civil service reform creates a major challenge for the future of the European principles as advocated by the European Commission and SIGMA.

\subsection{Civil service laws}

This section examines the status of civil service laws as a separate domain of civil service professionalisation. It focuses on the adoption and implementation of civil service laws as the main legal frameworks governing the civil service and on the clarity of the scope of these laws. The European Commission and SIGMA have paid particular attention to the adoption and implementation of civil service laws by pre-accession states ever since the formulation of the administrative capacity criterion for EU membership at the Madrid Council in 1995. Civil service laws are at the centre of the European principles of administration, and in particular of the rule of law, legal predictability and accountability.

It is important to recognise that the adoption of a civil service law is not sufficient for the professionalisation of the civil service. As with the adoption of reform programmes, the adoption of civil service laws does not go far beyond the stage of declarative and symbolic politics. However, it is an aspect of civil service professionalisation that is relatively predictable. Moreover, it is less complex in that few actors are typically involved in the preparation, drafting and subsequent passage of the law. The main challenge is the implementation of the law and the inability to foresee many problems at the time of institutional design. The initial threshold for meeting the European standards in the domain of civil service laws is lower than in other domains.

Bearing in mind these qualifications, the overall record of Western Balkan states in this domain is positive. All countries have adopted civil service laws and at the time of writing, all countries except Kosovo had civil service laws that were fully in force. ${ }^{6}$ Civil service laws are widely accepted by civil servants and there is no indication that their existence is at risk in any of the Western Balkan states. Indeed, in the Western Balkans, civil service laws have symbolised the modernisation and Europeanisation of the civil service as well as a break with the communist past.

Yet the difficulty of professionalising the civil service beyond the adoption of civil service laws will become apparent in the next sections of this report. Moreover, this section shows that civil service laws typically suffer from ambiguous and/or inadequate definitions of scope, which undermine their capacity to ensure the principles of legal predictability and accountability of the civil service. Recent developments suggest a growing pressure on narrowing the scope of civil service laws at the top end, in particular in order to facilitate political appointments to management positions in the public administration. Close oversight of the amendment of civil service laws and secondary legislation will be increasingly important in order to prevent a silent hollowing out of legal frameworks.

6 The implementation of the Civil Service Law in Kosovo is scheduled for 2012. 


\section{Wide acceptance of civil service laws}

All Western Balkan states have adopted a civil service law over the last decade. This positive feature indicates that the Western Balkans have successfully caught up with the new EU member states of Central and Eastern Europe, which passed civil service laws in the mid 1990s and early 2000s before joining the EU.

Albania and the former Yugoslav Republic of Macedonia adopted Civil Service Laws in 1999 and 2000 respectively. In $\mathrm{BiH}$, the Office of the High Representative imposed a civil service law for $\mathrm{BiH}$ in 2002 and for FBiH in 2003. In RS, the first civil Service Law was adopted in 2003. It was replaced by a new Law in 2008 following a major overhaul of the original Law. Montenegro, Serbia and Croatia passed their civil service laws in 2004-2005. ${ }^{7}$ Croatia had already passed a first Law in 1994, ${ }^{8}$ which was replaced by a new Law in 2001. The 2005 Law therefore represents the third Civil Service Law since independence in 1991.

Kosovo was the last country to adopt a Civil Service Law in the spring of 2010. Implementation was scheduled for 2011. Due to delays in the adoption of secondary legislation in the context of political turmoil that followed the parliamentary elections of late 2010, implementation is not expected to begin before 2012. Therefore, at the time of writing, Kosovo is the only country in the region that does not yet have a fully functioning civil service law subject to implementation. As long as the new Civil Service Law is not fully implemented, a regulation on the civil service published by the United Nations Interim Administration Mission in Kosovo (UNMIK) in 2001 remains the cornerstone of Kosovo's legal framework.

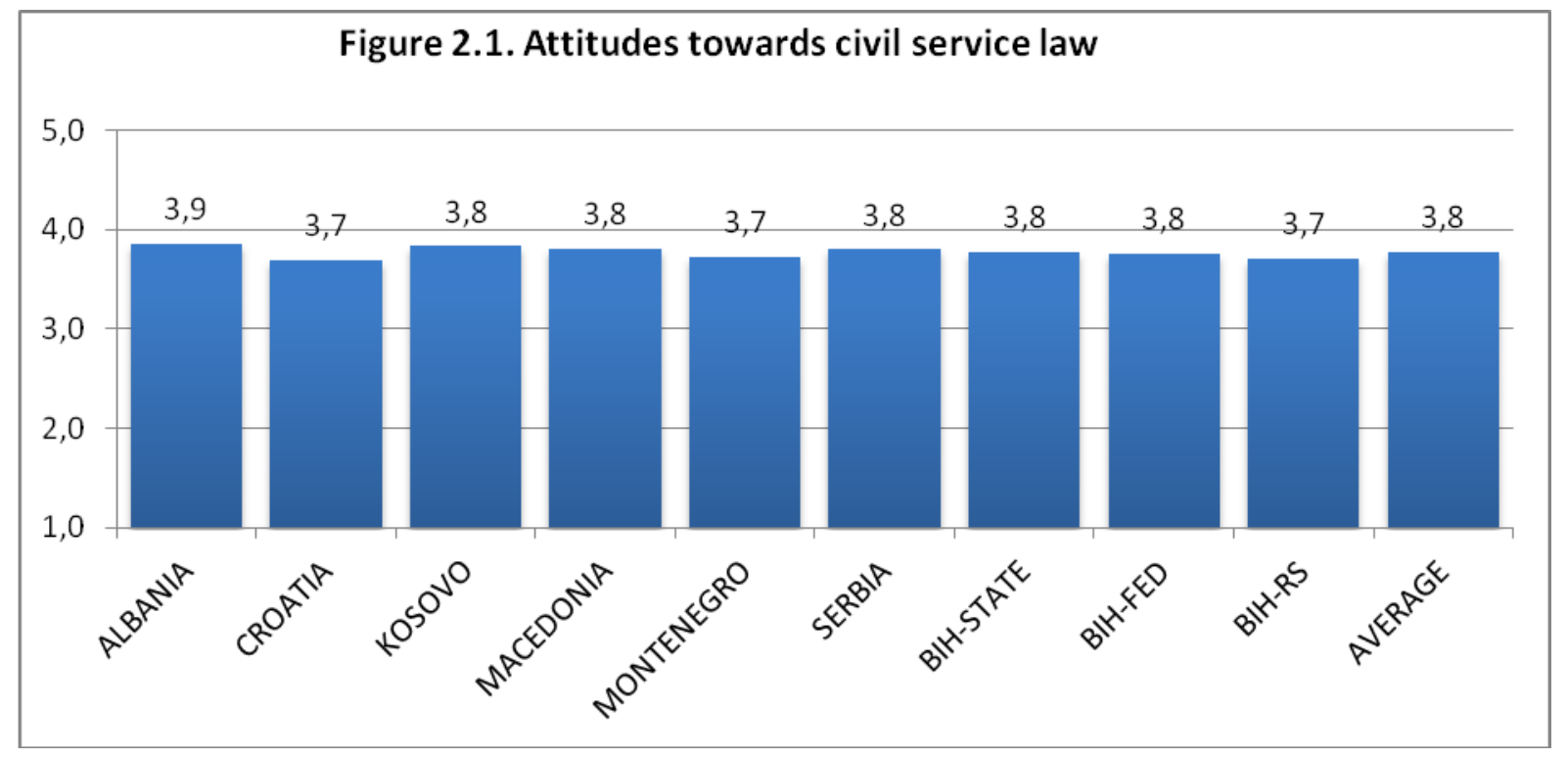

Figure 2.1 shows the level of rule internalisation in the domain of civil service laws. It shows clearly that civil service laws are widely accepted in the region. There is very little variation, with scores ranging from 3.7 to 3.9. These scores indicate a moderate to high degree of fit of civil servants' attitudes with European principles of administration in this domain.

In Montenegro, a new Civil Service Law was under preparation at the time of writing.

The Law on Labour Relations in State Organs that was passed in Serbia in 1991 under the Milosevic regime is not considered as a civil service law here. 
Civil service laws in the Western Balkans have generally defined the scope of the civil service narrowly. At the time of writing, Kosovo was an exception in that all public sector employees were covered by the 2001 UNMIK regulation. The 2010 Law brought Kosovo in line with the other countries in the region. The definitions of civil servants typically combine functional and organisational criteria. Functionally, the focus is broadly set on officials that exercise state authority while officials that exercise technical and ancillary functions are excluded from the civil service. For the large majority of civil servants in the Western Balkan states it is mandatory to have a university degree, meaning that the proportion of public officials covered by civil service laws who do not hold a university degree is small.

Organisationally, civil service laws refer to the state administration and in particular to institutions subject to central-level authority. Several civil service laws such as in the former Yugoslav Republic of Macedonia, Albania, Montenegro, $\mathrm{FBiH}$ and RS also include, at least partially, municipalities and the local administration. By contrast, uniformed employees of the state as well as employees in the health, education and cultural sectors are subject to separate legal statutes.

In several countries, civil service laws are ambiguous regarding to the scope of the civil service. For example, in the former Yugoslav Republic of Macedonia, employees of the Ministry of Interior are excluded, as are staff of the tax and customs administration. In Montenegro, there is a lack of clarity regarding the inclusion of staff in the civil service at both the central and (to an even greater extent) local level. Ambiguities in the scope of the civil service can easily be exploited politically to manipulate who is part of it and who isn't. The reliance on functional definitions of civil servants, combined with the lack of clear job descriptions, is largely responsible for this problem.

Furthermore, all countries except Croatia show a tendency to rely on temporary employment in the central administration, which is not adequately regulated and not covered by the civil service law. In the former Yugoslav Republic of Macedonia, it is typical to find large numbers of temporary employees in the central and municipal administrations. These temporary employees are subject to a separate legal status. They are recruited and rewarded differently from civil servants, most typically without much regard for the merit principle, and can be easily dismissed. According to estimates of the former Civil Service Agency, the Ministry of Finance, and of external and internal observers, approximately 20-30 per cent of central administration employees were in temporary positions at the beginning of 2010. Similarly, in Albania, it was estimated that approximately 25 per cent of central administration employees were in temporary positions. In both countries, efforts have been made to reduce the number of temporary staff following criticism by the European Commission. Yet the problem is likely to persist unless the status of temporary staff is properly regulated.

While the civil service laws generally define the scope of the civil service narrowly, they vary with regard to the extent to which they include the top level of the administrative hierarchy. In Serbia, Croatia and the former Yugoslav Republic of Macedonia, the state secretary, as the highest level manager in the ministerial bureaucracy, is formally a political appointee. In the former Yugoslav Republic of Macedonia, this provision has only been introduced recently, indicating a growing political pressure to control the civil service (also see below).

In $\mathrm{BiH}, \mathrm{FBiH}$ and RS, Albania, Kosovo and Montenegro the highest position in the ministerial bureaucracy is classified as a civil servant. However, in the latter three, it is common to find temporary appointees in the top positions. This situation undermines the principle of including the higher civil service manager in the scope of the civil service. Moreover, in $\mathrm{FBiH}$ and $\mathrm{BiH}$, there has been considerable political interest in formally turning the top position of the civil service into a political appointment and hence to take it out of the scope of the civil service law. 
The civil service's narrow scope has consequences on its actual size. For example, in Albania, the civil service has only 4,000 employees. This compares to the 90,000 employees in the public sector. In other words, less than 5 per cent of the public sector workforce is formally classified as civil servants. In the other countries, the ratio stands at around 10 per cent of the public sector workforce. In Croatia, this ratio goes up to 20 per cent, largely due to the inclusion of all employees of the Ministry of Interior

The small scope of civil service laws implies that the study and assessment of civil service systems focus on an elite that enjoys a high legal status and is located in high-level positions. The civil service can be expected to be the area of public administration with the highest level of professionalisation. Conversely, other areas of public administration are likely to demonstrate lower levels of professionalisation and hence a lower degree of fit with European principles of administration. Future assessments will have to examine in more detail the state of development in the wider public administration.

The reference above to the substitution of civil service laws in RS and Croatia points to a general problem of legal instability. Civil service laws are meant to provide legal certainty and predictability. If civil service laws are regularly replaced by new laws or if they are continuously amended, these principles become unattainable. Moreover, regular changes of the legal basis create considerable problems of implementation. In the worst case, managers ignore legal changes expecting that the next change will come sooner rather than later.

It may be understandable that the civil service laws in the Western Balkans are changed regularly when considering that these are new institutions that have only recently been established. Yet all civil service laws have undergone major revisions over the last three or four years. The most recent major change took place in the former Yugoslav Republic of Macedonia at the end of 2010 and in March 2011 after the adoption of the public administration reform programme (see above). Between the adoption of the Civil Service Law in 2000 and the summer of 2010, the Law had already undergone 17 amendments, some of which being significant.

The exception in this regard is Albania, which has not amended its Civil Service Law since its adoption in 1999. In Albania, the Constitution institutionalises a $3 / 5$ majority requirement for amending the Civil Service Law. The country's deep political polarisation around two political blocs was responsible for the failure of an amendment in 2005. New attempts to amend the Civil Service Law have been made since but have so far not even been tabled in Parliament for fear of failure.

The over-stability of the Albanian Civil Service Law has not been without trade-offs. It has increasingly presented problems of implementation for civil service managers and for the Department of Public Administration which is centrally responsible for civil service management. The super-majority requirement has made it impossible to adapt the legal framework to changes in the environment.

However, Albania's record of civil service law implementation does not rank below that of the other countries of the region. The super-majority requirement should therefore not be blamed for the inability to adapt the legal basis to problems of implementation and a changing environment. Super-majority requirements are a common feature of many modern democracies, but the polarisation between two political blocs in Albania has so far made it impossible for the political class to reach a consensus on amending the Civil Service Law. Indeed, the experience of other Western Balkan states and several new EU member states from Central and Eastern Europe suggests that the super-majority requirement may have prevented major de-regulation of the civil service in Albania since the mid 2000s. 
In particular with regard to the sustainability of civil service professionalisation, finding a higher degree of constitutional entrenchment and super-majorities that are required to amend civil service laws would be desirable. On normative grounds, it must also be recognised that an impartial and politically neutral civil service should be able to serve all democratically elected parties, which implies that today's opposition parties have a reasonable stake in the organisation and management of the civil service, as they could form tomorrow's government.

In summary, even if countries in the Western Balkans have reached a moderate to high degree of fit in terms of the adoption and implementation of civil service laws, and even if there is no sign that the very existence of civil service laws is at risk anywhere, the domain of civil service laws is not without problems. Ambiguities of scope have persisted and tendencies to inadequately narrow the scope with regard to senior civil service ranks are evident across the region. Moreover, special requirements for the amendment of civil service laws should be considered, in order to increase the sustainability of civil service professionalisation in this domain, which has major implications for all the other domains of civil service management.

\subsection{Central management}

This section examines the domain of central civil service management. Both the European Commission and SIGMA have emphasised the need to establish a central institution that has responsibilities for the cross-governmental management of the civil service and sufficient capacity to fulfil its mandate. A capable central management institution is a precondition for ensuring that the European principles of administration develop into common standards of civil service management across public administration institutions.

The European Commission and SIGMA do not stipulate the precise location and precise institutional make up of such a central body. This reflects the differences in central management structures in the old EU member states and hence the assumption that there is more than one institutional solution that can lead to the successful professionalisation of the civil service. Accordingly, the research examined the location of central management institutions, the fragmentation of central management, the centralisation of functions, and the resources that have been allocated to central institutions.

Overall, the domain of central management fits the European principles of administration remarkably well. All Western Balkan states have established at least one central civil service management institution. A wide range of management functions have been delegated to the centre, particularly when compared to the very high degree of decentralisation that still prevailed in the 1990s. In most countries, central management institutions have also acted as the main drivers of civil service reform, which gives them an important role for the future professionalisation of the civil service.

However, central management institutions suffer from a number of weaknesses, including the fragmentation of authority, a lack of enforcement capacity, and a lack of adequate resources to fulfil their role. The most worrying feature is the low degree of support for the centralisation of civil service management from other government institutions and civil servants themselves. These central institutions remain constrained in their capacity to bring about common standards of civil service management across government. Despite the contestation of central management institutions, strengthening these institutions will be critical for continuous investment in civil service professionalisation, and in particular for the improvement of the implementation record. 


\section{Contested central civil service management}

At first glance, the Western Balkan states perform well in this dimension of civil service management. All countries have established a central institution that is responsible for the cross-governmental management of the civil service. However, central management institutions differ with regard to location, the degree of fragmentation of authority, the degree of centralisation, the availability of resources, and the degree to which they are accepted by civil servants and other government institutions.

$\mathrm{BiH}, \mathrm{FBiH}$ and RS have all established independent Civil Service Agencies (CSA) that are directly responsible to the Council of Ministers. They were established in the early 2000s when Civil Service Laws were passed at the state and entity level. However, central civil service management is partially shared with Ministries of Justice in $\mathrm{BiH}$ and $\mathrm{FBiH}$ and with the Ministry of Administration and Local SelfGovernment in RS. In all three cases, reform development, legislative drafting powers and the authority to perform administrative inspections rest with the line ministries.

In Serbia, the central body is the Human Resource Management Service (HRMS), a separate Government service accountable to the General Secretary of the Government. As in Bosnia, authority is shared with the Ministry of Public Administration, which is responsible for reform development, legislative drafting and inspections. The HRMS was established in 2006 after the adoption of the Civil Service Law. The head of the HRMS was initially directly responsible to the Prime Minister. Following an amendment of the Civil Service Law in 2009, the status of the HRMS was downgraded, while that of the Ministry of Public Administration was (re-)elevated.

In Montenegro and Albania, the central civil service management bodies are autonomous within the jurisdiction of the Ministries of Interior. The Human Resource Management Authority (HRMA) in Montenegro was established in 2004 when the Civil Service Law was passed. The status of the Department of Public Administration (DoPA) in Albania is today similar. DoPA was established as early as 1994 but remained inactive until 1999. From 2000 to 2005, it was a department directly responsible to the Prime Minister. In 2005, DoPA was moved to the Ministry of Interior.

In Croatia, civil service management is located within several directorates of the Ministry of Administration, which was re-established in 2009. A Ministry of Administration existed in the 1990s but in the early 2000s public administration affairs including civil service management were moved to the Ministry of Justice. In 2004 (one and a half year before the adoption of the new Civil Service Law), a new Central State Office for Administration was established. It was at that time directly accountable to the Prime Minister.

In Kosovo, central authority rests with the Department for Civil Service Administration, which is located within the Ministry of Public Administration. The Department was set up in 2001 when UNMIK established a Ministry of Public Services. In 2010, the Ministry was re-organised as a Ministry of Public Administration. Yet some aspects of civil service management have been retained by the Independent Oversight Board, which is located in Parliament.

The former Yugoslav Republic of Macedonia has recently undergone a major re-organisation from a Civil Service Agency (CSA) located within Parliament to a new Ministry of Information Society and Administration. The CSA was established in 2000 when implementation of the Civil Service Law began. The reform programme passed in 2010 involved a transfer of many but not all responsibilities from the CSA, now re-labelled Administration Agency (AA), to the Ministry of Information Society and 
Administration. As a result, central management has moved from a unified to a divided structure, which is likely to create problems for the effective implementation of the Civil Service Law.

This overview of central civil service management structures shows a trend of moving away from independent civil service offices towards the establishment of ministries of public administration. By 2005 all countries except Kosovo and Montenegro had established an independent civil service agency at the centre of government. Since then Croatia has transferred the former agency's responsibilities to a ministry of public administration and the former Yugoslav Republic of Macedonia has done the same for many management functions. In Serbia the HRMS was significantly weakened at the expense of the Ministry of Public Administration and in Albania the department's responsibilities were moved to the Ministry of Interior.

Independent civil service agencies reflect the influence of international organisations in the early 2000s. Despite the existence of a variety of management configurations in Western democracies, independent civil service agencies were arguably the preferred institutional solution among international consultants The 'survival' of civil service agencies in $\mathrm{BiH}$ is best explained by the persisting influence of international actors. In particular, the OHR, which was directly responsible for their original establishment, remains the main guarantor of their existence, despite regular conflicts with them.

Independent civil service offices failed to survive in the new EU member states of Central and Eastern Europe after accession. In the Western Balkans, their fate has clearly been similar. Institutional rivalries in countries such as Serbia and the former Yugoslav Republic of Macedonia and the withdrawal of prime ministerial support in countries such as Albania have undermined their influence and hence institutional position.

Apart from in $\mathrm{BIH}$, the position of international organisations vis-à-vis civil service agencies has become increasingly ambiguous. For instance, EU pressure to invest in public administration reform has contributed to institutional change in Croatia. Similarly, an EU-sponsored project for the reform of public administration in the former Yugoslav Republic of Macedonia included international advisors with a known preference for ministries of public administration. In other words, the shift away from civil service agencies towards ministries of administration reflects both domestic developments and international preferences.

So far there is no evidence that ministries of public administration perform better than independent civil service agencies or management structures that are located within line ministries such as ministries of interior, justice or finance. Political leadership, and hence a seat at the cabinet table, is usually seen as one of the advantages of ministries of public administration over civil service agencies. Yet ministries of public administration tend to be politically weak and unattractive as a working place for civil servants.

Moreover, ministers of public administration cannot be expected to have special incentives to invest in civil service management in accordance with European principles of administration. As politicians, they can be assumed to seek re-election, which will inevitably direct their focus on aspects of public administration policy that attract the attention of the public. In the best-case scenario, a linkage is made between the quality of public service delivery (which is in the interest of the public) and the quality of human resources (that deliver the services). In the worst case, the focus will be on symbolic measures such as longer opening times of service delivery bureaus without any improvement in the infrastructure of public administration and the quality of the civil service. 
Even if ministries of public administration are not without trade-offs, they might over time perform better than the alternatives. The location of central management within line ministries such as ministries of finance, justice or interior runs the risk of crowding out civil service affairs in the context of large portfolios. This is a problem for DoPA in Albania, the MISA in the former Yugoslav Republic of Macedonia and the HRMA in Montenegro. Where relevant, a similar crowding out effect was visible in the new EU member states both before and after accession.

The two most effective options are hence civil service agencies that are directly accountable to the prime minister or located within strong prime minister's offices and ministries of public administration. It should be recognised that civil service agencies performed very well in the initial period following their establishment because they enjoyed support from the international community and, even more importantly, prime ministers. As long as they had prime ministerial support, they were usually able to assert their position in inter-institutional rivalries and turf wars. Once prime ministerial support was withdrawn, their position declined almost instantly. This pattern applies to all the cases discussed above. Therefore, the position of civil service agencies has been shown to be unsustainable because the support of the prime minister and the international community cannot be taken for granted in the medium and long term.

The EU should continue to support ministries of public administration in the region on condition that this support can prevent the fragmentation of authority over civil service management. The main institutional rivals in Montenegro and $\mathrm{BiH}$ at state and entity level are likely to be the Ministries of Justice, which will have to let go of a certain number of functions, as has recently been the case in the former Yugoslav Republic of Macedonia.

The discussion on the location of central management bodies further indicates problems of divided responsibilities in several Western Balkan states. Indeed, Croatia is the only country that has, by and large, unified civil service management functions in the Ministry of Administration. By contrast, in Serbia functions are increasingly divided between institutions. Over time the Ministry of Public Administration has reclaimed territory at the expense of the HRMS, in particular with regard to reform and drafting powers. In addition, the State Office for European Integration (SEIO) is involved in the provision of training for civil servants, adding one more actor to cross-governmental civil service management. The division of powers has provided opportunities for institutional blackmailing which has resulted in a curtailing of the HRMS' powers in the context of the 2009 amendment of the Civil Service Law.

An institutional division of functions also exists in the other countries, mainly in that reform development, legislative drafting and administrative inspection functions are separated from civil service management. In $\mathrm{BiH}$ and $\mathrm{FBiH}$, these powers are delegated to the Ministries of Justice and in RS to the Ministry of Administration and Local Self-Government. This situation has not led to major turf wars inside the administration but it significantly undermines the capacity of CSAs, as they are downgraded to basic administrative structures without strategic and enforcement powers.

In Montenegro, the division runs inside the Ministry of Interior, but in practice it is comparable to BiH's configuration. In addition, the Ministry of Justice has remained responsible for professional state exams, which are taken as part of the recruitment process, and for induction training for appointments to permanent positions.

In Kosovo, the former Yugoslav Republic of Macedonia and Albania, the functional overlaps are smaller but not negligible. In all three cases, the Ministry of Public Administration and/or Departments of Public Administration have to share authority with bodies located in Parliament. In Kosovo, the Independent 
Oversight Body shares powers of inspection and is involved in the recruitment procedures for directors. ${ }^{9}$ In Albania, the Civil Service Commission located in the Parliament is primarily an appeal board but it also has a role to play in the inspection of the implementation of the Civil Service Law. In the former Yugoslav Republic of Macedonia, the new Agency for Administration retains similar functions in relation to the new Ministry of Information Society and Administration.

In the former Yugoslav Republic of Macedonia and Montenegro additional divisions emerged vis-à-vis the centres of government in the context of recent reform developments. The reform programmes in both countries were developed in the Government Secretariats and by Offices led by a Deputy Prime Minister. Similarly, in Kosovo the Ministry of Public Administration initially had the lead in drafting the new legislation that was adopted in 2010 but the Office of the Prime Minister took over this role after the first draft had been prepared for submission to Parliament.

The institutional divisions are primarily the result of administrative traditions that have persisted beyond the (internationally driven) establishment of new civil service systems in the early and mid 2000s. In particular, ministries of justice had a strong role in the Yugoslav public administration. They have hence managed to retain parts of their traditional authority. By contrast, the overlaps with parliamentary bodies are primarily design experiments introduced at the time of preparation of the first civil service laws, often as a result of international advice.

Even if the negative effects of institutional divisions have been most visible in Serbia, it is evident that they generally undermine the capacity of central management institutions. Efforts should hence be made to unify management functions as much as possible in one institution such as a ministry of public administration or a civil service agency under the prime minister.

The discussion on institutional divisions leads to considerations regarding the adequate scope of functions that should be performed at the central level. The list of functions performed by central management structures in the Western Balkans is very long indeed. They include:

- Generic functions such as reform and strategy development, drafting of primary and secondary legislation, and administrative inspections of the implementation of civil service laws.

- General coordinative and administrative functions such as managing the central register, approving organisational rulebooks, job descriptions and staffing plans, preparing human resource management guidelines, convening networks and/or forums of human resource managers, preparing personnel staffing plans for government and finance ministries.

- Direct involvement in the recruitment of civil servants such as approving job announcements, preparing and placing job vacancy announcements, pre-screening applicants, organising general examinations, participating in examination and selection committees, nominating the winners of recruitment competitions, and managing professional state examinations to confirm appointment decisions.

- Supervision and administration of the performance appraisal process. procedure. 
- A wide range of functions related to training policy such as the preparation of strategies, plans, organisation of the delivery of training, management of training institutes.

- Management of integrity and disciplinary systems, in particular dealing with ethical codes, monitoring conflict of interest regulation and participating in disciplinary cases.

- Direct involvement in the management of the salary system.

- Organisation of collective bargaining processes and representation of the government in negotiations with trade unions.

- Management of appeals and complaints.

This long list of centrally managed functions demonstrates a major shift from a civil service management system that was almost entirely decentralised before 1999/2000 to a system that has become remarkably centralised. However, there are significant differences across countries.

In relative terms, Albania has the most centralised system of civil service management. Almost all functions (except collective bargaining and appeals) listed above are part of DoPA's task profile. As will be seen in the remainder of this report, this still leaves a large part of civil service management decisions with the ministries. In comparison to the other countries, DoPA plays a relatively larger role in both recruitment decisions and in the administration of the salary system.

By contrast, Kosovo has the least centralised civil service management system of the region. The DCSA has partial authority over salary policy but this is largely interpreted as a technical role of payroll management. In addition to the basic administrative and coordinative functions listed above, the DCSA is also responsible for monitoring the training policy of the Kosovo Institute of Public Administration (KIPA). Yet the DCSA has virtually no role to play in the recruitment procedure and the new Civil Service Law that will shortly be implemented will not change this situation.

The degree of centralisation in Serbia and, to a lesser extent, Croatia is similar to the situation in Kosovo, in that generic functions and basic coordinating functions are performed by central institutions but involvement in recruitment and career management is marginal. In contrast, $\mathrm{BiH}, \mathrm{FBiH}$ and $\mathrm{RS}$, the former Yugoslav Republic of Macedonia, and Montenegro are closer to the Albanian pattern in that civil service agencies are widely involved in the recruitment procedure but not in salary management. The recent establishment of a Ministry of Information Society and Administration has confirmed the level of centralisation in the former Yugoslav Republic of Macedonia.

One of the major weaknesses of civil service management throughout the region is the lack of control and enforcement capacity. All the countries have devised inspection functions in their legal basis. In several countries, inspection is separated from reform and management. This is the case in Serbia, the BIH state and entity levels and, with qualification, in Montenegro and Albania (see also above). To some extent this explains the weakness of enforcement in these countries. Inspection and enforcement are also extremely weak in Croatia, Kosovo and the former Yugoslav Republic of Macedonia. In Kosovo, inspections are only performed if they are requested by other institutions. In Croatia and the former Yugoslav Republic of Macedonia, inspection is by and large a matter of performing legal regularity checks that have no bearing on the quality of implementation. 
It is clear that the capacity of central civil service management bodies depends on both the extent to which authority is divided across institutions and on the range of functions allocated to the centre. It is difficult for the centre to shape civil service management across the state administration if authority is divided and the scope of functions is small. This is even more the case in a context of regime transformation and reform. Without a certain degree of centralisation, inducing change in civil service management practices in ministries and agencies is difficult. Therefore, a relatively high degree of centralisation is positive for the quality of civil service management practices across government institutions.

It is difficult to gauge the impact of the size of management bodies on capacity. For instance, even if Albania's DoPA performs a relatively large number of functions, it is a small body with merely 18 staff. In contrast, Serbia's HRMS has a smaller range of functions but employs 34 civil servants. In fact, there is a wide perception inside HRMS that the staff cuts that were made in 2010 in response to the IMF's demand to cut public administration employment have made it virtually impossible for the HRMS to fully perform its tasks.

Finally, we turn to the level of rule internalisation. In the survey, civil servants were questioned on their acceptance of central civil service management structures. Figure 3.1 shows the results and indicates a fairly low fit with the European principles of administration. The scores suggest that the decentralisation of civil service management is clearly favoured over (partial) centralisation. The involvement of central institutions is often considered as a form of unwanted and inconvenient interference by the ministries and by government agencies. Central institutions reduce the discretion of ministries and agencies and tend to lengthen the time needed for most procedures. The positive aspects of central involvement in civil service management are only rarely recognised by the 'customers' of central institutions.

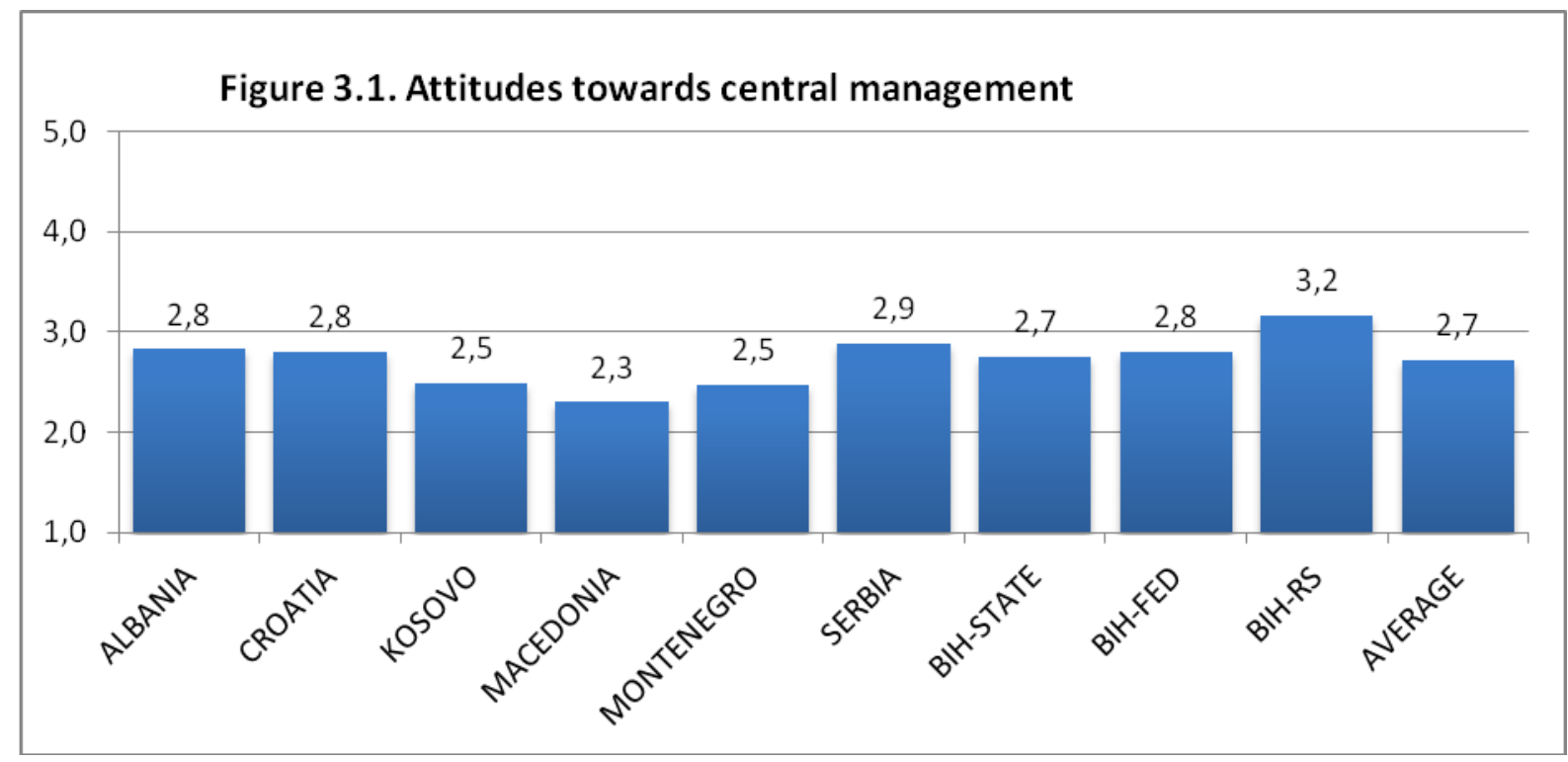

In Serbia, this opposition to central management has already led to institutional change, with the curtailing of the HRMS's authority through the 2009 amendment of the Civil Service Law. In other countries, the risk of return to a higher degree of decentralisation is also evident. For instance, it remains to be seen whether the new Ministry of Information Society and Administration in the former Yugoslav Republic of Macedonia will ever be able to assert itself as a capable institution in relation to other 
government institutions. The first signals following the re-organisation confirm the low score in Figure 3.1 and suggest that the new Ministry will not turn into a powerhouse of reform and implementation monitoring. It will therefore be important to monitor closely whether the symbolic boost of giving public administration ministerial status will be followed up by turning the new Ministry into a capable and respected actor.

Serbia's and the former Yugoslav Republic of Macedonia's situations also again highlight the limited resilience of any central management institution to challenges from both the political class and from within the public administration. The position of central management institutions in the other countries is not stronger. In general, the leadership of central management institutions has often represented the main driver of civil service reform and professionalisation in the Western Balkan countries. But their domestic support is too weak. Instead, they generate an important part of their institutional and political strength from the priorities of, and contacts with the international community. For the future of civil service professionalisation, strengthening central management institutions will be imperative. However, their position is likely to remain unsustainable for the foreseeable future if institutional safeguards are not established.

\subsection{Recruitment}

This section examines the domain of civil service recruitment. Both the European Commission and SIGMA pay particular attention to systems of open competition and merit recruitment. They are essential for bringing about civil service management that embodies principles of openness, fairness, professional competence and political neutrality. It is widely assumed that merit recruitment improves the performance of public administration and hence the prospects of successful implementation of EU policies in the Western Balkan states.

Accordingly, the research concentrates on various elements of civil service recruitment, including the mandatory advertisement of job vacancies, in particular for recruitment from outside the civil service, the existence of written and oral examination procedures, professional selection committees that take decisions free from political influence, and possibilities for appeal against the outcomes of recruitment processes.

Overall, this domain of civil service management reflects an intermediate degree of fit with European principles of administration. Western Balkan states have made major efforts to institutionalise procedures that are supposed to ensure merit-based recruitment to the civil service. Basic requirements such as compulsory advertisement of vacancies are applied in all countries. Examination by recruitment committees as opposed to unilateral decision-making by ministers and/or senior officials has been established in all countries. Basic examination procedures as well as the right of appeal against the outcomes of selection decisions also exist in all of them.

However, even if Western Balkan states present a very good record with regard to the application of merit recruitment, and even if merit institutions are widely accepted by civil servants, they perform poorly with regard to the effectiveness of merit rules. In particular, recruitment practices continue to be characterised by a high degree of informality and favouritism, the use and abuse of discretion, and a high degree of party patronage. International organisations including the European Commission have made major efforts to institutionalise merit recruitment in the Western Balkans but the social, political and economic context fails to provide conditions for the professionalisation of recruitment practices. 


\section{Ineffectiveness of merit recruitment procedures}

While all countries have invested in the establishment of merit recruitment procedures, there are considerable differences in institutional make-up and in particular in the capacity to ensure merit-based outcomes of recruitment processes. A basic dividing line exists between, on the one hand, Kosovo, Serbia, RS, Croatia and Montenegro who have a low capacity to ensure merit-based recruitment, and, on the other hand, Albania, the former Yugoslav Republic of Macedonia BiH, FBiH and RS who have a slightly higher capacity. However, it has to be recognised that the effectiveness of merit rules remains generally low across the Western Balkan states.

Looking across the region, Kosovo's recruitment system is the least capable of bringing about merit-based recruitment outcomes. At the time of writing, recruitment was regulated by the 2001 UNMIK regulation, which requires the advertisement of job vacancies. Yet selection is performed by three-person committees inside the ministries on the basis of oral examinations only. Inconsistencies in interviewing practices across ministries and agencies are widely reported. Moreover, the current system's capacity to screen applicants' competencies is very low. At the end of the procedure the permanent secretary has the discretion to choose his/her most preferred (not necessarily the highest scoring) candidates from a list.

Once the new Civil Service Law is fully implemented, ministries will be required to set a written test. The new Civil Service Law will therefore slightly improve the situation but the complete decentralisation of the examination procedure is unlikely to lead to major changes.

Serbia's recruitment system is hardly more capable of bringing about merit-based recruitment outcomes than Kosovo's system. Like in Kosovo, job vacancies have to be advertised. But in contrast, while examination committees also consist of three members, one has to be a representative of the central HRMS. In other words, there is greater potential for central control and hence for ensuring that human resource standards are respected across government institutions. In reality, the influence of the HRMS representative is very small. Key selection decisions are said to be taken by the representatives of the ministries.

Serbia's recruitment system is similar to Kosovo's in that job vacancies are advertised by the recruiting institution. This task was initially performed by the HRMS, but an amendment of the Civil Service Law passed in 2009 transferred announcement powers back to the ministries. As will be seen in this section, Serbia is also special compared to other Western Balkan states in that it does not stipulate written tests in the context of the recruitment procedures. Broad recruitment principles are issued by the Higher Civil Service Council. Even if written tests are regularly used, they remain an optional tool for the screening of candidates. At the end of the procedure, a so-called open list consisting of the three best ranked candidates is submitted to the minister, from which he/she can freely choose his/her preferred candidate. ${ }^{10}$ The low level of merit institutionalisation implies that recruiting institutions have a large degree of discretion over selection decisions.

Croatia's recruitment system is also largely decentralised. Job announcements prepared and issued by the recruiting institution are advertised on the web site of the Ministry of Public Administration. Committees of at least three people include a representative of the Ministry of Administration. All candidates have to take both a special and general examination, followed by an interview. The

10

An 'open list' allows the selection of any candidate regardless of their ranking on the list. In contrast, a 'closed list' does not provide this discretion, in that the selecting authority has to pick the top ranked candidate. 
examination is prepared and administered by the recruiting institution. The Ministry of Administration does not 'own' the process and hence has no role in ensuring common standards across institutions.

At the end of the process the minister can choose from an open list of successful candidates. This power can be delegated by ministers to state secretaries and directors but, as will be seen in the next section, their recruitment is openly politicised. The procedure therefore leaves a great deal of direct and indirect discretion in political hands. The main difference with Serbia is the requirement to pass a written test before being placed on the list of suitable candidates. This mechanism provides for a larger degree of fairness in the process and an additional instrument to screen the competences of candidates.

Montenegro's recruitment system is broadly comparable to Serbia's and Croatia's insofar as the capacity to ensure merit selection is concerned. In Montenegro, job vacancies have to be advertised by the HRMA and a HRMA representative sits on a two-person examination commission which also prepares an ad hoc written test for applicants. However, at the end of the procedure, an open list of candidates, which can potentially be very long, is passed to the minister who can make the final selection through an additional personal interview. The conditions for merit-based selection are hence very low. The minister or one of his/her subordinates can freely select among candidates that have passed the examination. A lack of consistency across competitions and a widely held view that ministers and their advisors choose whomever they prefer are widespread.

The recruitment system in RS varies in several respects from the systems discussed so far but it shares a low level of merit institutionalisation. In RS, candidates have to take a general examination that is exclusively administered by the CSA before they can apply for a vacant position. The examination procedure is comparable to the notion of concours or pool exams practiced in many Western European states. Once a vacancy arises, it is advertised by the Civil Service Agency. A committee of five, which includes two representatives from the CSA, then conducts an 'entry interview' with a short-list of applicants. The committee produces a closed list of successful candidates and the minister of the recruiting institution has to accept the list's ranking. The confirmed candidate is then appointed by the institution.

While this procedure reduces opportunities for informality and discretion, the absence of a written test in the final selection seriously undermines the capacity of the recruitment system to screen candidates and to overcome problems of unfair treatment. However, an upgraded version of RS's recruitment system might indeed provide a way forward for the reform of recruitment systems in the Western Balkans.

The recruitment systems in $\mathrm{BiH}, \mathrm{FBiH}, \mathrm{Albania}$ and the former Yugoslav Republic of Macedonia differ from the cases discussed so far in that they are more centralised and more standardised. Furthermore, in $\mathrm{BiH}$ and $\mathrm{FBiH}$, opportunities for the exercise of discretion were until recently considerably lower. On paper, the merit system is relatively more institutionalised in $\mathrm{BiH}$. Job vacancies are advertised by the CSA and committees of five include three CSA appointees, meaning that the recruiting institution is in a minority position. The CSA pre-screens applicants with regard to formal criteria. Eligible candidates have to pass a general written test prepared and administered by the CSA before passing a specialised written test that assesses the requirements for the advertised position. Successful candidates are interviewed and a closed list of candidates is submitted to the minister. The confirmed candidate is then appointed by the CSA.

The role of ministers is hence significantly reduced. Ministers retain the right to reject the list but a new competition cannot be run before six months. The minister has no more than a veto right, which is attached to temporal conditions. In institutional terms, this procedure is superior to the other configurations found in the Western Balkans and most of the new EU member states. However, in 
practice, the procedure does not run as smoothly as envisaged by law. As will be discussed in more detail below, informal influence mongering takes place at virtually all stages of the recruitment process.

Until recently, the procedure in $\mathrm{FBiH}$ was nearly identical to that of $\mathrm{BiH}$. However, committees of five included only two representatives of the central CSA, which increased the influence of recruiting institutions. The main change was introduced in 2010, when a new government decree stipulated the submission of an open list to the minister for selection. The list is meant to be sorted in alphabetical order, which implies that the selecting minister has no indication of the performance of candidates in the examination process. Moreover, there is no limit with regard to the number of candidates put on the list. Despite the existence of centralised and standardised elements, it is evident that the recruitment procedure has become very discretionary.

The persistence of discretionary power is also characteristic of the recruitment systems in Albania and the former Yugoslav Republic of Macedonia. On the one hand, both countries provide for the central advertisement of vacancies. Moreover, representatives of DoPA in Albania and the AA (formerly CSA) in the former Yugoslav Republic of Macedonia are represented on the selection panels. In the former Yugoslav Republic of Macedonia, candidates have to pass both a general and a specialised exam. In Albania, a specialised exam suffices. At the end of the process, an open list with the three highest scoring candidates is submitted to the recruiting institution. In the former Yugoslav Republic of Macedonia, the state secretary has the discretion to freely choose his/her preferred candidate from the list. In Albania, this discretion rests with the direct superior but in practice it is unusual for selection decisions to be taken without consulting the minister or one of his/her close advisors Personal interviews conducted revealed that ministers regularly do not choose the top-ranked candidate from the list.

An outline of the recruitment procedure in all nine settings indicates that the basic components of merit recruitment procedures are indeed institutionalised across the region. Yet a considerable degree of institutional variation has emerged between countries. More centralised, standardised and less discretionary systems in $\mathrm{BiH}$ and, until recently, in $\mathrm{FBiH}$ co-exist with highly decentralised, fairly unstandardised and highly discretionary systems in Kosovo and Serbia. Moreover, even if the formal rules of recruitment show a relatively high degree of fit with European principles, they tend to suffer from a number of deficiencies. At least four pathologies can be singled out, all of which undermine the extent to which recruitment decisions can be considered as 'meritocratic'.

(1) Several institutional choices have turned out to be dysfunctional in the Western Balkans context and, as a result, have undermined trust in merit institutions. Initially most recruitment systems opted for a 'phased' approach to competition. In the first phase, a vacancy is advertised for the civil servants of the recruiting institution. If no candidate is found, the vacancy is re-advertised for candidates from within the civil service. Then, and only if no internal candidate has been found, a public announcement of the vacancy is made. While this approach was chosen (and advocated by international organisations) in order to give internal candidates an advantage and hence to promote a career civil service in the Western Balkans, it has not been successful. The phased approach typically takes far too long, with recruitment procedures of 4-6 months being common rather than exceptional. In an institutionally dynamic environment, this is seen as too long, in particular by managers who want to fill vacant positions. Several countries such as Serbia, have responded to this problem by abolishing the phased approach to recruitment. However, it can be argued that this loss of support for the initial institutional solution has bred informality and attitudes that favour the circumvention of procedures that will be difficult to eliminate in the future. 
(2) Civil service systems in the region are largely position-based systems, even if recruitment systems were meant to provide incentives for the eventual emergence of career systems. As a consequence, each and every vacancy within the civil service tends to require an announcement followed by an examination procedure. The procedure not only takes a lot of time, as argued above, it is also costly and has further undermined the credibility of the examination procedure. In BIH state level, for instance, announcing vacancies in all official languages in official publications and in several local newspapers is a requirement. Competitions are hence becoming very costly.

Furthermore, many competitions turn out to be fake competitions, as the winner is known in advance before the start of procedure. For instance, if a superior wants to promote a civil servant inside an institution, announcing the vacancy is usually a requirement. If the identity of the person who will get promoted is widely known, it becomes difficult to find applicants and competitions are undermined as credible selection procedures.

In countries like Albania, the institutional requirements are especially dysfunctional since a competition is only valid if at least four persons apply. Personal interviews conducted with civil servants and outside observers in Albania suggest that expected winners of competition procedures need to ask their friends and colleagues to apply in order to meet the quorum.

Under these circumstances, informality becomes the norm, even if the formal procedure was originally established with a good intention. Even worse, and even if civil servants are generally in favour of written and oral examinations as a means of selecting candidates, this situation significantly damages the credibility of the current recruitment systems.

(3) One of the main weaknesses of examination systems is their inability to properly screen the competencies of candidates. According to the interviews conducted, the threshold for passing general examinations is usually very low (and it appears to be low even for specialised examinations), meaning that the pass rates tend to be high. Typically, a large proportion of applicants is screened out by failing to meet formal requirements or by failing to turn up at the exam (e.g. the former Yugoslav Republic of Macedonia). Yet pass rates of 70-80 per cent imply that examinations do not discriminate between candidates even if that should be their purpose. Moreover, there is usually a lack of differentiation in examination requirements. Senior officials have to pass the same kind of general exam as trainees or other civil servants without any management responsibilities.

Under these circumstances, examinations become a procedural requirement without any substantive purpose, which further undermines the credibility of the examination system. The high pass rates also strengthen the discretionary powers of ministers and state secretaries, in that they enjoy the freedom to choose from an even longer list of candidates. Examinations should clearly be retained in future recruitment systems, but one of the first reform steps should involve upgrading their content.

The problem of low thresholds also concerns the so-called professional state exams that civil servants in countries such as Croatia, Serbia and Montenegro have to take at the end of their probation period. In Croatia, for instance, personal interviews revealed that exams are kept deliberately easy in order to make sure that everybody passes the exam. Therefore, the professional state exam has no purpose whatsoever when it comes to identifying civil servants' competency levels and is effectively nothing more than a procedural hassle.

(4) The culture of discretion, informality and rule circumvention is reinforced by the presence of parallel routes of entry into the civil service. In particular, the reliance on so-called temporary appointments has 
significantly undermined the credibility of the merit-based system in the Western Balkans. In most cases, temporary appointments are not regulated by the civil service law but by separate legislation. For example, in the former Yugoslav Republic of Macedonia, temporary staff are hired by private personnel recruitment agencies who then 'lease' their staff to state institutions. This regulation was adopted in 2006 and successive governments have discovered the advantages of a flexible employment system for the public sector. The number of temporary appointees employed at any point in time is not know, with estimates ranging between 25 and 35 per cent of the total workforce of institutions meant to be staffed by civil servants.

Temporary staff are hired without being subject to any recruitment procedure, which contradicts the notion of merit based recruitment into the state administration. Most commonly, temporary staff subsequently apply for 'proper' civil service jobs in order to change their status. The credibility of the civil service competition procedure was further undermined by the fact that insiders in temporary jobs were effectively selected before the competition was announced.

Following pressure from the European Commission, the Prime Minister issued a decree stipulating that the proportion of temporary staff should be reduced to 2 per cent of the workforce. All temporary staff who wanted to stay in the public administration had to go through the civil service recruitment procedure. Hence, a large number of competitions tailored for temporary staff were held in 2010 and 2011. European Commission pressure had the unintended effect of reinforcing informal recruitment.

Albania's and Serbia's practice of making temporary appointments is very similar to that of the former Yugoslav Republic of Macedonia. For instance, in Albania, even inside observers admitted that in some ministries, 100 per cent of new civil servants had been on temporary contracts before winning competition procedure. Similar estimates do not exist for Serbia but the practice of progressing from temporary to permanent employment is virtually identical. In both Albania and Serbia, the proportion of temporary staff has recently been capped (10 per cent in Serbia, 2.5 per cent for Albania) but the cap has so far failed to stop the entrenched practice and is unlikely to do so in the future.

In Montenegro, the situation is even more peculiar in that temporary appointments are not foreseen by the Civil Service Law or by other legislation applying to state institutions. Temporary appointments are hence an illegal practice that persists even though the state audit office has criticised it in public reports.

Croatia is the only country that has properly regulated temporary appointments in the civil service law. The problem of temporary staff running for permanent jobs and undermining the openness of competition procedures also exists in Croatia. However, the requirements to advertise temporary posts and limits on the duration of temporary appointments have to be seen as small steps in the right direction.

It is clear that the practice of making temporary appointments has for the time being had a detrimental effect on the credibility and the effectiveness of recruitment procedures in the Western Balkan states. Examinations have become rules that exist for their own sake. They are followed but are not trusted and their effectiveness in bringing about merit recruitment that is free from informality and patronage is very low.

The strikingly low effectiveness of merit institutions in the Western Balkans can be traced to these institutional deficiencies. However, social, political and economic conditions further undermine the capacity of merit recruitment institutions to bring about merit outcomes. 
(1) Merit recruitment procedures tend to conflict with the requirements of ethnic representativeness that is fundamental for the identity of several Western Balkan states. In the former Yugoslav Republic of Macedonia, the requirement for ethnic representativeness was established by the 2001 Ohrid Agreement. It requires that state institutions demonstrate so-called passive representativeness, that is that the proportion of ethnic minorities in state bodies should reflect the proportion of ethnic minorities in society as a whole. In particular, the Ohrid Agreement meant that ethnic Albanians were to enjoy preferential access to the civil service. Quotas for the recruitment of ethnic minorities are fixed annually. Candidates are selected centrally by the Secretariat for Implementation of the Framework Agreement. After passing the examination procedure, they are allocated to state institutions.

While the practice of increasing passive representation would appear to have been highly successful in numerical terms, it presents a challenge for the credibility of the merit recruitment system. Even though state institutions have to submit their requirements, they tend to be allocated more employees than they have asked for. In many cases, there is no work for new civil servants, and indeed, offices and computers are not even available. In many cases, officials recruited through the Ohrid system receive a civil servant salary but do not actually spend their working day in the office.

The policy might be considered as successful in promoting social peace and integration, yet it appears to have facilitated the politicisation of the civil service. Even if regular procedures are nominally followed, their inability to guarantee relative merit selection of candidates has helped to undermine the credibility of the competition procedure. Other factors should not be discounted but the challenge of reconciling the principles of ethnic representativeness and merit recruitment are likely to have reduced the rule effectiveness of the recruitment system.

In $\mathrm{BiH}$, ethnic representativeness is also part of the constitutional make up of the country and features in the Civil Service Law as a general principle that has to be respected. Yet, contrary to the situation in the former Yugoslav Republic of Macedonia, there is no formal procedure regulating the interpretation of the ethnic representativeness principle. Instead, the recruitment system is based on merit rules, as outlined above. The research conducted found that the ethnic representativeness principle is indeed applied in practice. Members of selection committees are very much aware of the ethnic distribution of their institutions. The kind of ethnic background desired, if not required, from a winning candidate is usually clarified in advance. Informal practices, in this case in order to achieve ethnic representativeness, are therefore an essential element of the recruitment process.

The issue of ethnic representativeness does not have the same importance in all countries. In $\mathrm{BiH}$ and $\mathrm{FBiH}$ and in the former Yugoslav Republic of Macedonia, it is one factor that certainly conflicts with the merit orientation of the recruitment system. In Serbia, Montenegro and Croatia, ethnic representativeness plays a minor role in (formal and informal) recruitment decisions. The same can be said for Albania, but the country is, by and large, ethnically homogeneous, which explains the lower importance of the issue. Finally, in Kosovo, ethnic representativeness is given major importance formally, but it should be recognised that the population subject to the authority of the Government is by and large ethnically homogeneous.

(2) Political parties in the Western Balkans have demonstrated a particular appetite for positions in the civil service, which directly contradicts the principles of merit recruitment. All countries except Montenegro have experienced some form of polarised political competition. This political polarisation entrenches problems of mutual trust between political opponents and between politicians and civil servants. Political appointments for the sake of enhancing the responsiveness of and control over the civil service are a direct consequence of this. 
(3) The economic situation in most Western Balkan states reinforces the role of political parties as agents that supply selective goods to their supporters. Weak private sectors, high unemployment and underemployment have increased societal demand for jobs in the public sector. Political parties have stepped up as facilitators to satisfy the demand for jobs from their supporters. The problem of party patronage for the sake of rewarding party activists and their entourage is endemic throughout the region.

(4) International organisations including the European Commission have proactively promoted the establishment of merit recruitment institutions over the last decade and a half. They have been successful in diffusing formal procedures to all countries, even if their influence has varied over time. However, institutional design is never perfect and in a context of unfavourable domestic political, economic and social conditions, it is virtually impossible to generate merit outcomes by means of institutional design.

Despite these constraints on increasing the effectiveness of merit recruitment institutions, the evidence suggests that there is no major risk of de-institutionalisation. Importantly, civil servants themselves remain, by and large, supportive of merit institutions and outcomes. Figures 4.1 addresses the attitudes of civil servants towards a) merit institutions including job advertisement and oral and written examinations and $b$ ) the embodiment of European principles in recruitment processes such as a focus on recruitment based on skills and the absence of party patronage and informality.

Figure 4.1 shows that merit institutions are widely supported, which indicates that merit instruments such as advertisements and written examinations are widely accepted. The average scores of 4.2 and 4.1 clearly indicate a high degree of fit with European principles. By and large, the same applies to civil servants' general support for the merit principle in civil service management.

Figure 4.1. Attitudes towards merit recruitment institutions and principle

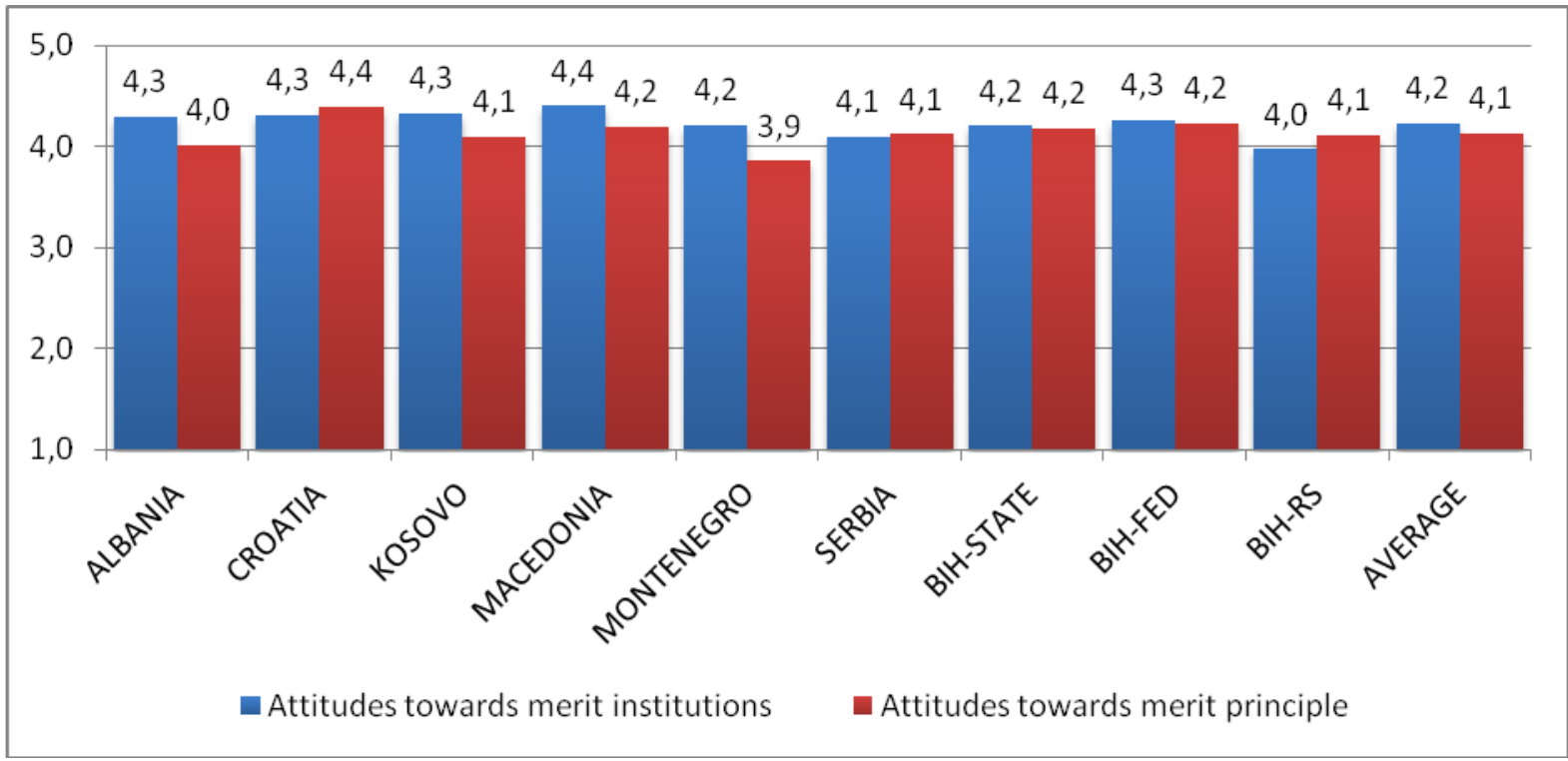

Support in the Western Balkans for merit institutions such as written examinations differs greatly from the new EU member states in which civil servants tended to be critical of written examination procedures. This lack of support facilitated the abolishment of written examinations in many new EU member states after accession in 2004. 
The positive attitudes of civil servants towards merit recruitment and selection should be considered as encouraging, as civil servants themselves might become important anchors of the future professionalisation of the civil service. For the European Commission and other international organisations, they become the main stakeholders for the implementation of merit recruitment procedures.

However, whether the positive position of civil servants will overcome the contradictory incentives of political parties in government is questionable. Without a significant demand for change, it is unlikely that sustainable merit recruitment practices will be established in the Western Balkans in the near future.

\subsection{Tenure}

This section examines the domain of civil service tenure. The European Commission and SIGMA have been particularly concerned with the stability of public administration in transition and accession countries. After the fall of communism, public administration typically underwent major re-organisations and personnel turnover. The stabilisation of the civil service by means of civil service tenure rules has therefore been a major objective in the European Commission's and SIGMA's approach to civil service professionalisation.

Moreover, the protection of employment in the civil service serves to promote principles the political neutrality and impartiality of the civil service. It lengthens the time horizons of civil servants and hence their incentives to serve the public interest and to work for governments from different political sides. At the same time, SIGMA has placed great emphasis on the establishment of rules and practices that ensure the fair and equal treatment of civil servants in case of dismissal. Accordingly, the research examined the lengths of civil service appointment terms, the conditions under which dismissal from the civil service is possible and turnover rates, in order to capture the stability of the civil service.

The overall record in this domain in terms of European principles was, until recently, by and large positive. However, this domain symbolises the shift away from the European principles even more than the domain of civil service reform programmes. Job protection used to be moderate to high in all Western Balkan states except Kosovo. However, over the last year, civil service tenure rules have been de-regulated in line with private sector practices without taking into account principles such as the fair and equal treatment of civil servants. This de-regulation enjoys a considerable amount of support among civil servants, as SIGMA's survey shows. This reflects a general tendency of civil servants to support a more managerial approach to civil service management, also evident in the other domains discussed in this report. The prospects of returning to a high degree of fit with European principles of administration are therefore small, which might have negative long-term consequences for the capacity of civil service systems to promote principles of political neutrality and impartiality.

\section{Towards the de-regulation of civil service tenure rules}

Until recently, all Western Balkan states except Kosovo provided a moderate degree of employment security and stability. In Kosovo, where civil servants were appointed on three-year renewable contracts, job security was very low as contracts could be interrupted for reasons of organisation, redundancy, lack of budgetary resources, and poor performance. Turnover in the civil service has remained high in Kosovo. According to local observers it fluctuates around $15-20$ per cent per year. The low level of institutional job protection is likely to have contributed to this high turnover. The new Civil Service Law has changed the situation by making indefinite terms the basis of civil service contracts, but it remains to be seen whether the new conditions for dismissal will be able to stabilise the civil service. 
The other countries differ in that appointments to the civil service are generally for indefinite terms and dismissals are limited to more or less clearly defined circumstances. Notwithstanding the case of Kosovo, Serbia's civil service system provides the least protection from involuntary dismissal. First, reorganisations and redundancies are a common instrument to change personnel in the ministries. In accordance with the Yugoslav administrative tradition, the ministerial organisation and personnel are subject to systematisation in so-called 'rulebooks'. Rulebooks are then changed and, as result, unwanted staff are made redundant to create space for preferred officials.

A rulebook change cannot be made unilaterally by a minister but requires approval by the Ministry of Public Administration, the Ministry of Finance, the HRMS and the Government. However, due to political pressures, proposed rulebook changes are usually accepted. For instance, rulebook changes were made after the staff cuts made in response to the economic crisis. They are also common after changes in the political leadership of ministries, in particular after government changes.

For ministries, rulebook changes are a flexible instrument to make personnel changes. However, for civil servants they are problematic as the procedure cannot ensure their fair treatment. In the worst case, the procedure is used to get rid of civil servants who are seen as politically unsympathetic, in order to fill positions with political cronies. Even if the civil servants who are made redundant are subsequently transferred to civil service 'waiting lists' and/or government disposal lists, they will lose their civil servant status after a short while.

The second method of dismissing civil servants is based on the use of regular performance evaluation. In Serbia, a civil servant is dismissed after two negative evaluations. Conducting quarterly reviews of agreed performance objectives is possible and if a review is negative, a second review can be conducted within 30 days, possibly leading to a rapid termination of employment. The provision was introduced in 2009 in order to create a more flexible tool for managers to lay off poorly performing civil servants. In practice, the tool has rarely been used primarily because the outcome of the procedure is likely to be challenged in the courts.

Until recently, the other countries differed from Serbia. Rulebook changes are also practiced but to a lesser extent. Albania is an exception here in that the tool was very popular after the last change of government from left to right in 2005. In 2006 and 2007, more than 20 per cent of all civil servants formally employed in the central government ministries were on the government's waiting list. In this case, the use of re-organisations to make politically motivated dismissals was evident. In addition, it is worth noting here the enormous costs of paying redundant civil servants for a whole year before they are taken off the government's payroll.

The main difference between Serbia and the other countries had to do with the method applied for dismissal on the basis of poor performance. In most cases, a dismissal could be justified with only two successive negative annual performance evaluations. While this approach is largely consistent with the European principles (assuming the evaluation system works adequately), it was hardly ever used in practice. Managers considered the tool to be inefficient as dismissing a poorly performing civil servant took a very long time. Even if the procedure led to a dismissal, managers faced the risk that courts would subsequently rule in favour of the civil servant.

Against this background, one needs to consider the amendment passed in Serbia in 2009 and the wave of amendments passed in 2010 and 2011 in several other Western Balkan states. In the former Yugoslav Republic of Macedonia, it has become possible to dismiss civil servants on the basis of two negative semiannual reviews, which considerably accelerates the procedure. In addition, a civil servant can be 
dismissed at the request of the minister after 30 days if he has been warned in writing about unsatisfactory performance. This provision minimises the employment protection of civil servants.

Montenegro has moved to a system whereby one negative annual evaluation suffices to dismiss an official from the civil service. Similarly, in Croatia, it is possible to dismiss civil servants on the basis of one negative annual performance assessment following a warning issued three months before the end of the assessment period. Finally, in $\mathrm{FBiH}$, dismissal has become possible after two negative reviews whereby the second review is conducted within 90 days of the first negative annual review.

By the middle of 2011, only Albania, $\mathrm{BiH}$ and RS had not lowered the threshold for dismissing civil servants However, in $\mathrm{BiH}$ and RS, managers have a considerable amount of influence over dismissal decisions, as civil servants can be dismissed after two consecutive negative semi-annual reviews. Kosovo differs from the other countries in that the new Civil Service Law will require two consecutive negative annual reviews for the dismissal of civil servants.

In terms of the European principles of administration, the regional trend is largely negative. The managerial approach to managing job security is common in the private sector but unusual in public administration. The flexible use of performance reviews for the dismissal of civil servants creates a risk of unfair treatment, favouritism and politicisation. This problem is especially striking when the performance evaluation system does not properly function properly, as will be examined in more detail below.

The shift towards flexible employment patterns reflects attempts to mobilise and energise the civil service to reduce staff numbers in a context of austerity. Yet one of the most pressing public administration problems in the Western Balkans is the misallocation of human resources. Even if many positions cannot be filled with adequately qualified staff, the civil service is considered to be too big. In other words, too many officials have the wrong skills and work in the wrong positions.

The current institutional framework does not allow governments to rectify this situation. The flexibilisation of dismissals is not sufficient to address this systemic problem, as governments would first need to improve central civil service management structures and, above all, mechanisms for human resource planning. Yet it appears that the austerity crisis provides a welcome excuse to reduce job security.

This being said, the rules for the protection from dismissal have had a considerable impact on the stabilisation of public administration in many, but not all, Western Balkan states. Turnover in the former Yugoslav Republic of Macedonia, Montenegro, $\mathrm{BiH}, \mathrm{FBiH}$ and RS has recently been very low. For example, in the former Yugoslav Republic of Macedonia, the turnover rates have consistently averaged 1-2 per cent per year for civil servants in non-managing ranks (for senior ranks, see next section).

In Albania, Serbia, Kosovo and Croatia, turnover is higher. For Albania, DoPA estimates that approximately 15 per cent of all civil service positions are advertised every year. However, this includes a large number of movements within the civil service. Turnover involving departures from and new entries into the civil service is hence significantly lower. In fact, turnover is considered to be a major problem for the public administration only in Serbia and Croatia. Estimates range between 15 and 20 per cent per year. When changes in government occur, turnover ratios are higher, especially in senior ranking positions.

Most of the recent turnover in Serbia was the result of IMF pressure to reduce the government's wage bill. Ten per cent of staff in public administration was required to leave. The general target was not 
accompanied by clearly defined rules and procedures for the reduction of staff numbers. In Serbia, managers were largely left to their own devices. In some cases, performance appraisals were used as a tool to determine which officials had to leave, but there were no guarantees of equal and fair treatment. In contrast, the Croatian Government adopted an "Economic Recovery Programme" in 2010 that included downsizing measures representing approximately 5 per cent of the workforce, but this measure was not systematically implemented.

Interestingly, civil servants in the region are fairly supportive of reducing the level of job protection. Respondents were asked whether managers should have more freedom to fire civil servants who perform poorly. This question directly addresses the recent institutional changes but it also goes directly against the European principles. A low score indicates a positive response to the question and therefore a disagreement with the European principles.

Figure 5.1 suggests that support for a managerial approach to dismissals is very strong in Montenegro, Kosovo and Serbia and lower in the other countries. Ironically, civil servants in the former Yugoslav Republic of Macedonia are the least supportive of discretionary dismissal rules, in opposition to the recent institutional change in the country. The widespread support for the de-regulation of dismissal procedures is puzzling as it seem to indicate that civil servants support a lower level of job protection and hence a weakening of their own position.

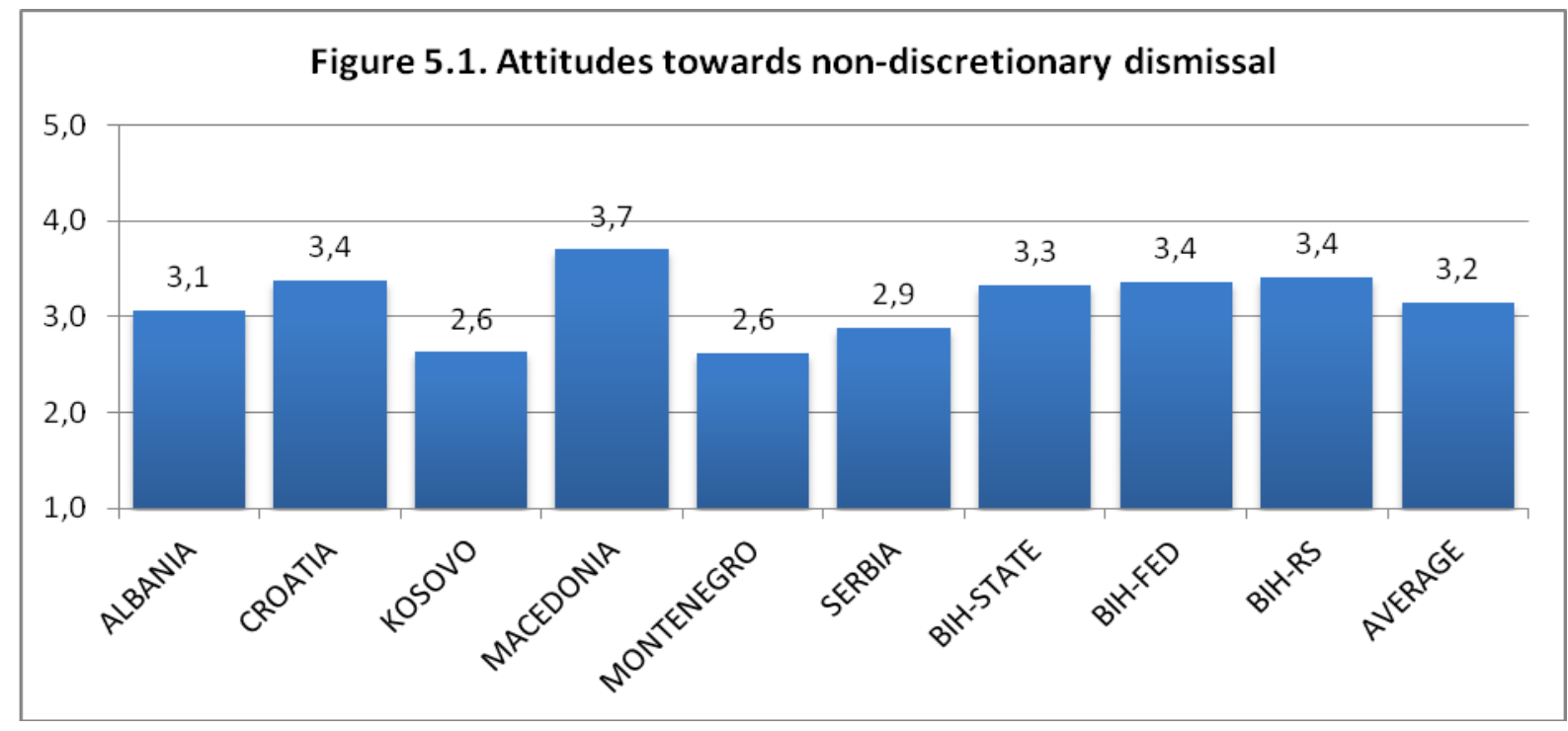

However, this support for a more managerial approach to civil service tenure is certainly compatible with trends in other areas of civil service management assessed in this report. Moreover, the evidence so far suggests that civil servants in managing positions and young civil servants are more supportive of the deregulation of tenure rules than their colleagues. For managing civil servants, this perspective is plausible in that it enhances their own position in the civil service. In the case of young civil servants, it reflects a change in career expectations. Young civil servants do not necessarily seek to pursue a life-long career in public administration and often consider their current job as a springboard into a better-paid job in the private sector. As a result, a high level of job protection appears to be less important for them.

In sum, the domain of civil service tenure demonstrated until recently a relatively high degree of fit with European principles. This applies to both the level of formal rules and the level of rule implementation, despite a range of factors that undermine the principle of fair and equal treatment. Recent institutional 
changes have clearly made systems move away from the European principles. Civil servants support a shift towards discretionary dismissal rules and practices, which is peculiar in that the new regimes are potentially disadvantageous for them.

The normative challenge of the principle of protection from arbitrary dismissal from the civil service, the clear political interest in using employment rules as an instrument of political control, the economic and fiscal crisis, and the lack of EU intervention at a time when it would have been possible to prevent deprofessionalisation will make re-professionalisation in accordance with the European principles unlikely in the near future.

\subsection{Senior civil service}

This section examines the domain of senior civil service management. The European Commission and SIGMA place particular emphasis on the professionalisation and de-politicisation of the senior civil service. Civil service managers have a key role to play in promoting and diffusing European principles of administration within their organisations. At the same time, civil service managers are directly located at the politics-administration nexus and, therefore, are exposed to more political influence than their subordinates. In many respects they are the least likely cases for successful professionalisation in line with the European principles.

In order to assess the domain of senior civil service management, the research examines the scope of the senior civil service, and in particular the inclusion of senior officials with responsibilities for the management of ministerial departments in the scope of the civil service, the procedures for the appointment, promotion and dismissal of senior civil servants, and the extent to which political considerations influence the management of senior civil servants in practice.

This domain of civil service management is the weakest when assessed against the European principles of administration. In several countries, the top managers of the ministerial bureaucracy are not classified as civil servants but rather as political appointees of the government. Furthermore, appointment procedures are less capable of ensuring merit recruitment and promotion than the procedures for ordinary, nonmanaging civil servants.

In addition, there is a strong general perception that promotion decisions are subject to politicisation rather than merit-based. As a result, it is common to see an intense politicisation of the upper two (or even three) echelons of the senior civil service in the Western Balkan states. Due to relative political continuity in government, political turnover rates have been moderate over the last few years in the Western Balkans. Yet the trend clearly points towards more rather than less politicisation in the future. Therefore, it is important that the European Commission and SIGMA continue to emphasise the need for senior civil service de-politicisation.

\section{Persisting politicisation of the senior civil service}

All Western Balkan states have formally defined the managing ranks of public administration, most typically in state administration laws. Yet they differ with regard to the positions that are nominally included in the civil service and with regard to the rules and procedures that apply for appointment and promotion to and dismissal from senior positions.

First, senior civil service systems differ with regard to the positions that are included within the scope of the civil service. In Albania, Kosovo, BIH state and entity levels, and Montenegro, all managing positions 
of the ministerial bureaucracy are classified as civil servants. In Albania, the top ranked manager is the general secretary, followed by directors general and directors of departments. In BiH state and entity levels, the top position is general secretary of the ministry followed by assistant ministers who head policy sectors within ministries. In Montenegro, the top positions are labelled secretary and deputy minister in accordance with the Yugoslav tradition of public administration but they are nonetheless part of the civil service. In Kosovo, the top position in the ministries is general secretary, which until recently was labelled permanent secretary. ${ }^{11}$

By contrast, in Croatia, Serbia and the former Yugoslav Republic of Macedonia, the top position of the ministerial bureaucracy (the state secretary) is excluded from the civil service. The position is explicitly formalised as a political appointment. In the former Yugoslav Republic of Macedonia, the state secretary was removed from the scope of the civil service by an amendment passed in 2010 . This clearly shows a gradual shift away from the European principles in the country, as already discussed in earlier sections.

In Croatia, discussions during the preparation of the 2005 Civil Service Law favoured the classification of state secretaries as civil servants but this proposal was politically unacceptable. In fact, the most recent institutional change made after the 2011 elections and the signing of the EU Accession Treaty has even turned the position of director general back into a political appointment. Therefore, Croatian ministers have a very deep formal reach into the senior bureaucracy.

Other countries have also discussed changing the scope of the civil service law. For example, in $\mathrm{FBIH}$, the Government made several attempts to turn general secretaries and assistant ministers, as the top two levels of the civil service, into political appointments. These attempts were thwarted by the joint efforts of the OHR and the EU. However, the political pressure to facilitate political appointments is likely to intensify, especially as the role of the OHR diminishes in future.

Second, the countries differ considerably with regard to the procedure that they apply for the appointment of senior officials. In $\mathrm{BiH}$ and $\mathrm{FBiH}$, the procedure is by and large equivalent to the procedure applied to non-managing civil servants (see above). Vacant positions at the level of general secretary and assistant minister are advertised by the CSA, committees conduct general and specialised examinations, and ministers have the discretion to select from an open list of suitable candidates. This means that in the case of $\mathrm{BiH}$, ministries, by being able to pick from an open list instead of the CSA, have more discretion when compared to the standard procedure for non-managing civil servants.

In Albania, the procedure for general secretaries and other managing civil servants is identical to the procedure for non-managing civil servants. Positions up to the level of general secretary are advertised by DoPA and committees prepare specialised examinations. Ministers then have the discretion to pick a general secretary from an open list of three suitable candidates, while the General Secretary does so for other managing civil servants. ${ }^{12}$

In RS, the general secretary and the assistant minister are also selected like other civil servants. Vacant positions are publicly advertised and committees conduct interviews. Written tests are not required but

11 In Albania, Kosovo and the former Yugoslav Republic of Macedonia, the Government also appoints deputy ministers who have no managing role in the ministerial bureaucracy. They are accountable to the minister and do not head any departments. They are therefore excluded from the discussion here.

12

The three candidates are ranked but the list is open in that the selecting authority can pick any of the three regardless of their position in the ranking. 
candidates have to pass a general exam before entering the competition. Ministers then make an appointment from a closed list of candidates.

In the former Yugoslav Republic of Macedonia, the appointment procedure varies across levels of the hierarchy. State secretaries as political appointments are proposed by the minister and appointed by the Government. State advisors, heads of departments, their deputies and heads of units are selected via the 'normal' recruitment procedure, which involves the public announcement of an open competition, examination by a committee, and discretionary selection by the state secretary.

In Montenegro, the procedure requires less testing for secretaries and deputy ministers who act as heads of policy sectors within ministries than for ordinary civil servants. While vacant positions have to be advertised for open competition, they merely require an interview with the minister, subject to the presence of a HRMA representative. Written tests are not required, leaving almost unlimited discretion to ministers.

In Croatia, the appointment procedure is differentiated. State secretaries are proposed by the minister and appointed by the government. In contrast to the other countries, there is usually more than one state secretary per ministry in place. Following the coming into force of the civil service law in 2006, the government waited until 2008 (that is, until after the 2007 parliamentary elections) to regulate the senior civil service with a decree. ${ }^{13}$ Many state secretaries were then 'promoted' from a position of director general or secretary general in order to circumvent the formal criteria applying to top civil service positions. For instance, in the Ministry of Economy, seven state secretaries were appointed in 2010, and can be seen as forming a political superstructure of the ministry.

The procedure for the appointment of the secretary general and directors general as the top senior civil servants consists of only an interview and there is no written test. This means that in Croatia, it is easier to become a director general than a junior civil servant. The next levels of head of department and head of sector and the junior managing level of head of unit are subject to the same procedure as other civil servants. A written test is prepared by an examination committee but the process is entirely decentralised and involves a large degree of discretion for the selecting minister.

Serbia differs from the other countries in that the appointment procedure for senior officials is not fully implemented. As a result, appointments are subject to more discretion. The Higher Civil Service Council is responsible for the official procedure for appointing general secretaries and assistant ministers. The Council appoints an examination committee and vacant positions are publicly advertised. In contrast to the standard procedure which typically relies on an entry interview, written tests are required. Ministers then pick from an open list of three successful candidates but can reject the list.

The procedure was formalised with the passing of the Civil Service Law in 2005 but it has not yet been fully implemented. The deadline for the implementation of the procedure was postponed for several years. In 2010, five years after the adoption of the Civil Service Law, 35 per cent of all assistant ministers and general secretaries were not appointed through the procedure prescribed by the Higher Civil Service Council.

Instead, ministers make temporary appointments, which are subject to unconstrained political discretion. Many temporary appointees are subsequently moved through the official competition procedure in order

13

In fact, the Decree was adopted in 2007 and before coming into force it was again amended in early 2008 after the elections of 2007. 
to officialise their status. Even if the appointment procedure seems elaborate on paper, it has so far had virtually no effect on the intensity and depth of senior civil service politicisation in Serbia. The decline in the proportion of temporary appointments to senior positions is misleading in that many former temporary appointees have simply been moved to formal senior civil service posts.

Until recently, opportunities for the exercise of discretion were the highest in Kosovo. In order to make appointments to the most senior positions in the civil service transparent, permanent secretaries were officially appointed by a Special Public Appointments Committee (SPAC) consisting of the prime minister, senior ministers and representatives of civil society. In practice, however, the Committee met only once over several years, meaning that permanent secretaries were simply appointed on the basis of temporary contracts. Candidates for positions below permanent secretary are interviewed by ministerial commissions and selected by ministers, and there is no requirement for further testing. Recruitment is hence both decentralised and discretionary.

The new Civil Service Law envisages new evaluation committees for the selection of general secretaries as the nominal successors to permanent secretaries. Written tests are still not required for the top level although they will be introduced for levels below the general secretary. The rules for the appointments of other managing civil servants do not differ from those for other civil servants. Discretion will hence remain significant.

This brief overview of appointment procedures shows the existence of a formal separation of politics and administration and the institutionalisation of open competition procedures for most, although not all, senior officials. However, thresholds for appointments are often remarkably low and political discretion over selection decisions is hugely important in all Western Balkan countries. Under these circumstances, de-politicising the senior civil service is difficult. The overall degree of fit with European principles of administration therefore remains fairly low.

The pressure for politicisation is reinforced by the presence of parallel recruitment procedures. As already mentioned for Serbia and Kosovo, temporary appointments to senior positions are highly common in the Western Balkans. Based on the interviews conducted, temporary appointments are widespread in Croatia, Albania and the former Yugoslav Republic of Macedonia. They are also used in BiH and Montenegro, albeit to a lesser extent.

The duration of appointments differs between the Western Balkan states. Due to their formal status, the appointment of state secretaries in Croatia, Serbia and the former Yugoslav Republic of Macedonia is tied to that of the minister. In RS, Serbia and Montenegro, general secretaries and assistant ministers are appointed for five-year terms. These terms are longer than the constitutionally defined electoral cycle. In practice, the slightly longer appointment terms are without consequences for job security and/or the behaviour of top officials.

In Albania, $\mathrm{BiH}$ and $\mathrm{FBiH}$, general secretaries and assistant ministers are appointed for indefinite terms. On paper, their job protection is greater than that of their peers in Serbia, Montenegro and RS. However, in practice, the distinction between indefinite and fixed term appointments makes no difference in terms of job security and/or the behaviour of top officials.

Because of the existence of multiple recruitment procedures, it is extremely difficult to determine which levels of the civil service are politicised in practice (as opposed to the letter of the law). Personal interviews conducted suggest that, despite their formal status, the top two levels of the civil service are by and large political in $\mathrm{BiH}, \mathrm{FBiH}$ and RS, Montenegro and Albania. The third level of the hierarchy is 
usually located in a grey area between politics and administration. In Croatia, Serbia, Kosovo and the former Yugoslav Republic of Macedonia, politicisation reaches slightly deeper, with the third level of the ministerial hierarchy also usually a political appointment and the fourth level being in a grey area between politics and administration.

Recent senior civil service turnover rates in the region are remarkably low, in particular when compared to the new EU member states (discussed in SIGMA Paper No. 44. Following the last elections across the region, turnover in the top ranks was quite moderate everywhere (except RS). Turnover rates were significantly higher in the mid 2000s. For instance, turnover rates were very high in Croatia in 2003, in Albania in 2005 and in the former Yugoslav Republic of Macedonia in 2006. At the top level, the rates reached 70-90 per cent. Interestingly, $\mathrm{BiH}, \mathrm{FBiH}$ and Montenegro have been seen less turnover over the last three elections.

The turnover patterns are best explained by the patterns of government alternation of the last decade. The alternations in Croatia, Albania and the former Yugoslav Republic of Macedonia were all characterised by wholesale pendulum changes from one side of the political spectrum to the other. The recent change in RS also follows this script. The government changes in Serbia and Kosovo did not involve similar alternations. However, they usually brought a new senior governing party to power, which raised the interest in the political control and replacement of senior level staff.

The relatively lower turnover in $\mathrm{BiH}, \mathrm{FBiH}$ and in Montenegro is strongly influenced by the relatively large degree of continuity of parties in government. Governments have changed during the last two decades but changes have mostly involved replacement of smaller coalition partners rather than wholesale changes from one political bloc to another.

However, in the case of $\mathrm{BiH}$ and $\mathrm{FBiH}$, it is important to recognise that political continuity was largely driven by the international community and in particular the OHR. Without the OHR's presence, it is likely that senior civil service management would rapidly re-politicise.

Therefore, Montenegro is the only country of the region that has political conditions in place that might support a partial de-politicisation of the senior civil service in the near future. Montenegro's small size and the limited supply of sufficiently competent political appointees will provide further incentive for the government to professionalise the top levels of the civil service. As long as the EU accession process remains on track and policy-making remains relatively complex, even the country's political class will have a lot to gain from senior civil service professionalisation.

This being said, there is little evidence that EU policies that directly address the senior civil service have had a major influence on the (de)politicisation of the senior civil service in the Western Balkans. The overview of appointment procedures above indicates that the European Commission, SIGMA and other international organisations and consultants were not able to persuade governments in the Western Balkans of the benefits of higher merit standards. Even if public competition procedures were established, and even if they can often be directly traced to the intervention of international organisations, low entry thresholds, political discretion and parallel recruitment procedures such as temporary appointments have remained widespread in the region.

As the Montenegrin example shows, this is not to say that the EU has no effect on the professionalisation of the senior civil service. In fact, ministries and directorates of European Integration, as well as state offices of European Integration, tend to be more professional and hence less politicised than other ministries at the central government level. Personal interviews conducted indicate that politicisation 
levels are significantly lower in institutions exposed to EU policy-making and coordination. Bodies that manage EU affairs enjoy a standing as islands of excellence in public administration.

So far, this status has not spilled over to other sectors and has not found its way into the procedural basis of senior civil service management. However, it is clear that an increasing exposure of Western Balkan administrations to the EU will involve a greater exposure of civil servants to demanding and complex forms of policy-making. As a result, governments will increasingly demand more professional senior civil services to remain on track in the EU accession process.

This mechanism, however, will require positive signals from the $E U$ as to the prospects of accession in the not-too-distant future. The granting of candidate status to Montenegro has sent a positive signal in an environment that is otherwise characterised by "enlargement fatigue", the euro crisis and a growing euro-scepticism in old and new member states.

It is positive to see that contrary to the common practice of senior civil service politicisation, civil servants widely support the principle of merit promotion and hence career advancement to senior ranks. Figure 6.1 shows civil servants' attitudes towards the principles of merit promotion. It is clear that civil servants are highly supportive of merit based promotions while opposing the principle of promotion on political grounds. In fact, there are very few differences across the countries. Croatia's very high score might not only indicate support for merit promotion but also strong dissatisfaction with the current practice of promotion in the country. The positive evaluation of merit promotion by civil servants provides a strong signal to governments in the region that merit-based reforms will receive a great deal of support inside the public administration and are likely to have a positive effect on the motivation of civil servants.

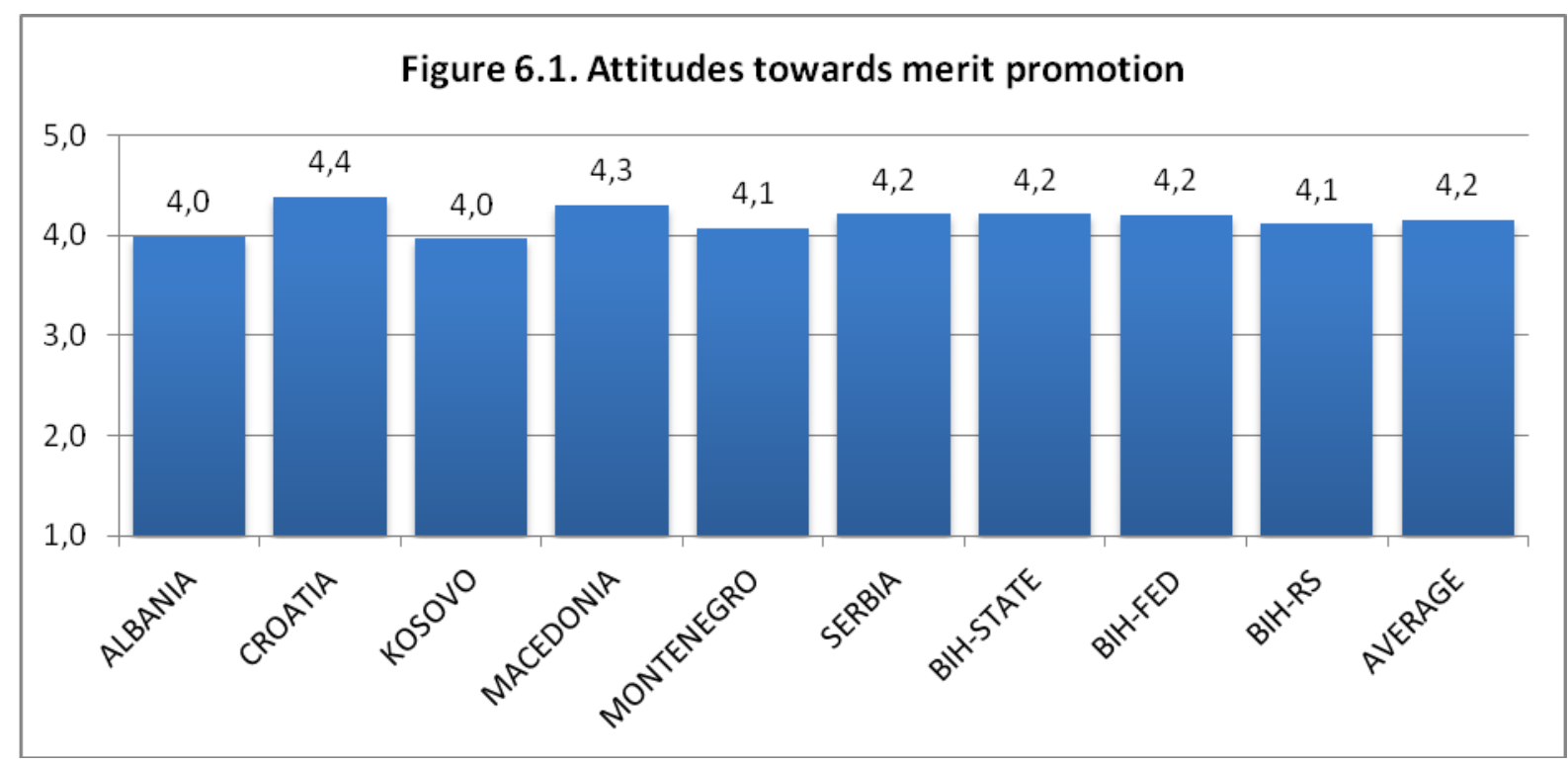

In sum, all Western Balkan states have institutionalised a separation between politics and administration and have established open competition procedures for the selection and appointments of senior officials. Yet the procedures have proven to be fairly ineffective, in that senior civil services are generally subject to a considerable degree of politicisation. The political incentives for the control and politicisation of the senior civil service are evident. Therefore, the European Commission's and SIGMA's main role might be to prevent further re-politicisation, while de-politicisation is unlikely without raising prospects and intensifying the process of EU accession management. 


\subsection{Performance management}

This section examines the domain of performance management in the civil service. The European Commission and SIGMA address performance management as a cross-cutting domain relevant for areas such as training, salaries, promotions and civil service tenure. Performance evaluation mechanisms play an important role in promoting principles of effectiveness in the civil service while ensuring the fair and equal treatment of civil servants. Accordingly, the research concentrates on the existence and application of performance evaluation systems, as well as on their ability to define transparent and fair incentives for civil servants when performing their job.

Overall, performance management systems in the Western Balkans reach a moderate to low level of fit with the European principles of administration. They share many features of the domain in terms of the recruitment of civil servants. On the one hand, performance evaluation systems have been established in all countries, they are regularly applied in practice and they are widely accepted by civil servants. On the other, the impact on training and development, promotion decisions and salary outcomes is negligible in most countries. Instead, performance evaluations are increasingly related to decisions to dismiss civil servants. In line with the discussion above of civil service tenure rules, performance evaluation systems have increasingly been turned into disciplining tools at the disposal of civil service managers who lack the capacity to ensure the fair and equal treatment of civil servants. Whether the new approach will increase the performance of the civil service is questionable.

\section{Towards performance management as a disciplinary tool}

Performance evaluation systems have been established in all Western Balkan states and they are regularly applied in all countries except Montenegro. Yet their ability to create positive incentives for civil servants to perform better and to invest in specific skills must be questioned.

In Albania, performance evaluation has been implemented since 2002. It involves an annual review performed by the direct superior and counter-signed by the superior's superior and the director general or the general secretary of the ministry. The reviewee has the right to file an appeal with the Civil Service Commission. Formally, the review serves to identify the training needs of civil servants. The review is also linked to promotion prospects and to the size of the salary bonus paid out at the end of the year (see also next section).

In practice, the review is largely a box-ticking exercise. Managers do not tend to pay much attention to staff development. The payment of salary bonuses has been frozen since the onset of the financial crisis. Promotion prospects are minimal because even appointments to higher positions within the same ministry require a job advertisement and a competition procedure. The positive incentives associated with the review are therefore entirely theoretical. On the other hand, civil servants face the prospect of dismissal if they receive two consecutive negative performance reviews. In practice this is unusual, as dismissals are typically managed via re-organisations.

As a consequence, the performance review is almost without any consequences for both civil service managers and their subordinates. In fact, the majority of reviewees receive top marks, which would qualify them for a reward. The performance review does not discriminate between civil servants but classifies the large majority of them in the same top category. In practice, it means that the performance review becomes a procedure that exists for its own sake. 
While the general usefulness of performance evaluation systems are uncontested (see also below), the current approach is largely discredited in the eyes of civil servants and their managers. It lacks the capacity to steer civil servants and to motivate them to perform tasks as desired by the leadership. This is unlikely to change unless the review has tangible effects.

The performance review systems in the other Western Balkan countries fit the European principles even less than in Albania. In most cases, the review does not set any positive incentives, and there has been a clear trend towards setting negative incentives without strengthening the procedural aspects.

In $\mathrm{FBiH}$, the performance review is conducted annually by the superior on the basis of objectives agreed at the beginning of the assessment period. The review is counter-signed by the superior's manager and then by the minister. Civil servants have the right to appeal the outcome. The review is only linked to training needs analysis and there are no linkages to promotions and salary increases. As indicated above, $\mathrm{FBiH}$ has recently passed a reform to facilitate dismissals on the basis of poor performance. If a civil servant receives a negative review, it is possible to schedule another review 90 days later. If this extraordinary review also turns out to be negative, the civil servant can be dismissed from the civil service. The new review system hence accelerates the process of dismissal on the basis of poor performance but the procedure (which relies only on the judgement of the superior, the superior's manager and the minister) does not ensure fair and equal treatment of the reviewee.

The systems of performance evaluation in $\mathrm{BiH}$ and $\mathrm{RS}$ are similar to $\mathrm{FBiH}^{\prime}$ s system, especially since the 2011 revision. Performance evaluations were first introduced in RS in 2003 but have not been used regularly by institutions. BiH introduced performance evaluations in 2004 but many state bodies do not conduct the regular semi-annual reviews required by legislation. At both $\mathrm{BiH}$ and RS levels, a formal linkage exists between performance review and the award of salary bonuses. However, in $\mathrm{BiH}$, bonuses have in practice not been awarded due to the lack of secondary legislation for the implementation of the Law on Salaries. In RS, the possibilities for salary advancements are fairly small in practice, as the maximum number of salary steps is limited to three. The rules regarding the dismissal of civil servants after two semi-annual appraisals have been in place for several years but have rarely been applied. Performance appraisal is understood primarily as a disciplining tool rather than a development tool or a system that sets positive incentives for civil servants.

An even clearer trend towards the use of performance reviews as a disciplining tool can be found in the other Western Balkan states. In the former Yugoslav Republic of Macedonia, the periodicity of the review cycle has recently been changed from annual to semi-annual. The review is conducted by the superior ${ }^{14}$ and is linked with training needs analysis, promotion prospects and salary bonuses.

Civil servants can receive salary bonuses by progressing along horizontal career steps. The number of steps is limited to four, which implies that the positive incentives are exhausted after a certain period of time. Moreover, promotions are only indirectly linked since a positive review outcome is a precondition for participation in internal job competitions. In other words, a positive review does not necessarily trigger a positive reward.

14 Subsequently, the assessing superiors have to provide information on the assessment process to their superiors. The minister then submits a summary report of the assessment process to the Ministry of Information Society and Administration. Dissatisfied civil servants have the right to complain to a commission formed internally in the ministry and subsequently appeal before the AA. 
The recent reform in the former Yugoslav Republic of Macedonia has facilitated dismissal based on bad performance, in that two negative reviews directly lead to dismissal from the civil service. The shift towards semi-annual reviews has significantly accelerated the procedure for dismissal, but it remains to be seen whether the procedure will be used in practice. ${ }^{15}$

Croatia's current performance review framework is very similar to that of the former Yugoslav Republic of Macedonia. In Croatia, performance evaluations were introduced in 1994 when the first Civil Service Law was passed. The system was revised after the adoption of the Civil Service Act in 2005.

The review cycle itself remains annual but civil servants who are assessed by their direct superior are also subject to mid-term reviews. Final outcomes are signed by the ministers and can be appealed against in the Civil Service Board. Following the 2011 amendment of the Civil Service Law, a civil servant can be dismissed if his/her end of the year review is negative and if he/she had received a written warning at least three months before the end of the assessment period. The negative incentives associated with the performance review are as intense as they are in the former Yugoslav Republic of Macedonia. At the same time, there is no linkage to the salary system because Croatia has so far failed to pass a salary reform. In short, the Croatian approach provides virtually no positive incentives while it has introduced serious negative consequences for civil servants who receive a negative review.

Serbia was the first country in the region to shift towards the use of performance evaluations as a disciplining tool. The review cycle is annual but managers can assess their subordinates on a quarterly basis. If one of these reviews is negative, an extraordinary review can be conducted 30 days after the first negative review. If the second review is also negative, the civil servant will be dismissed from the civil service.

It is therefore possible to dismiss a poorly performing civil servant in four months. In practice, this procedure has hardly ever been used. Managers who have tried to give negative reviews run the risk of being taken to court due to the vagueness of the procedure. Moreover, the general lack of consistent application across institutions raises the likelihood of reinstatement by the courts. Managers also tend to criticise the large amount of time needed to conduct the semi-annual and quarterly reviews. It therefore remains to be seen to what extent it will be possible to use the new procedure in the other Western Balkan states.

Finally, it is in Kosovo and Montenegro that the performance review mechanism is applied the least consistently and (relatively) least frequently. In both countries, the review is conducted annually by the superior. In Kosovo, it is primarily linked to training needs analysis even though in practice it is also used to inform salary bonus decisions and career progression. The new civil service law and the associated regulations have created a system of quotas that will no longer permit the award of top marks to the overwhelming majority of civil servants. However, it remains to be seen whether the quota system will have negative effects on the motivation of civil servants.

In Montenegro, the review is linked to training needs analysis, promotion prospects and salary bonuses to be paid at the end of the year. Yet the link to promotions is by and large theoretical and the link to the salary bonus has been frozen since the beginning of the financial crisis. Instead, the performance review

15 The new Civil Service Law provides an even faster provision for dismissing civil servants which is not formally linked to the performance assessment system. At a minister's request, a civil servant can be dismissed if, within a period of 30 days after he/she has been warned in writing about the dissatisfaction with his/her performance, his/her performance does not improve. This provision clearly minimises the protection of civil servants. 
has mainly become a tool to facilitate dismissals from the civil service. In contrast to the other countries, receiving one negative performance appraisal is enough to be dismissed.

Particularly in Montenegro, the performance review cannot ensure the fair and equal treatment of civil servants. It is estimated that only 30 per cent of all civil servants are regularly evaluated by their superior. Personal interviews conducted revealed that managers in many central government ministries are explicitly opposed to the notion of evaluating their subordinates because they consider performance evaluations unsuitable for small teams. Notwithstanding this opposition, the lack of consistency in the application of the performance review creates major risks of arbitrariness in a setting such as Montenegro.

The wide application of performance evaluations in all countries except Montenegro is reflected in the results of the survey. Figure 7.1 refers to the regular application of performance reviews. All countries reach very high scores of between 4.6 and 4.9, which indicates that around 90 per cent of civil servants are subject to at least annual performance reviews. Montenegro is clearly an outlier with a low score of 3.5. This score suggests that more than half of the civil servants are still regularly subject to a performance review, which is higher than the estimate of 30 per cent given by internal and external observers.

Even though they are widely regarded as fairly ineffective, civil servants remain supportive of performance evaluations. Figure 7.2 shows that the intensity of support is nearly as high as for other elements of civil service management such as merit recruitment and promotion. The high degree of support for performance evaluations is indeed remarkable, as civil service managers and ordinary civil servants rarely indicated in personal interviews that they were particularly convinced about the usefulness of the review system. However, it remains to be seen whether their attitudes will change as a result of the institutional changes that have turned evaluation systems into a disciplining tool.

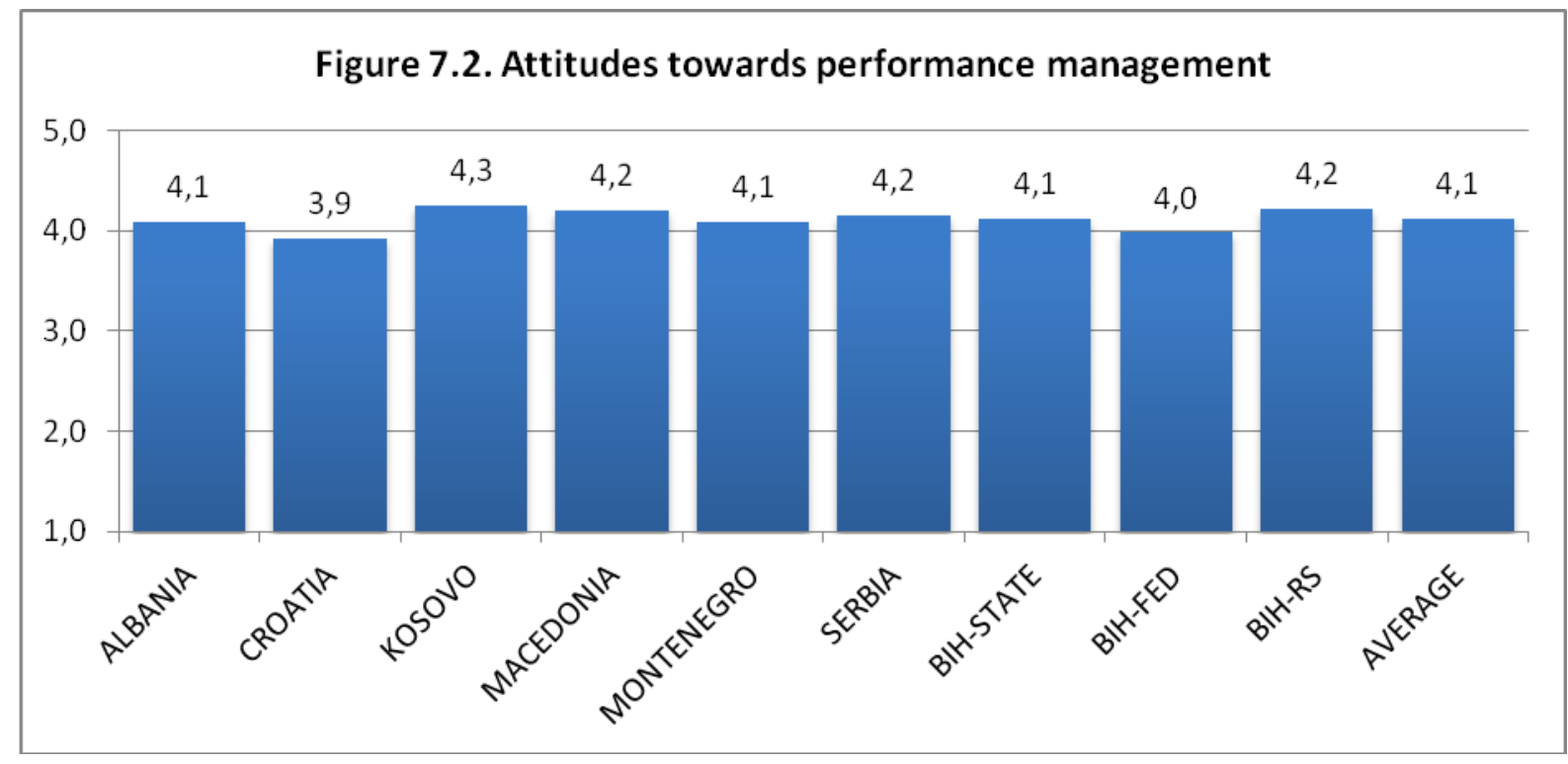

Performance evaluation mechanisms have been institutionalised in all Western Balkan states but most of them do not have the capacity to promote principles of effectiveness and fair and equal treatment in the civil service. As a result, performance evaluations have largely become a box-ticking exercise without any 
substantive consequences for the training, promotion and remuneration of civil servants. It remains to be seen whether recent reforms will change practices and attitudes. In any case, performance management systems are complex to administer. In order to make them work, Western Balkan states would need major domestic commitment and external support.

\subsection{Salary management}

This section examines the domain of civil service salary management. The European Commission has paid particular attention to civil service salaries, in particular with regard to the principle of effectiveness, and it emphasises the need to pay adequate salaries in order to provide positive incentives for civil servants, to prevent competent civil servants from leaving the civil service for the private sector, and to attract talented candidates.

SIGMA has complemented this concern for effectiveness by emphasising the need for transparent and predictable salary systems that ensure the fair and equal treatment of civil servants across government institutions. Accordingly, SIGMA has paid particular attention to the existence of civil service wide salary scales that ensure equal pay for equal responsibilities across government institutions. Moreover, SIGMA has favoured non-discretionary solutions to salary management and in particular that variable bonus payments and vaguely regulated supplements and allowances should only have a small role.

Overall, the domain of civil service salary management fits the European principles of administration to a moderate to even high degree. In light of the fact that salary systems was clearly the domain with the lowest degree of fit in the new EU member states of Central and Eastern Europe in the early days after accession, this is remarkable.

In the Western Balkans, Kosovo and Croatia are the only two countries that continue to perform poorly when assessed against the European principles. However, Kosovo passed a new Salary Act in 2010 and can be expected to slowly catch up with the other countries once the Act starts being implemented properly. The current situation in Croatia is uncertain. A reform of the salary system in 2008 failed and no attempt has been made since to re-launch the process.

The main weakness of the salary systems in the region is the inability to reward good performance. Predictability and transparency have been achieved at the expense of providing performance incentives. Civil servants clearly support transparent and predictable salaries but it is also clear that performance orientation and managerial flexibility in managing salaries have gained popularity. The prospects of retaining a moderate to high degree of fit with European principles are hence uncertain.

\section{Salary management between transparency and a lack of incentives}

Salary systems are relatively transparent in Albania, FBiH, Montenegro, the former Yugoslav Republic of Macedonia, Serbia, RS and BiH. Differences between countries are relatively small. Only in Kosovo and Croatia do the current salary arrangements achieve a low degree of transparency (in comparison to the other countries).

In Albania, salaries are regulated by the 1999 Civil Service Law and complementary government decrees. Implementation of the salary system started in 2002 and has since undergone only minor changes. The basic salary of civil servants consists of four components. First, a group salary applying uniformly to all civil servants is paid. Second, the main component of the basic salary is a position-based supplement. For civil service managers, it covers up to 91 per cent of the basic salary. Third, since 2007 civil servants 
receive a qualification bonus that rewards holders of MA and PhD degrees as well as professors. Fourth, civil servants receive a seniority bonus of 2 per cent per year of experience in relation to the group component of the salary. Because the group component is very small, the seniority bonus is very small, even for long-serving civil servants.

The salary system is hence primarily position-based. The Government sets the levels of the individual salary components by decree. Because job categories are fixed and controlled by both DoPA and the Ministry of Finance, there is virtually no possibility for managers to influence the basic salary levels of civil servants.

The variable part of the salary is regulated by the Civil Service Law. It refers to an end of the year bonus payment of up to one monthly salary. The award of the bonus is based on a successful performance appraisal but also depends on the availability of financial resources. Because such resources have been lacking, ministries have effectively stopped paying end of the year bonuses to their employees. Instead, it has become common practice to pay an equivalent amount as a guaranteed bonus to all employees of the ministry. Therefore, in practice, the salary system operates without any variable pay component.

Civil service salary levels are generally considered as adequate for low and mid-level positions. Problems of low salaries are limited to top-level civil servants in the sense that they could earn much higher salaries in comparable jobs in the private sector. Salary levels in Albania are perceived as both relatively adequate and transparent. At the same time, the salary system provides very few incentives for civil servants to perform well.

FBiH's salary system differs in its institutional set-up but performs equally well in terms of the adequacy of salary levels and transparency. The system also only has few specific incentives for civil servants. The Salary Law was only passed in 2010 and it remains to be seen to what extent the regulations can be successfully implemented. Montenegro's salary system shares the features of the systems discussed so far in terms of achieving basic transparency and offering virtually no incentives. Yet, in contrast to Albania and $\mathrm{FBiH}$, salary levels in Montenegro are very low.

The salary systems of the former Yugoslav Republic of Macedonia, Serbia, RS and BiH differ in that they incorporate performance-based elements. However, the system has so far only been fully implemented with limited success - in the former Yugoslav Republic of Macedonia. Even if well-defined regulations have typically been established, the inclusion of performance-based elements tends to reduce the predictability of the salary systems.

In the former Yugoslav Republic of Macedonia, the salary system is regulated by the 2000 Civil Service Law. Implementation started a few years later in 2004. Salaries consist of several components, each of which is allocated a certain number of salary points. First, civil servants receive points based on their level of education. Second, the main component of the basic salary is position-based. The system has three groups of positions which are divided into sixteen positions.

To calculate the basic salary, the civil servant's number of salary points is multiplied by the monetary value of a salary point as defined by the Government. The third component refers to a seniority supplement of 0.5 per cent of the basic salary for every year of employment in the civil service. The basic salary is hence largely transparent and predictable. Educational attainment and the category of positions are clearly defined in ministerial rulebooks and seniority supplements are non-discretionary. Civil service managers have virtually no discretion to influence the size of civil servants' basic salary. 
The basic salary structure is complemented by mechanisms for horizontal career progression which represent a 'light' system of performance-related pay. All civil servants can progress horizontally along four steps, which provide a salary bonus of up to 20 per cent. Progression requires three excellent or satisfactory performance evaluations. Excellent performers may be promoted to a higher career step after two years. While the salary system provides modest performance incentives, it suffers from problems of discretion and favouritism. Even if performance reviews are widely applied in the former Yugoslav Republic of Macedonia (see previous section), they struggle to guarantee the fair and equal treatment of civil servants.

The system of horizontal career progression also suffers from problems of maturity. After several years, civil servants have moved up to the top class of their category. There are hence no more performance incentives for civil servants who have made it to the top of the system. As a result, the carrot (incentive component of the salary system) has effectively been 'consumed', in particular because of the large proportion of top marks generally awarded.

In addition, the former Yugoslav Republic of Macedonia's salary system provides opportunities for the award of bonus payments for exceptional performance. Like in Albania, the award can reach up to one month's salary. In practice, this award is handed out only very rarely, implying that performance incentives exist on paper but not in practice.

Despite the lack of incentives and proper implementation, the salary system has been able to provided adequate salaries for low and mid-level civil servants. In a country where the unemployment rate is over 30 per cent, a job in the civil service is valued very highly. The state is able to provide a competitive and predictable and safe salary, which is not always the case in the private sector.

The salary systems of Serbia, RS and BiH share many features of the former Yugoslav Republic of Macedonia's set-up but they have been operational for a much shorter period of time. Yet it is still worth presenting Serbia's system (developed through a World Bank project) because in many respects it has become a model for other Western Balkan states.

Serbia's salary system was reformed following the adoption of the Civil Service Law in 2005. The Salary Act was passed in 2006 and came into force in 2007. Basic salaries are position based. The classification system distinguishes thirteen job categories, which are associated with salary coefficients. The basic salary is calculated by multiplying salary coefficients with the salary base that is set annually by Parliament in the Budget Law. Managing positions are allocated one salary coefficient. Non-managing positions are allocated eight coefficients, which are conceptualised as horizontal careers. In order to progress horizontally from one salary coefficient to the next, a civil servant is required to successfully pass the performance evaluation. In addition to the performance-based element, civil servants receive a seniority supplement of 0.4 per cent of their basic salary.

The implementation of the new system has only just begun so it is difficult at this stage to evaluate to what extent the horizontal career system is able to provide effective performance incentives. The vertical and horizontal division of salary classes provides for a large degree of transparency. Yet the reliance on performance evaluation for progression along the horizontal career steps undermines the reliability and trust of civil servants in the salary system.

According to personal interviews conducted, civil service managers consider the size of the performance bonus as too small. In order to reward effort, managers have to use legal provisions to pay for special 
work conditions, over-time work and temporarily deputising for higher-level positions. The transparency and consistency of the salary system inevitably suffers as a consequence.

The salary systems in BiH and RS share many features of those in Serbia and the former Yugoslav Republic of Macedonia but, for now, have much less implementation 'experience'. At this stage, it is difficult to say whether the systems will be able to deliver the right mix of transparency, fairness and incentives to perform effectively.

Finally, Kosovo and Croatia are the region's two laggards in terms of salary systems. Kosovo passed a new Salary Act in the spring of 2010. Implementation was scheduled for 2011 but, at the time of writing, it had not begun. The relevant legal framework therefore remained the 2000 UNMIK instruction on salaries in the public sector, which established general salary scales with each job being given a salary coefficient. While the Ministry of Public Administration and the Ministry of Finance have to approve the salary coefficients set in each ministry, ministries are responsible for the allocation of coefficients in the first place and can choose freely on the scale of coefficients. According to estimates, at least 70 different salary classes have emerged over time, meaning that managers have a great deal of discretion in setting basic salary levels.

In Kosovo, civil servants do not receive a seniority bonus, there is no horizontal career progression that would amount to a form of performance-related pay, and there are no specially designed awards for exceptional performance. The salary system rests to a large extent on the payment of salary supplements, which are not specifically regulated and not necessarily paid out of the salary budget designated by the Ministry of Finance. It is nearly impossible to verify the proportion of the salary being paid as a supplement relative to the official basic salary. According to estimates, approximately 50 per cent of the salaries are usually paid out of supplements. During personal interviews conducted, examples were given of salary levels representing twice the overall amount of the basic salary. In short, Kosovo's salary remains largely discretionary, which will be a major challenge for the implementation of the new salary system.

According to the new salary system, salaries will be tied to job categories. The system distinguishes four groups of jobs. Each group is divided between four levels of salary coefficients, which will provide for horizontal careers comparable to the experiences of the former Yugoslav Republic of Macedonia, Serbia, $\mathrm{BiH}$ and RS. In addition, there will be quotas for progression from one salary level to the next, which is likely to create resentment among civil servants, though it facilitates the management of the government wage bill. Inevitably, the implementation of the new salary system will be a major challenge that will take time to accomplish.

Croatia's salary system has remained largely unreformed over the last decade. Salaries continue to be governed by the 2001 Salary Act and several decrees adopted after the passage of the Civil Service Law in 2005. After the adoption of the Law, the passing of a salary act sharing many of the features of Serbia's Salary Act (and also sponsored by the World Bank) was envisaged. It would have rationalised the number of job categories, harmonised the allocation to job categories and, therefore, salary grades across government institutions, and introduced a system for horizontal career progression based on the outcomes of the performance appraisal. The reform failed because of disagreements within the Government and opposition from civil service trade unions. The unions were particularly concerned that the system of horizontal career progression would open the door to favouritism because of the unreliability of the performance evaluation system. 
As a result, the salary system has remained largely unchanged since the early 2000s. It distinguishes four broad salary grades for civil servants. For each grade, a range is provided for setting salary coefficients. Even if job categories are defined in ministerial rulebooks, the current system provides a certain degree of discretion over the allocation of jobs and salary coefficients. The incoherence of the salary system is reinforced by the presence of separate legal frameworks for the remuneration of various categories of officials such as police officers, foreign service officials, etc. The salary system cannot guarantee equal payment for equal responsibilities across government institutions.

In comparison to other countries, Croatia's salary system provides even fewer incentive instruments. There is no system for horizontal career progression and there are no special awards for exceptional performance. Bonuses are largely paid out of the system of supplements and allowance, for instance, for over-time work or for deputising in higher-ranking positions. Notwithstanding the marginal role of bonuses, the current system inevitably becomes non-transparent for both insiders and outsiders.

Interestingly, the main incentives that managers can provide are related to the provision of training. Participation in attractive training modules or in study trips abroad and, to an even greater extent, financial contributions to university studies are major incentives for civil servants. As we will see in the next section, the distortion of the incentive system also has implications for the management of the training system in Croatia.

The attitudes of civil servants towards the principles of transparency, predictability and performance orientation are particularly relevant for civil service salary management. Figure 8.1 shows that civil servants are generally in favour of transparent salary systems in that they favour civil service wide salary scales. Differences between countries are small and the mean score of 3.9 is high.

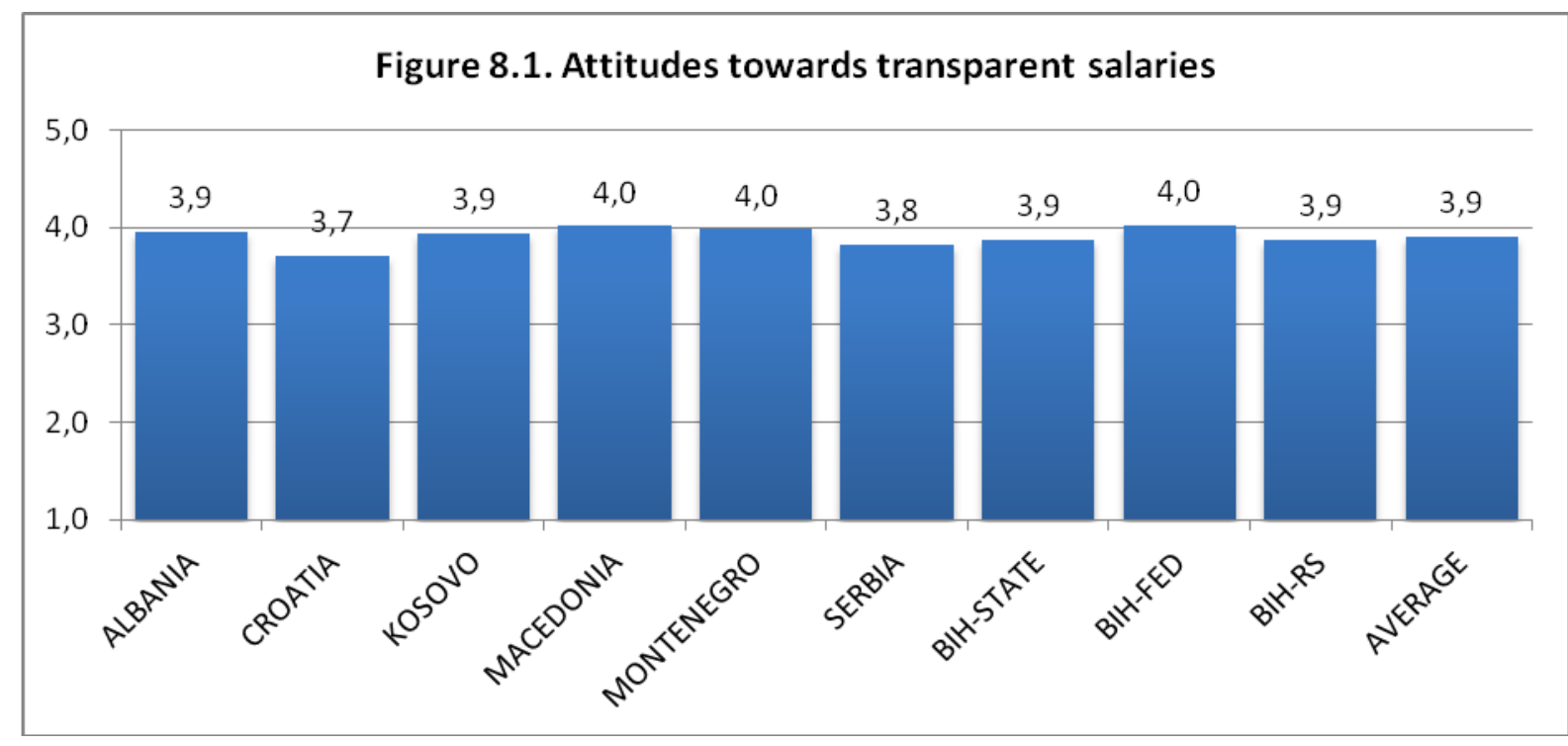

Figure 8.2 shows civil servants' attitudes vis-à-vis predictable salaries. The indicator includes civil servants' support for seniority-based salaries and their views on discretionary salary management. A preference for discretionary salaries should be considered as a negative attitude in the context of the European principles of administration. 
With a mean score of 3.1, figure 8.2. shows a medium to low degree of fit with European principles in most countries. It is clear then that discretionary salary systems have gained popularity in the Western Balkans. This finding creates new challenges for the future of existing salary systems. It effectively indicates dissatisfaction with systems that are seniority-based and fail to provide performance incentives. The pressure to de-regulate salary systems is therefore likely to grow.

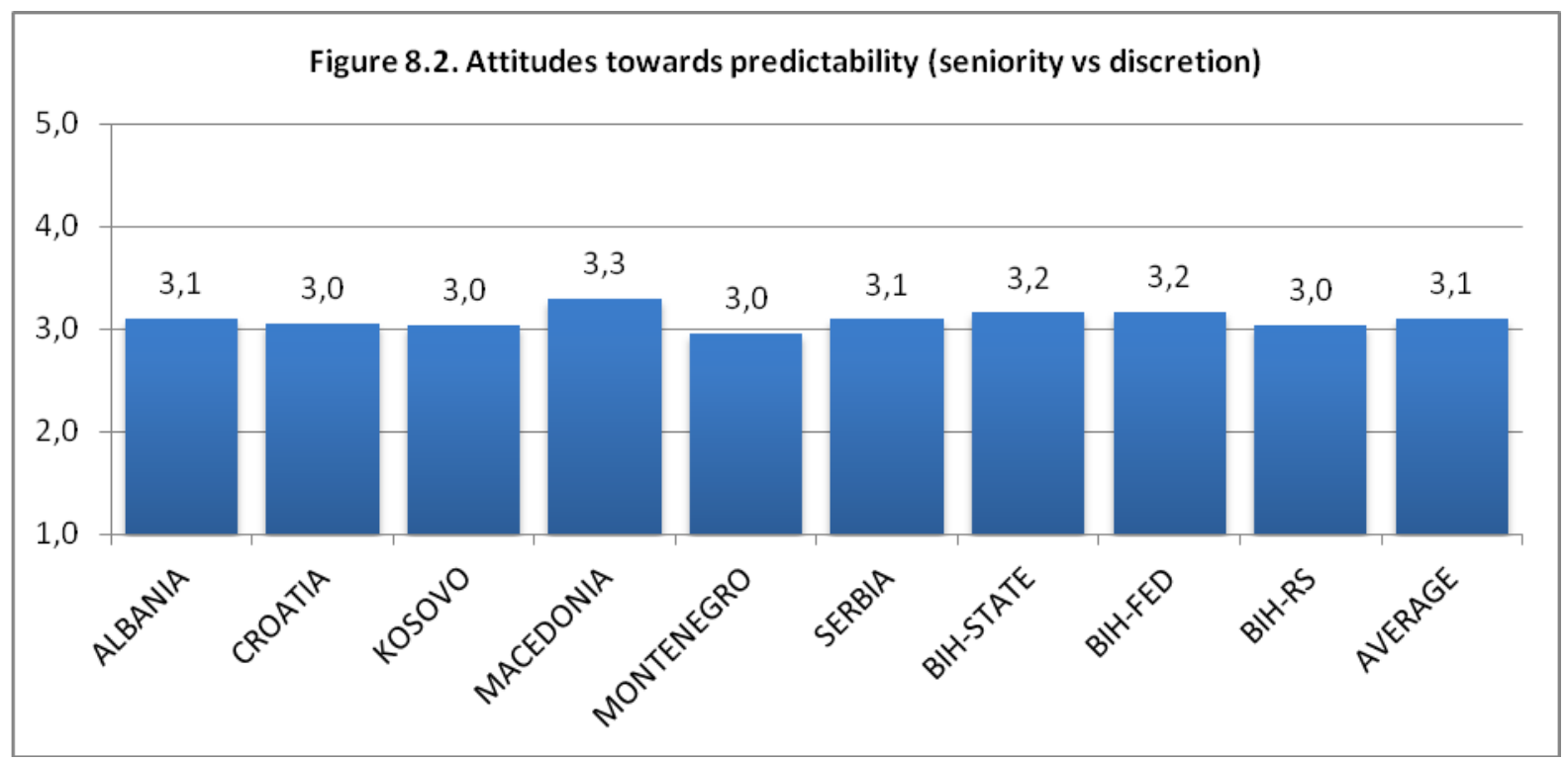

Figure 8.3. illustrates civil servants' support for performance-related pay in the public administration and shows that pay for performance is a very attractive principle for the management of salaries in the Western Balkans. All levels indicate a high to strong support for performance-related pay, at a level comparable to support for merit promotion and merit recruitment.

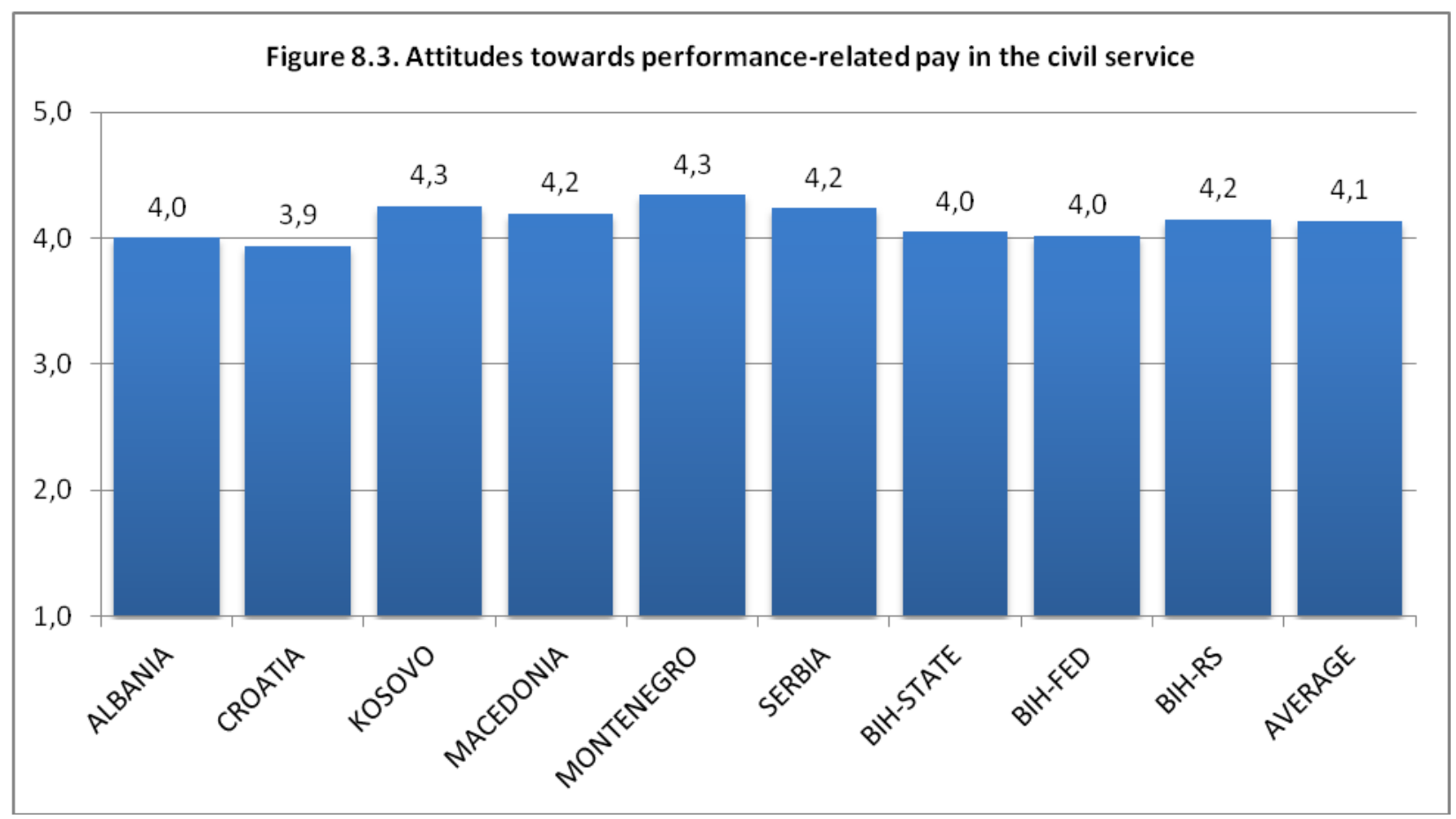


Performance-orientation can certainly be in alignment with the European principles of administration. However, in the civil service of pre-accession states, it is typically associated with discretion, favouritism and a lack of predictability and transparency.

The attitudes of civil servants and the general lack of performance incentives in the existing salary systems imply that the normative basis of salary management will be increasingly contested in the future, because of the mismatch with the European principles. In fact, even if salary systems continue to have a moderate to a high level of fit (except in Kosovo and Croatia), institutional changes comparable to the recent changes in the domain of civil service tenure can be expected shortly.

A shift towards the managerialisation of civil service salaries is also attractive politically, in that it provides opportunities for politicians to present themselves as modernisers or, in a slightly more populist dress, as bureaucracy-bashers who will not reward the slackers but only civil servants who work hard. For the European Commission and SIGMA, this situation creates dilemmas, as it will be difficult to prevent a gradual shift away from the European principles of administration.

\subsection{Training}

This section examines the domain of civil service training. The European Commission and SIGMA have addressed the training and development of civil servants as key instruments for the development of administrative capacity in pre-accession states. Civil service training is directly linked to effectiveness as a central European principle of administration. Accordingly, SIGMA has paid particular attention to the establishment of central institutions responsible for the development, coordination and delivery of civil service training in order to promote the effectiveness of the civil service. In addition, SIGMA addresses the development of training programmes and the regular participation of civil servants in training activities as conditions for developing civil service skills and competencies.

The overall record in this domain is moderate in that Western Balkan states have established training institutions, regularly developed and renewed training strategies, adopted annual training programmes, developed an impressive amount of training modules, and participation is wide-reaching when compared to where training policy in the Western Balkans stood at the beginning of the 2000s. The opening of the Regional School of Public Administration in Danilovgrad (Montenegro), whose development was primarily financed by the EU, contributed to the emergence of training capacity in the region. ${ }^{16}$

Yet, recent developments are less promising. The fragmentation of training policy has remained a major problem in the Western Balkans, in particular the poor coordination of the training activities of line ministries and of the training provided in the context of international assistance programmes. The incoherence in training programmes and delivery is reflected in civil servants' perception that training activities have limited effectiveness. More worryingly, training institutions in several countries have suffered major budget cuts as a result of the global financial crisis, leading to a decline in the capacity to sustain achievements

\section{Limited capacity of civil service training systems}

All Western Balkan states have established institutions responsible for the development, coordination and delivery of civil service training. Civil service training is typically included in the responsibilities of the

16 For further information on ReSPA, see www.respaweb.eu. 
central civil service management institutions: the HRMS in Serbia, the HRMA in Montenegro, the CSAs in BIH state and entity levels, and, following a transfer of responsibility from the CSA, in the Ministry of Information Society and Administration in the former Yugoslav Republic of Macedonia.

In Albania, Croatia and Kosovo, autonomous bodies for the management of civil service training have been set up and report directly to the Minister of Interior (Albania) or Public Administration (Croatia and Kosovo). However, they have to closely coordinate their activities with the main civil service management institutions: the Civil Service Training Centre (CSTC) within the Ministry of Administration in Croatia, the Kosovo Institute of Public Administration (KIPA) attached to the Ministry of Public Administration in Kosovo, and the Training Institute of Public Administration (TIPA) in the Ministry of Interior (which also hosts DoPA) in Albania.

The type of civil service training institutions established is relatively similar across the Western Balkans. None of them follows the concept of a national school of public administration that develops and directly delivers civil service training such as, for instance, the National School of Administration (ENA) in France or the School of Public Administration (KSAP) in Poland. Instead, training institutions are coordinating bodies. They develop training strategies (typically in collaboration with civil service management departments), develop annual training programmes, conduct training needs assessments, develop the curriculum of training courses, coordinate the recruitment of trainers from inside and outside the civil service, and conduct some ex-post quality control of training participation and provision.

All countries have developed training programmes that provide courses to introduce civil servants to basic issues such as the legal framework of public administration and the budgetary process. In all countries except Serbia and Kosovo, training bodies offer induction training for new civil servants. Specialised training in languages and information technology are regularly offered. Training that addresses the political system of the EU and the management of EU accession is offered in all countries.

These general training courses remain the basis of civil service training in the Western Balkan countries and these activities should continue. Civil servants in countries such as Kosovo will continue to receive basic training in order to become familiar with the new legal framework of the politico-administrative system. Moreover, the transposition and implementation of EU policies requires that civil servants continuously update their knowledge of the body of law in their country. Even in countries such as Croatia which is known to have a civil service that values legal competencies, personal interviews conducted indicate that an upgrade of the legal knowledge would be beneficial for the functioning of public administration.

At the same time, examples of more complex training programmes that address systemic weaknesses of the civil service are rare. For instance, leadership skills are commonly identified as one of the major weaknesses of civil service managers in the Western Balkans.

The most comprehensive programme has been developed in Croatia, where all new civil servants in managing positions below the level of director are required to pass a certified course that lasts three semesters. The programme was developed in collaboration with the Danish School of Public Administration. Participation has so far been modest primarily due to limited organisational capacity, but the initiative should nonetheless be considered as positive. The demand for participation among managers has been high since the inception of the programme.

The differences in the scope of activities are reflected in the number of courses developed and in participation rates. In Montenegro, 3,700 civil servants participated in training courses in 2010. In 
contrast, the number of participants in Serbia during the first seven months of 2010 stood at just over 1,800 participants. This figure seems fairly low when comparing the size of the Montenegrin and the Serbian civil services.

The degree of participation varies across ranks in the civil service. Managing civil servants are generally less willing to participate unless they are required to do so, as is the case in Croatia (see above). Among non-managing civil servants, it is possible to find figures of participation of $10-15$ days per year for countries such as Kosovo. However, in most cases, the number of days in training is lower.

Although central civil service training bodies have been established in all countries, training policy continues to suffer from fragmentation and lack of coordination problems.

First, in several countries including Serbia, BiH and Kosovo, the Government allocated the responsibility for the coordination and delivery of EU-related training policy to the institutions responsible for coordinating EU affairs: the Serbian European Integration Office, the Ministry of European Integration in Kosovo, and the Directorate for European Integration in BiH.

EU affairs units tend to stand out as more professional in comparison to other central government institutions and their superior knowledge of the needs for EU-related training may be beneficial for the targeting of institutions and civil servants. Yet the delegation of training on EU matters to units in charge of EU affairs increases fragmentation and it undermines the reputation of central civil service training in the eyes of ordinary civil servants. In terms of developing institutional capacity for the development and delivery of civil service training, this division of competencies is regrettable.

Second, central civil service training institutions differ in their ability to coordinate training activities across government institutions. In Albania and Montenegro, training policy is relatively more centralised and, as a result, more strategically oriented than in the other countries. Budgetary resources for training are exclusively allocated to the central training institutions and training activities are hence largely channelled through the centre. Line ministries are not prevented from delivering and procuring their own training but they cannot refer to separate budget lines for training for civil servants.

In the former Yugoslav Republic of Macedonia and $\mathrm{BiH}$, training policy is by and large decentralised in that ministries are as important in the delivery of training as the central training institution. Yet in both cases mechanisms for coordination exist. In the former Yugoslav Republic of Macedonia, government institutions and municipalities are required to submit annual training programmes for approval by the Ministry of Information Society and Administration (previously by the CSA). In practice, the system does not work as desired because only a minority of state bodies submit their training plan. Hence the degree of central coordination is effectively very low.

In $\mathrm{BiH}$, civil servants are required to pass a certain number of training credits every year, which are assessed in the context of the annual performance evaluation. Non-managing civil servants have to pass five credits and managing civil servants seven. Credits can be acquired by attending central training modules as well as training modules offered by ministries, provided they have been accredited by the CSA. The completion of training credits is required in order to receive an excellent performance evaluation, thereby providing an incentive for participation in training. Personal interviews conducted show that in practice, managing civil servants in particular fail to complete the required number of training credits. The actual ability to coordinate training policy across Government is inevitably limited. 
In Croatia, Serbia FBiH and RS, there are far fewer opportunities for the effective coordination of training policy. In fact, the evidence suggests that ministries in these countries (but also in the former Yugoslav Republic of Macedonia and $\mathrm{BiH}$ ) tend to protect their influence over training activities and hence prevent the delegation of training funds to the central training bodies. In Croatia, for instance, the CSTC has made many attempts to gain control over the training budget but ministries have so far resisted this loss of control. The common argument is that training needs are better identified at the institutional level and special training can easily be sought when necessary.

Yet this perspective fails to recognise that training activities play an important role as incentives for civil servants. Especially in a context where salary incentives are very small, civil service managers use access to training in order to hand out various kinds of training-related rewards to their employees. Small rewards may involve participation in conferences abroad or even small study abroad programmes. Larger rewards include the financing of university master degree programmes. Especially in Croatia, this is an important incentive that can be handed out by individual ministries.

Third, on top of the difficulty central training institutions have in coordinating training activities across government institutions, coordinating training programmes provided by the international community has also been a major challenge. The proportion of training provided by international organisations has declined over the last few years as domestic efforts to fund and provide training have increased. Yet international training continues to play an important role. In Bosnia, for instance, it was estimated that approximately 40 per cent of training activities continue to be funded by the international community. It is generally extremely difficult to estimate the amount of training by the international community because it is usually not coordinated across government. For instance, KIPA in Kosovo has the mandate to coordinate technical assistance but has not been able to establish an inventory of international projects. Apart from Albania and Montenegro, the largest part of training activities is channelled through the ministries rather than through central training institutions.

In most countries, ministries have little interest in delegating the coordination of technical assistance to the centre. Training activities included in technical assistance provide contact and access to international actors as well as tools that can be handed out to reward employees of the ministries. At the same time, it is far easier for donors to coordinate with one ministry rather than with a central training institution, which has to include the training component of international projects into the wider training strategy and programme. Even if a decentralised approach to managing internationally funded training activities is unlikely to yield effective results, the incentives for ministries and donors do not support greater coordination and hence centralisation of training policy.

Fourth, one of the most worrying developments in the area of civil service training is the negative budgetary developments of the last few years. Regardless of the relative success of domestic institutions, governments in Albania, the former Yugoslav Republic of Macedonia and Kosovo have reduced the training budget that is delegated to central training institutions. In Albania, for instance, the annual budget was cut from 90,000 Euros to 9,000 Euros as a result of which TIPA is no longer able to supply the training activities prepared in the annual programme.

Albania is an extreme case but exemplified the vulnerability of training institutions to changes in government policy and in the economic environment. Budgetary cuts are usually justified in terms of the need to tighten fiscal policy and training budgets are among the first items that can be cut without threatening the operations of government. In Albania it has been possible to compensate parts of the budgetary cuts through support from the international community. This again highlights the role of the international community in anchoring domestic civil service policy. Training policy is yet another area that 
lacks sustainability and that would be severely cut if the international community decided to withdraw support.

Finally, one of the major developments in the area of civil service training has been the opening of the Regional School of Public Administration (ReSPA) in Danilovgrad in 2010. ReSPA is supposed to act as a school of public administration for all Western Balkan states. It provides training at its premises, organise networking events and aim to diffuse good practices in public administration across the Western Balkans.

While promising, the role of ReSPA remains contested. It has been argued that the establishment of ReSPA means that major training efforts by national governments are no longer required; an argument that is clearly incorrect and merely another way to justify budgetary cuts in the area of training.

For example, in Albania, as mentioned above, ReSPA has been used domestically to justify the cuts in TIPA funding by 90 per cent. Moreover, senior civil servants in several ministries share the dream of creating an Albanian school of public administration that would act as a feeder institution for the public administration and a focal point for alumni of the school. Similarly, in Serbia and Croatia, ReSPA has created renewed interest in the establishment of a national school of public administration, as interest in regional cooperation remains lukewarm, apart from a specific group of relatively more outward-looking civil servants.

Croatia, for instance, has recently made a step towards 'independence' by setting up its own school of public administration. The school had been part of the domestic debate for nearly a decade and an agreement on its establishment was finally reached in the context of the Civil Service - Human Resource Development programme adopted in 2009. The school will primarily have a coordination role in civil service training. It remains to be seen how the new school will collaborate with the existing CSTC.

Arguments to establish a school of public administration have also been raised in Kosovo and BiH. Graduates of public administration programmes in the USA and France have created a major interest in a school of public administration for Kosovo.

The role of ReSPA is recognised but a domestic institution remains the gold standard of national training and development policy and of the creation of a visible social status for civil servants.

$\mathrm{BiH}$ has seen long-standing discussions regarding the establishment of an institute of public administration with responsibility for $\mathrm{BiH}, \mathrm{FBiH}$ and $\mathrm{RS}$. In practice, this model is blocked by $\mathrm{FBiH}$ and $\mathrm{RS}$ (and in particular the latter) who are opposed to the intensification of coordination efforts with BiH. While a school of public administration is given an important symbolic value in most Western Balkan states, this is not the case of $\mathrm{FBiH}$ and RS whose see it as an element of the unification of the civil service, which they contest.

Finally, civil servants were questioned on their support for mandatory training for all civil servants in order to collect their views on participation (including their willingness to participate) in government provided training activities. While the effectiveness of civil service training is widely questioned, Figure 9.1 shows that training is generally seen by civil servants as highly desirable, with only very few differences across countries. Further investment in training will therefore be welcome and is likely to have a positive effect on the motivation of civil servants in the region. 
Figure 9.1. Attitudes towards regular training

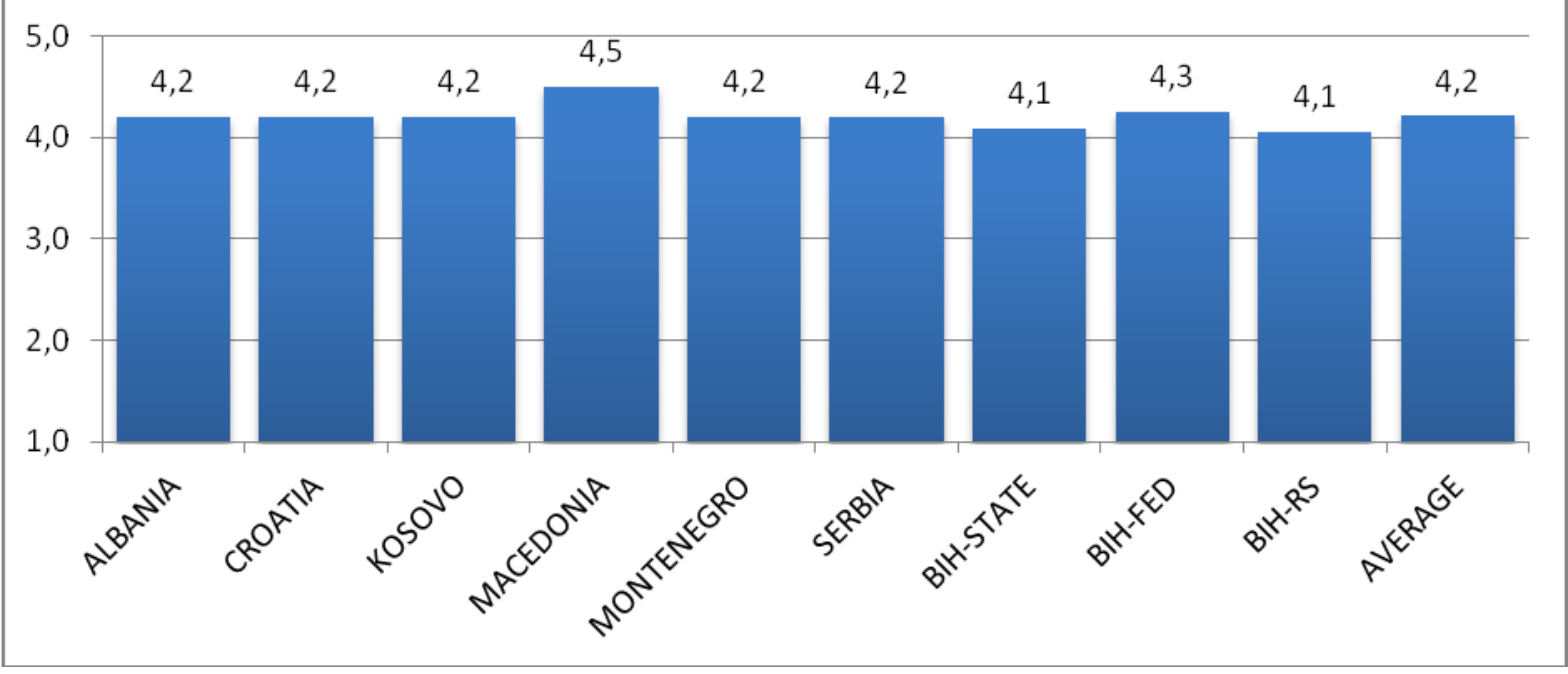

All in all, the area of civil service training has shown considerable progress over the last decade, and especially in Albania and Montenegro. However, problems of coordination persist and undermine the effectiveness of training policy. Problems of coordination and fragmentation exist both in the relations between government ministries and training institutions and in the relations between training institutions and international assistance programmes. Recent developments suggest that the achievements are not sustainable. In particular, training budget cuts in several countries run the risk of at least slowing down, if not rolling back, the positive developments made in most countries over the last decade.

\subsection{Integrity management in the civil service}

This section examines the domain of civil service integrity management. Integrity management refers to the formal frameworks that serve to induce ethical behaviour on the part of public officials. The European Commission addresses this domain in the context of anti-corruption policies. SIGMA has assessed integrity frameworks for public officials from all branches of government. This section focuses on integrity management insofar as civil servants are concerned. Integrity management frameworks seek to promote several European principles of administration, in particular the political neutrality and impartiality of the civil service.

The paper examines the establishment of conflict of interest regulations, in particular the restrictions on political and professional activities of those employed in the civil service, the role of codes of ethics as softer mechanisms of inducing professional conduct, mechanisms for monitoring conflicts of interests, and mechanisms for sanctioning misconduct in the civil service, and in particular the ability of disciplinary procedures to provide adequate sanctions while ensuring fair and equal treatment of civil servants.

The research shows that systems of civil service integrity management remain at a moderate to low degree of fit with the European principles of administration. Even if formal legal frameworks and ethical codes are in place, they tend to be insufficient. In particular, the laissez-faire approach to political incompatibilities opens the door to a politically active civil service, which totally contradicts the principles of political neutrality and impartiality.

Moreover, although mechanisms for the disclosure of conflict of interests exist, they have so far remained toothless because they lack the capacity to verify information and to threaten negative 
consequences for offenders. Disciplinary procedures exist in all countries but they remain both underutilised and under-developed in that they fail to provide conditions for the fair and equal treatment of civil servants in many, though not all, Western Balkan countries.

Generally, civil servants broadly accept conflict of interest regulations but their purpose is not always well understood. There is considerable interest in exploiting problems of corruption and integrity for political gain but there is much less appetite for tighter regulations. Yet the international discourse surrounding the fight against corruption as well as the domestic receptiveness to international pressures provides opportunities for the further development of this domain of civil service management.

\section{Limited effectiveness of civil service integrity management}

The legal basis governing integrity management in the civil service is scattered across several pieces of legislation. All Western Balkan states address the issue in their civil service laws, for instance, by broadly defining conflict of interest in the civil service. In addition, separate conflict of interest legislation and laws for the prevention of corruption have been adopted in most countries.

The legal frameworks are meant to be complementary but run the risk of creating inconsistencies for the integrity management of civil servants. They differ in their scope, for instance conflict of interest laws usually refer to high-ranking state officials such as members of parliament, cabinet ministers and political appointees such as state secretaries in the former Yugoslav Republic of Macedonia, Serbia and Croatia. In addition, conflict of interest laws include senior civil servants such as general secretaries, assistant ministers and directors general in Serbia, Croatia and Montenegro.

As a consequence, senior civil servants are lumped together with high-ranking state officials from other branches of government, while the integrity management for ordinary civil servants is limited to the civil service statute and is hence under-regulated. Instead, it would be desirable to create a specific, unified framework for integrity management of civil servants, primarily through an upgraded civil service law.

All Western Balkans countries except BiH have adopted a code of ethics or equivalent, usually passed shortly after the passage of civil service laws. The code of ethics was passed in FBiH 2004, in Croatia in 2006 (and again in 2011), in Serbia in 2008, and in RS a new code of ethics was adopted in 2009 in the context of the revision of the Civil Service Law.

The former Yugoslav Republic of Macedonia and Albania differ in that codes of ethics are conceived as acts of law. In the former Yugoslav Republic of Macedonia, a code of ethics was passed in 2001 by the Civil Service Agency as a piece of secondary legislation. Albania even passed a law on ethics in 2003, which creates major problems of enforcement. Codes of ethics and, more generally, ethical behaviour in public administration are usually subject to civil service training. Moreover, the violation of codes of ethics is regarded as a major offence leading to the initiation of disciplinary proceedings.

Code of ethics have an important symbolic value but their effectiveness is generally questioned. Even if code of conduct violations can lead to the initiation of disciplinary proceedings, behavioural guidelines are typically too general to create a significant constraint on civil servants' work. In addition, some countries such as Croatia have established an ethics commission as an independent working body that provides opinions on the implementation of the codes of ethics, as well as appointed individual ethics commissioners in each state institution in order to promote the application of the code of ethics. Whether these efforts have in practice made a difference for the effectiveness of integrity management is questionable. 
Civil service laws in all Western Balkan states explicitly refer to the principles of political neutrality and impartiality. Yet the formal restrictions on political activities are not aligned with these principles. Instead, civil service laws adopt a political laissez-faire approach, which allows civil servants to be widely involved in political parties and elections. Most typically, civil service laws permit political activities as long as they are conducted outside the office. For example, in the former Yugoslav Republic of Macedonia, the Civil Service Law merely forbids the use of political symbols in the office and electoral campaigning during working hours. In Croatia, civil servants shall not encourage political activities in the office, and in Serbia and Montenegro they are simply to refrain from political activities during their working hours.

As a result, the legal basis allows civil servants to be both members and functionaries of political parties, an unusual situation when compared to other European states. In addition, civil servants can run in national and sub-national elections without having to suspend professional activity, and only have to do so if voted in. The rules are only slightly more restrictive in Albania, Kosovo and $\mathrm{BiH}, \mathrm{FBiH}$ and $\mathrm{RS}$, with political activities generally acceptable but not official posts in political parties.

The low degree of restrictiveness is typically justified in terms of democratic norms such as the freedom of association and the freedom to stand in elections. For instance, in the former Yugoslav Republic of Macedonia, the Constitutional Court confirmed the political rights of civil servants rather than allowing even minimal restrictions.

However, the legal basis fails to support the principles of political neutrality and impartiality of the civil service. In fact, it is very common to find civil servants who are politically active in one way or another. In the former Yugoslav Republic of Macedonia, it is estimated by internal and external observers that approximately 30 per cent of civil servants were involved in the electoral campaign of the governing parties in 2011. Under these circumstances, the civil service, instead of being a politically neutral institution, turns into an arm of the ruling party to ensure re-election. Similarly, in Kosovo, which formally does not allow civil servants to hold official posts in political parties, it was common knowledge that even the head of the civil service department ran for a position of mayor.

The professional activities of civil servants that are conducted on top of their job in the civil service are only slightly more restrictively regulated than their political activities. Most commonly, civil service laws and laws on conflict of interest stipulate that civil servants are in conflict of interest if they own companies and/or shares, sign employment contracts, are on the boards of companies or NGOs, or if their work involves direct contact and/or an authority relationship with companies and/or NGOs. If a conflict of interest arises, they are required to notify their superior who then needs to decide whether or not to grant the relevant permission.

In practice, this approach has so far been ineffective. For instance, civil servants might simply fail to notify their superior of any conflict of interest or they may not be aware that a conflict of interest has actually arisen. In fact, even if a conflict of interest is reported, it is still possible to receive permission, as heads of institutions have the discretion to grant consent in these situations. It is therefore unsurprising that the number of reported conflicts of interest is extremely low, even if internal and external observers of public administration are convinced that conflict of interest is a widespread problem in the civil service of most Western Balkan states.

The laissez-faire approach to extra-professional activities of civil servants applies to Montenegro, Croatia and Kosovo and to ordinary civil servants in Serbia. By contrast, the regulation is slightly more restrictive in the former Yugoslav Republic of Macedonia, Albania and for senior officials in Serbia. In the latter, a new law on the prevention of corruption was passed in 2008, and it applies to state secretaries, political 
advisors, general secretaries and assistant ministers as top civil servants. It forbids ownership of private companies, parallel employment in the private sector and board memberships. The implementation of the law has just begun so it is too early to expect it to have had a major effect on the Serbian senior civil service.

All Western Balkan states have established mechanisms for the disclosure of public officials' assets and income. These disclosure systems are typically regulated by conflict of interest laws or by separate laws on asset declarations (e.g. Albania). Their scope varies considerably across countries. In Croatia, Serbia, Montenegro, Kosovo and $\mathrm{BIH}$ state and entity levels the requirement to disclose assets and income is limited to the senior civil servants included in the category of high-ranking public officials. These officials typically have to submit a declaration at the time of appointment, when their asset and income position (or that of a close relative) changes, and when they depart from the civil service.

In the former Yugoslav Republic of Macedonia, the requirement to disclose assets and income applies to all civil servants. The regulation was only introduced in 2010. It creates the same regulation for senior and ordinary civil servants. In comparison, civil servants in Albania have to submit a declaration at the time of appointment that they are not subject to any conflict of interest. The declaration is submitted to DoPA and is a precondition for an appointment to the civil service.

The main weakness of disclosure systems is not the veracity of the forms submitted but the enforcement of conflict of interest legislation. In all countries, legislation identifies separate bodies for the verification of asset and income declarations. Most typically these are special parliamentary committees or state commissions attached to parliament.

These bodies tend to lack the capacity to check declarations and to identify potential conflicts of interests. For example, in the former Yugoslav Republic of Macedonia, the state commission located in the Parliament holds approximately 8,000 files but, at the time of writing, had not started verifying them.

In Serbia, the new Serbian Anti-Corruption Agency was established in 2010 as a successor organisation to the former Board for the Prevention of Corruption. At the end of 2010, the office kept 16,000 files and had just outlined a programme for the verification of a small group of top state officials such as cabinet ministers.

In Croatia, one of the main concerns of internal and external observers of the integrity management system is the lack of professionalism of the Parliamentary Committee for the Prevention of Conflict of Interest. As the Committee is only constituted of members of the parliament, it has effectively been impossible to follow up the income and asset declarations submitted by high level state officials.

The lack of enforcement capacity is a general problem of the integrity management systems in the region. The politicisation of senior appointments to anti-corruption bodies is an additional constraint on the effectiveness of the disclosure system. Moreover, anti-corruption agencies pass on cases to the state prosecutor's office but a follow-up is not guaranteed. In Kosovo, for instance, it has been reported that none of the cases referred has been pursued further by the general prosecutor.

For senior civil servants and political appointees (as well as most other high-level state officials), this state of affairs implies that the risk of conflict of interest detection is low and hence that the impact of the deterrence established by the existing integrity management system is minimal. In fact, this conclusion applies even more to ordinary civil servants than to senior officials. 
Finally, all Western Balkan states have established and apply special disciplinary codes for civil servants. Disciplinary codes provide sanctioning mechanisms, while ensuring the fair and equal treatment of civil servants. Institutional solutions differ across the Western Balkan states. In Albania, for instance, disciplinary proceedings can generally be initiated and decided by the direct superior of the civil servant, meaning that conditions for fair and equal treatment are clearly lacking. In fact, most disciplinary decisions are appealed against in the Parliament's Civil Service Commission and the majority of cases end with the annulment of the original decision.

Similar provisions apply to minor disciplinary offences in the other countries but for major irregularities decisions are commonly taken by special disciplinary committees. In the former Yugoslav Republic of Macedonia, committees used to include a representative from the Civil Service Agency. In addition, a representative of the civil service union is invited if a union member is concerned. In Croatia, the proceedings are even delegated to separate civil service tribunals that include a limited number of judges. Disciplinary proceedings become quasi-judicial processes delegated away from the heads of administrative institutions.

Besides the inability of the current legal framework to ensure the fair and equal treatment of civil servants insofar as ordinary civil servants are concerned (in particular in Albania, Montenegro and Serbia), it is evident that disciplinary codes are generally under-utilised. The disciplinary code is typically used as a means to put pressure on unwanted civil servants but it is seen by managers as time-consuming and uncertain in terms of outcome. There is generally only a limited number of disciplinary cases every year in the civil service of Western Balkans.

In most countries, managers have other instruments available to discipline civil servants. In Kosovo for example, civil servants have so far been employed on temporary contracts, which provides a powerful tool for managers. In Serbia and Albania, managers use changes in rulebooks and hence the ministerial organisation as justification for dismissals, transfers or demotions.

In addition, it should be remembered that conflicts of interest are loosely regulated in Western Balkans countries and that the mechanisms for the disclosure and verification of information provided by civil servants are highly ineffective. Sanctions resulting from violations of conflict of interest regulations and codes of ethics are hence unusual. It is therefore not surprising that civil servants question the adequateness of sanctioning mechanisms for unethical behaviour.

All in all, Western Balkan states have made considerable progress in the area of integrity management since the late 1990s. Yet, assessed against the European standards of administration, it is clear that the formal-legal basis remains incomplete in all countries. The main weakness is not the disregard for formal rules, as existing frameworks are indeed applied in practice. Rather, conflict of interest regulation, even when followed in practice, and the existing monitoring and enforcement mechanisms do not provide conditions for the promotion of political neutrality and impartiality of the civil service.

Differences across countries can be identified but even the relatively more developed integrity frameworks of the former Yugoslav Republic of Macedonia and Albania are clearly unable to create conditions that promote the political neutrality and impartiality of the civil service. As a first step, legal frameworks in the region will benefit from an upgrade.

However, the survey of civil servants indicates only lukewarm support for further regulation and management of conflict of interest in the civil service. Figure 10.1 shows general attitudes towards problems of conflict of interest. Both political and professional activities are combined into a single index. A mean score of 3.6 indicates a moderate fit with the European principles and hence a broad acceptance 
of the need to restrict political and professional activities. The understanding of and support for conflict of interest regulation is higher in the three BIH levels, Serbia and Croatia. By contrast, in Albania and especially in Kosovo, the score indicates only a medium to low degree of fit with European principles.

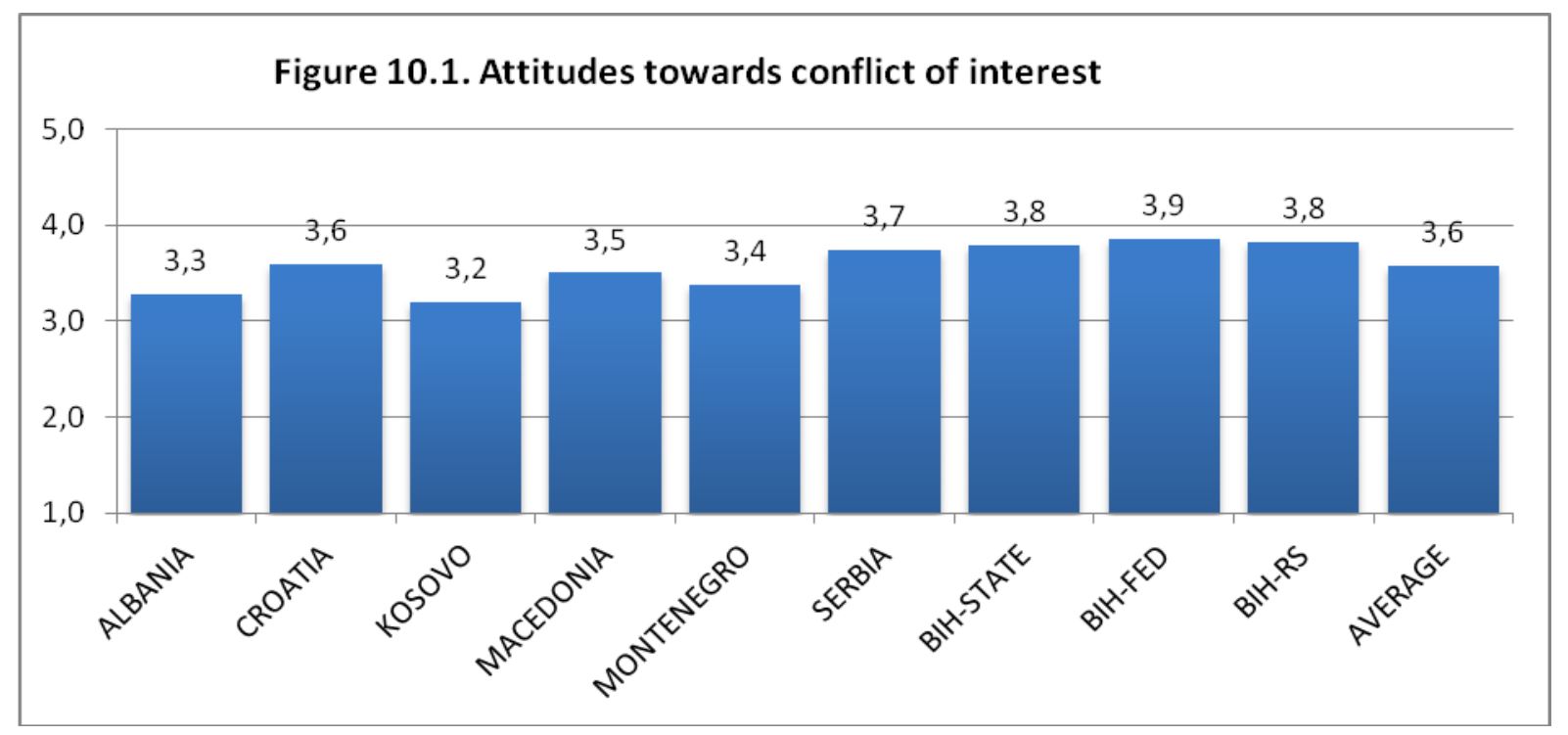

It is remarkable to consider the difference in the score between, on the one hand, merit-based principles such as merit recruitment and merit promotion and, on the other, integrity-based principles. Support for integrity-based principles is much lower than for merit-based principles. This applies above all to Kosovo, Albania and Montenegro where sensitivity towards problems of integrity is limited. By contrast, support for integrity-based principles is much higher in BIH and Serbia.

It is surprising that the international discourse on fighting corruption and the importance attached to the issue by the European Commission have so far not led to the creation of more effective integrity management frameworks, since there are no credible competitors in the normative discourse on corruption.

The issue of corruption is also extremely prominent in domestic political discourses, in that political parties have a tendency to use corruption as an instrument for blackmailing and political gain. Moreover, the new EU member states, in particular Poland, have shown that the fight against corruption is an issue that can win elections.

In light of this, there should be considerable potential for moving this domain forward. But this will require a higher degree of involvement from the European Commission and SIGMA, including a willingness to specify the criteria for integrity management and to engage in active monitoring and implementation support. 


\section{DISCUSSION AND CONCLUSION}

This paper has examined the professionalisation of the civil service in the Western Balkans. It has assessed the degree to which civil service systems fit the European principles of administration as the concept that has guided the European Commission's and SIGMA's civil service reform policy for the last 15 years. This section summarises the main findings of the analysis. It first compares the findings across levels of institutionalisation and across domains of civil service management. It then discusses the main drivers of civil service professionalisation in the Western Balkans since the late 1990s, emphasising the interplay of international and domestic factors. Recommendations for the re-orientation of the European Commission's approach to civil service reform in the Western Balkans are integrated into the discussion.

\section{Comparison across levels of institutionalisation}

The analysis has shown that the European principles of administration are far more institutionalised at the level of formal rules than at the levels of management practices and attitudes. First, Western Balkan states have made significant efforts since the late 1990s to build new formal-legal frameworks governing the civil service. Major institutional reforms were passed in Albania and the former Yugoslav Republic of Macedonia at the end of the 1990s, in BiH in the early 2000s, in Montenegro, Serbia and Croatia in the mid 2000s and in Kosovo at the end of the 2000s.

In terms of the European principles of administration, the formal institutional frameworks of the civil service reach a moderate to high degree of fit. The assistance of the international community is clearly visible in the contents of civil service legal frameworks. The influence of the European Commission and SIGMA was particularly relevant at the time of original reform design, but it has been increasingly difficult to shape processes of formal institutional change and fine-tuning. The analysis has shown that most formal-legal frameworks in the region require upgrades and revisions of specific aspects of civil service management. However, no institutional framework is in need of a major overhaul.

The main weakness of civil service governance in the Western Balkans is the low quality of rule implementation. The analysis has shown that formal civil service rules are routinely applied in practice and there are no signs of major rule evasion. However, formal rules tend to fail to achieve their expected outcomes. The domain of merit recruitment provides a paradigmatic case. Formal procedures for merit recruitment such as the public announcement of job vacancies, written examinations, selection by committee and opportunities for appeal have been established and are widely applied, but the outcomes of the recruitment processes are widely criticised for the persistence of informality, favouritism and political patronage.

Even if the impact of formal procedures has often been disappointing, it is widely agreed by internal and external observers that the management outcomes would in practice have been far worse without the existence of formal civil service procedures. Formal institutions do indeed matter. Formal institutions that fit the European principles to a high degree are associated with implementation patterns that also fit the European principles to a high degree. In other words, even if outcomes are disappointing, some positive aspects can be found.

The influence of the European Commission and SIGMA on the quality of implementation has so far been limited. Problems of rule effectiveness are the result of inconsistencies in the formal institutional frameworks of civil service governance and, in particular, in the incentives of governing political parties, 
political advisors and civil service managers insofar as they are classified as political appointees (see also below). The low degree of rule effectiveness presents a major challenge for the European Commission and SIGMA, since a greater role in rule implementation will require clearer, more concrete policy guidelines and in particular greater monitoring and communication efforts vis-à-vis Western Balkan states.

Third, civil servants' attitudes towards the professionalisation of the civil service in accordance with the European principles are positive for most but not all management domains. Civil servants generally support merit-based management practices as opposed to partisan influence. Yet the principle of managerial flexibility has become increasingly popular among civil servants in the Western Balkans. This has become especially evident with regard to support for the de-regulation of employment protection rules, discretionary pay systems and opposition to the centralisation of civil service management functions.

The increasing contestation of the European principles as the best concept to guide civil service reform will create additional challenges for the future of civil service professionalisation in the Western Balkans. So far, the direct influence of the European Commission and SIGMA on civil servants' attitudes towards European principles of administration is difficult to assess empirically. Attitudinal change is typically the result of complex socialisation processes that are virtually impossible to steer from outside. Exposure to the European principles, communication and education are among the few measures that can be taken. Yet the outcomes of these efforts inevitably remain uncertain, not least because of the long time horizons required.

Figure IV.1 shows the extent to which civil servants believe themselves to be familiar with the European principles of administration. It is remarkable that not even 50 per cent of respondents state that they 'know the European principles of administration well'. Even if additional efforts to communicate the contents and purposes of the European principles will not guarantee more support, it appears that the European Commission and SIGMA have not promoted the message well enough. Furthermore, there are good reasons to believe that politicians know about the European principles of administration much less than civil servants.

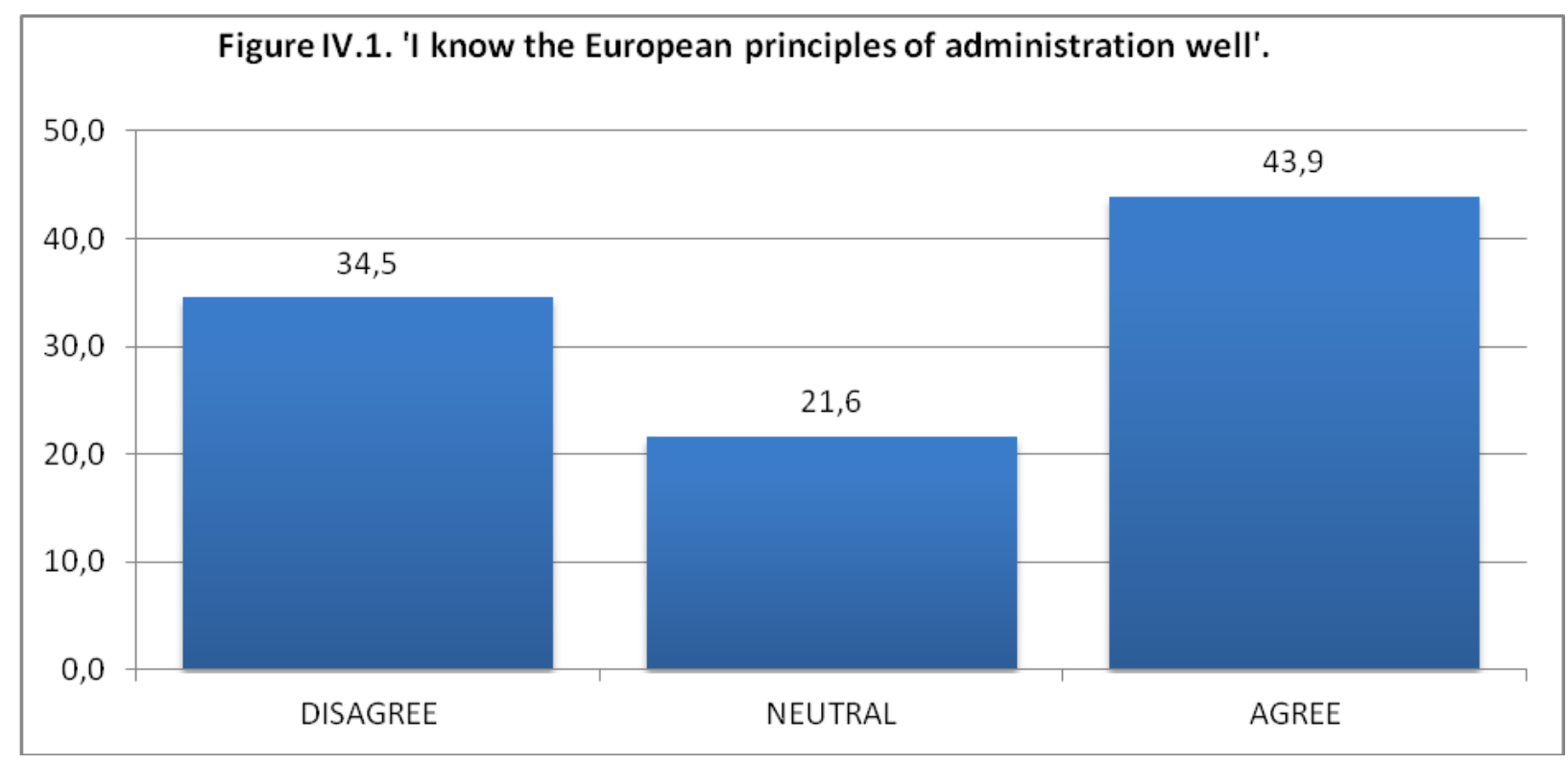


Consequently, there is a large scope for additional investing in the communication of the European principles to civil servants and politicians. Ideally, such an effort will address both the principles and their translation into structures and processes of civil service management. As a result, civil servants and even politicians might themselves be in a position to monitor the fit of civil service management practices with European principles of administration.

Overall, civil service governance remains inconsistent between formal rules of civil service management, the quality of rule implementation and the attitudes of civil servants towards principles of civil service management. The incongruence across levels of institutionalisation indicates that civil service governance has not yet stabilised. For the European Commission and SIGMA this provides further incentive to maintain, if not reinforce, support for civil service reform and professionalisation in the region.

\section{Comparison across domains of civil service management}

The analysis has shown that none of the domains reaches a high degree of fit with the European principles of administration. This conclusion reflects the general need to upgrade and revise institutional frameworks and to improve the quality of implementation discussed in the previous section. At the same time, it is also clear that not one of the domains of civil service management still only has a low degree of fit with European principles.

Focusing on the quality of implementation and the attitudes of civil servants, the analysis reveals three distinct groups of domains. The first group consists of the domains of senior civil service management, performance management, recruitment, training, and integrity management. These domains share a relatively low degree of fit with regard to rule implementation and a relatively high degree of fit with regard to rule internalisation. In other words, the quality of implementation is low but civil servants widely support the institutionalisation of the European principles in these domains.

In this first group, senior civil service management is clearly the weakest link. In fact, it is the area with the worst record in all countries except Montenegro. ${ }^{17}$ Formal-legal frameworks suffer from a larger number of gaps and inconsistencies. They are poorly implemented and provide a large range of opportunities for the exercise of political discretion. The practice of senior civil service management is widely characterised by politicisation and informality.

Differences across countries are moderate. In Montenegro and $\mathrm{BiH}$, the top level is relatively more stable due to lower party turnover in government, but links to parties and politicians are no less important than elsewhere. The development of the senior civil service will have to be a priority in future European Commission and SIGMA activities in the region.

A low degree of rule effectiveness in the area of civil service recruitment was discussed above. As with the domain of senior civil service management, a poor implementation record combines with a high degree of general support for merit-based principles of recruitment and selection. Differences across the countries are small. The area of recruitment suffers from a number of governance deficiencies that are partially connected to an inappropriate legal framework and partially to an environment that is not conducive to merit-based recruitment.

While conditions in the environment are difficult to change, especially in the short and medium term, options for improving the institutional framework exist. For instance, an adequate regulation of temporary appointments beyond the setting of simple quotas, a re-appraisal of competition procedures

17

In Montenegro, the area with the lowest fit is performance management. 
and efforts to raise the degree of difficulty of civil service examinations should contribute to better basic quality of outcomes in the area of recruitment.

The two domains of performance management and training share the general situation of poor implementation with wide support of civil servants for investment in training and the use of performance reviews. Countries differ to a larger extent in these two domains. In the area of training, Albania and Montenegro stand out as two cases with a relatively high degree of training effectiveness. They share the characteristic of a more centralised approach to civil service training. By contrast, more decentralised approaches suffer from a lack of coordination and training effectiveness.

The improvement of outcomes will depend to a large extent on the better coordination of training policies, including a stronger role for central civil service training centres, institutes and schools. The shift towards more central control of civil service training will require explicit support from the European Commission and SIGMA, as ministries and agencies will oppose further centralisation in this area. The Regional School of Public Administration may develop an important role in the development and coordination of training programmes and public administration degree programmes in the region. However, its position is not yet fully accepted by the Western Balkan states. Efforts will have to be made to demonstrate its added value for partner countries.

In the domain of performance management, differences between countries concern the quality of implementation. Montenegro stands out in particular with a poor implementation record. However, none of the other countries manages a good performance in this area of civil service management. The underdeveloped links to training and promotion decisions and the freezing of the links between performance reviews and salary levels since the onset of economic crisis have largely turned performance management systems into paper tigers without tangible purposes.

It is questionable whether the recently developed practice of using performance reviews mainly for dismissal purposes in many countries will have a positive effect on the quality of implementation and support from civil servants. The evidence from Serbia, which started to experiment with this form of linkage in 2009, is clearly negative. The European Commission and SIGMA will need to consider carefully what role they want to give to performance management in the civil service. A shift towards a constructive use of performance evaluation mechanisms will have to be a necessary element of any reorientation.

Finally, the domain of integrity management shares the general features of a fairly low quality of implementation. In contrast to the domains discussed so far, the attitudes of civil servants differ in that they are less supportive of the European principles. With regard to the implementation of integrity management frameworks, there is evidently a problem of rule effectiveness in the region. However, these weaknesses can to a large extent be traced to the under-regulation of conflicts of interest, especially with regard to political activities, and the low capacity of monitoring, verification and enforcement mechanisms. Differences between the countries are moderate. However, Croatia, Serbia, Montenegro, Kosovo and $\mathrm{BiH}$ demonstrate a relatively lower degree of fit in this area of civil service management.

In the future, formal institutions will need to be reviewed and particular attention paid to integrity management for civil servants. Much of the debate has been driven by international actors and most measures have taken a holistic approach to addressing politicians, top civil servants and possibly high level judges, with civil servants below the very top positions usually only partially included. In addition, 
the institutional framework for the integrity management of civil servants increasingly suffers from fragmentation. A separate effort to address integrity management in the civil service might be beneficial.

Such an effort would also have to address the monitoring and enforcement capacity of the integrity management frameworks in the Western Balkans. Measures in this area do not necessarily have to reinforce penalties and other deterrence measures. While it is arguably important to strengthen institutions that monitor conflict of interest issues, a much cheaper approach might concentrate on rewarding civil servants for complying and monitoring the integrity management framework within their area of work.

In addition, there is considerable scope for better measures to communicate the principles and purposes of institutions to civil service managers and their subordinates. In particular, in the area of integrity management, there is often a lack of awareness of problems of conflict of interest. The European Commission and SIGMA should therefore elaborate and promote mechanisms that enhance the dissemination and diffusion of principles and processes of integrity management. Information is the first condition for integrity management to work better than it has hitherto.

The second group of domains includes the areas of central-level civil service management, civil service tenure and salary management. These three domains share a moderate degree of fit with European principles in terms of rule implementation but only a low or a medium to low degree of fit in terms of rule internalisation.

The discrepancy between a relatively good implementation record and a lack of support from civil servants is evident in the area of central civil service management. Civil service offices and agencies, as well as ministries of public administration, have undoubtedly been instrumental in pushing government institutions towards common civil service management standards. The record of central management bodies is even more impressive when taking into account the fact that in several countries, the authority over civil service management is fragmented. This is particularly true for Serbia, where fragmentation has undermined the capacity of the centre to induce a consistent approach to civil service management across government.

At the same time, the analysis has revealed that the delegation of authority to central institutions is highly contested by civil servants. In practice, central management institutions would benefit from more powers in order to lift the civil service of Western Balkans countries to the next level of development. Yet the lack of support for central institutions is likely to increase the pressure for the de-centralisation of civil service management in the future. The establishment of ministries of public administration is a promising way forward. However, their effectiveness will depend on, first, the pooling of authority over civil service management as well as other areas of public administration reform and, second, the provision of both technical and political support in order to raise the status of this type of ministry.

The domain of civil service tenure differs slightly, in that the differences between countries are greater than in the area of central civil service management. In particular, Serbia and Croatia have a low degree of fit with regard to the quality of rule implementation. In the case of Serbia, this reflects to a large extent the inadequate procedures applied during the implementation of the recent staff cuts requested by the IMF. The downsizing measures were combined with institutional changes that allow the dismissal of civil servants on the basis of poor performance within a very short period of time.

Until recently, the fit with European principles was relatively high in all Western Balkan states except Serbia and Kosovo. Formal rules aimed to stabilise civil service employment while seeking to ensure, by 
and large, fair and equal treatment in case of dismissal. The institutional changes introduced in Serbia in 2009 and in several other countries since the end of 2010 have led to the de-regulation of civil service tenure rules. Even if the economic and fiscal crisis justifies measures to increase the efficiency of the civil service, the changes have created conditions that institutionalise a large degree of discretion that is not compatible with the European principles of administration. Apart from paying closer attention to the content of institutional reforms, it is therefore necessary to clarify the boundaries of the European principles in the area of civil service tenure.

A similar shift away from the European principles is arguably looming for the domain of salary management. Salary systems in the Western Balkans achieve an overall moderate to high degree of fit with European principles in all countries except Kosovo and Croatia. The low degree of fit for these two countries significantly reduces the average score for this domain of civil service management. However, the analysis has shown that transparency and predictability have been achieved at the expense of providing performance incentives in the salary systems. Moreover, civil servants' attitudes show growing support for performance-related salary management, opening the door for de-regulatory reforms in the future.

This will present a challenging context in the future for the EC and SIGMA, as performance-related elements will have to be integrated into the EU approach to salary management in order to reach a basic degree of compatibility with civil servants' attitudes. In fact, the structure of salary systems in the Western Balkans has been heavily influenced by the World Bank. Most typically, salary reforms were a condition for World Bank loans. World Bank conditionality targeted specific aspects of civil service management. This approach has been successful in a country like Serbia. In Croatia however, it failed as a result of the opposition of civil service unions to a salary reform that included performance-related pay elements. Croatia's poor performance in this area indicates that a salary reform is urgently needed. The European Commission and SIGMA will have to clarify their position in this area of civil service management.

Finally, the third group of domains includes the areas of civil service laws and reform programmes. First, civil service laws reach a moderate to high degree of fit with regard to both the implementation and the general internalisation of rules. Moreover, the differences across the countries are small, indicating a satisfactory institutionalisation of this domain across the Western Balkans.

However, the analysis has shown that civil service laws run the risk of being hollowed out, especially at the top, as politicians demonstrate strong interest in removing top civil service positions from the scope of the civil service law. For the European Commission and SIGMA, this calls for a closer monitoring of the contents of civil service laws and in particular of the amendments proposed by governments.

The area of reform programmes also displays an overall moderate to high fit with European principles. Moreover, the contents of civil service reform programmes provide a useful indicator for the future of reform in the Western Balkans. Most countries are currently at the end of a reform cycle and it remains to be seen to what extent they are able and willing to renew their reform programmes. The adoption of the first major new reform programmes in the former Yugoslav Republic of Macedonia and Montenegro has created concerns regarding the future direction of reforms. Even if the European principles of administration are prominently included, reforms point to a move away from the European principles. The former Yugoslav Republic of Macedonia in particular has seen a shift towards de-regulation and the institutionalisation of managerial flexibility which is likely to spill over to other Western Balkan states. 
In sum, the extent to which the European principles of administration are institutionalised in the Western Balkans differs both across levels and domains of civil service management. By contrast, the differences between the countries are relatively small. Not one of the civil service systems attains an overall high degree of fit with European principles, but at the same time, none remains at a low degree of fit. An overall intermediate degree of fit with European principles indicates that civil service professionalisation remains work in progress in the Western Balkans.

Kosovo is the only country in the region that overall remains at a medium to low degree of fit with the European principles of administration. However, following the start of the implementation of new legislation, it can be expected that Kosovo will soon catch up with the other Western Balkan states insofar as the management of the civil service is concerned. As with the other countries, the challenge will be to ensure high quality implementation of the new Civil Service Law and new Salary Law.

\section{Reform trajectories}

The discussion on the outcomes of civil service reform raises new questions with regard to the drivers of and obstacles to civil service professionalisation and the future of the civil service in the Western Balkans. The question of the future of the civil service touches upon issues of civil service reform sustainability and future involvement of the European Commission and SIGMA in civil service reform in the region. Accordingly, the emphasis here is placed on the interplay of international and domestic factors in shaping civil service reform trajectories.

Civil service reform trajectories in the Western Balkan states are largely split into two periods. From the late 1990s until the mid 2000s, civil service professionalisation progressed rapidly, in particular with regard to the development of reform programmes and the establishment of formal-legal frameworks, usually with some kind of international assistance. Since the mid 2000s, civil service professionalisation has been stagnating in all countries except Kosovo. Institutional reforms have not progressed further and the quality of implementation has been low. How can this development over time be explained?

\section{Credibility of the European perspective}

The ups and downs of civil service reform are closely related to the general prospects for Western Balkan states of moving closer to the EU. Most civil service reform initiatives were implemented during the period that shortly followed the opening of EU membership negotiations with the Central and Eastern European countries. Even if the accession process for Western Balkan states was structured separately, the Central and Eastern European process had a general European perspective that was also relevant for the Western Balkan.

The European perspective created a particular opportunity structure for domestic politicians and administrative policy-makers in the Western Balkan states. Indeed, pro-European, reform-oriented governments were voted into office in all countries within a short period of time. The modernisation and Europeanisation of the political systems, the economy and society was at the top of these governments' agendas.

The civil service reform initiatives of the late 1990s and early 2000s have to be seen in this context. They were an essential part of the modernisation agenda of reform-oriented governments. The European principles of administration were uncontested as the dominant reform paradigm. Governments, in particular prime ministers, provided high-level support for the reform and professionalisation of the civil service, which was in most cases coordinated by central civil service agencies. 
The stagnation of civil service reforms and professionalisation from the mid 2000s onwards is closely related to the fading European perspective for Western Balkan states and the growing "enlargement fatigue" in the old EU member states. Following the 2004 Enlargement, it became quickly evident that Bulgaria and Romania would be the last two countries to join the EU for some time.

Although the weakening of the European perspective did not usher in reactionary governments, the opportunity structure for politicians in the Western Balkans changed. The domestic opportunities and constraints politicians and administrative policy-makers faced became increasingly important for civil service development, even if the European Commission, SIGMA and other international organisations continued to provide active assistance. The domestic opportunity structure has been mainly shaped by the structure of political competition, private sector development, the integration of ethnically diverse societies, national administrative traditions and central civil service management institutions.

First, the weakness of the private sector means that the demand for jobs in the public sector has remained high. Indeed, the public sector is usually the most important employer in the region. In this context, political parties have increasingly acted as agents that supply jobs for their supporters at all levels of public administration and the wider public sector. Patronage of this kind is widely entrenched across the region and it is unlikely to decline without the development of a stronger private sector.

Second, the ethnic division of society in several Western Balkan states further hampers the establishment of merit-based civil service systems, as political pressures to achieve some form of ethnic representativeness are simply too strong. The mechanism of equitable representation established in the former Yugoslav Republic of Macedonia in 2001 has largely turned into a licence to politicise the civil service. In other places, especially $\mathrm{BiH}$ and $\mathrm{FBiH}$, politicisation via equitable representation is less formal but certainly no less prominent.

Third, the structure of political competition, and in particular the patterns of government alternation, has created additional incentives for civil service politicisation. Bipolar competition that led to wholesale changes of government from one political bloc to another created in the mid-2000s major trust problems for new governments vis-à-vis bureaucrats 'inherited' from outgoing governments. For instance, the government changes in Albania (2005), the former Yugoslav Republic of Macedonia (2006) and Croatia (2003) led to major pressures in terms of politicisation of the senior civil service. ${ }^{18}$ Government changes in Serbia in 2003 and 2007 had a similar effect. Montenegro is an exceptional case in the region in that governments have been very stable. Everything else being equal, political continuity facilitates the professionalisation of the civil service.

Fourth, the capacity of central civil service management institutions has been instrumental in enhancing the level of professionalisation. During the first half of the 2000s, civil service offices and agencies were the preferred institutional solution. They tended to enjoy political support, primarily from the prime minister, and the leadership of civil service agencies usually represented the most important reform 'entrepreneurs' in the countries.

As civil service professionalisation has increasingly come to contradict the domestic incentives of politicians, civil service agencies first lost their political support and then, in several cases, their central location. Even if central management institutions and their leadership have tended to maintain close contacts with international organisations, their position has turned out to be unsustainable, conditional upon domestic political interests and a wider European perspective.

18 The recent change of government in Croatia has also followed this pattern. 
Fifth, administrative traditions create their own opportunity structure especially for administrative policymakers. The Yugoslav administrative tradition is generally regarded as more compatible with the objectives of post-communist administrative transformation. Relative to the legacy of other communist regimes, it placed greater emphasis on legalism and retained elements of professional competence in the recruitment and promotion of officials.

In particular, Serbia's and Croatia's administrative tradition is widely seen as more 'usable' in the postcommunist, pre-accession context. However, this perception has also reduced the appetite for institutional change in these two countries. The weakening of the European perspective in the second half of the 2000s has shifted the focus of administrative policy-makers back to the 'usable' elements of the administrative tradition. ${ }^{19}$

As long as the European perspective was perceived as sufficiently credible, it could at least to some extent over-ride the domestically-generated incentives of politicians and administrative policy-makers. When the European perspective started to fade, this mechanism no longer worked. The central role of external incentives for civil service professionalisation and weakness of the domestic ones do not bode well for the sustainability of reforms. Without international engagement, the prospects for professionalisation are largely negative, whatever the content of official statements in the region.

For the future role of the European Commission and SIGMA, this conclusion constitutes a major macropolitical constraint largely beyond their control. It is simply impossible to set an external incentive that is nearly as powerful as a credible EU membership perspective. However, if the external opportunity structure for Western Balkans governments does not improve, the prospects of getting civil service reform back on track are very modest.

Several examples from the region suggest a second-best option in the context of a weak overall European perspective. First, over the last years the accession process has been increasingly subdivided and differentiated. Therefore, it might be desirable to link civil service reform progress to specific milestones. For instance, the analysis has shown that the World Bank has a reasonably good record in the area of salary management. World Bank loans were typically tied to particular reforms such as the development and passage of a new salary system. Accordingly, in order to re-energise the reform process, the European Commission could hand out specific rewards in exchange for institutional reforms and the improvement of management practices in fairly specific, circumscribed areas of civil service management.

Second, notwithstanding the general European perspective, conditionality in the area of civil service reform suffers from a lack of credibility. There is no acquis communautaire on public administration issues and no chapter as part of the accession negotiation can be opened and closed when reform progress is sufficient. Because these structural constraints are unlikely to be resolved by the EU in the near future, the European Commission will have to look for alternative mechanisms to raise the political importance of civil service reform issues.

Several positive initiatives have recently emerged. In Montenegro, public administration reform has been included in the list of conditions that have to be addressed before it can progress from being a candidate

19 The return to the administrative tradition has been less important in other countries for various reasons. In Albania, the legacy of the past was not at all usable in the post-communist context. In the other countries, either the interest in entrenching state independence overrode the attractiveness of the administrative legacy or the international community actively tried to prevent such a return. 
to opening negotiations. As a result, the opportunity structure of the government changed and public administration reform, including civil service reform, received new political support.

For the former Yugoslav Republic of Macedonia, the European Commission initiated a structured dialogue on public administration in the context of the Stabilisation and Association Process. As a result, public administration reform has attracted growing attention from the highest political level and within the administration. The institutionalisation of these kinds of mechanisms that shape the opportunity structure of Western Balkan governments will be a key condition for getting civil service reforms back on track.

\section{Conditional effectiveness of international assistance including SIGMA}

The role of international organisations in shaping public administration reform in the Western Balkans cannot be separated from the presence or absence of a European perspective. Following the election of pro-European, reform-oriented governments in the late 1990s and early 2000s, channels of international aid and assistance opened almost instantly. International assistance played a major role in setting the pace of reform and in particular the contents of reform programmes and civil service laws. In some cases, the same consultants moved from one country to the next in order to provide assistance in the preparation and drafting of civil service laws.

The European Commission lacks in-house expertise in the wider area of public administration. Because there is no acquis communautaire on public administration, there is no line DG responsible for public administration issues. The expertise available within DG Enlargement and the EU Delegations and Liaison Office in the Western Balkan is inevitably limited. Country Desks in Brussels and Delegations in the Western Balkan have to manage a wide and diverse agenda. The capacity to directly guide and monitor public administration developments is limited, meaning Country Desks and EU Delegations have to rely on external sources of expertise on public administration reform.

Over the last few years, DG Human Resources, formerly DG Administration, has started to engage in civil service reform issues in member and candidate states. For instance, DG Human Resources coordinates a working group on human resource management in the context of EUPAN, the European Public Administration Network. DG Human Resources also monitors civil service developments in current preaccession states and was instrumental in sponsoring the evaluation of the post-accession sustainability of civil service reforms in the new EU member states, which led to the publication of SIGMA Paper No. 44.

Under these conditions, SIGMA has been an important yet under-utilised source of external public administration reform expertise for the European Commission ever since the beginning of the accession negotiations with the Central and Eastern European countries in the late 1990s. SIGMA has been a key actor in the development of reform programmes and in particular legal frameworks in the Western Balkans. Yet, like other international organisations, SIGMA's influence is largely conditional upon the presence of a European perspective and the importance that the European Commission attaches to public administration reform issues. Hence, even if SIGMA is widely recognised as an institution of relevant expertise, its influence has declined since the mid 2000s, as the European perspective for the Western Balkans has increasingly deteriorated.

Both the European Commission and SIGMA would benefit from closer coordination of their activities. Even if the European perspective remains weak, this would allow SIGMA to enhance its authority vis-à-vis pre-accession states and help the European Commission enhance its position in terms of expertise. In particular, the Country Desks and the EU Delegations would be able to guide public administration reform 
more effectively than hitherto. Closer coordination would also improve the European Commission's capacity to monitor the implementation of civil service reforms rather than continuing to focus on reform programmes and formal institutional changes, which is insufficient to assess civil service professionalisation.

\section{Clarification and update of the European principles of administration}

At the time when civil service reform programmes were developed and civil service laws were adopted, the European principles of administration were largely uncontested as the dominant paradigm for the reform of the civil service. To be sure, administrative traditions differ widely among old EU member states and New Public Management was arguably the main source of reform inspiration in Western democracies in the 1990s. However, there was a wide consensus among policy makers and academics that a Weberian type bureaucracy is the most suitable reform model for transition and pre-accession states. SIGMA's and the European Commission's interpretation of the European principles of administration in accordance with a traditional continental Rechtsstaat model of public administration reflects this perspective.

This report has shown that the European principles of administration as applied by the European Commission and SIGMA have recently become increasingly contested in the Western Balkans by the growing popularity of managerialist ideas. This trend has become evident at the level of reform development, institutional reform and attitudes of civil servants. As the European principles of administration have slowly lost their hegemonic position in the administrative reform discourse, it has become increasingly difficult for the European Commission and SIGMA to influence the direction of reform.

The notion of European principles of administration was developed only in the late 1990s by SIGMA on behalf of the European Commission, in order to provide a model for the reform of public administration in accession countries. Apart from SIGMA Papers No. 23 and 27, article 41 of the European Charter of Fundamental Rights (Treaty of Lisbon) and the 2001 decision of the European Parliament on the principles of good administrative behaviour, there is no explicit formulation of the European principles of administration. A short 'baseline' prepared by SIGMA is the only attempt to operationalise the European principles at the level of institutional reform and management practices insofar as the civil service is concerned. ${ }^{20}$

Accordingly, European officials and international consultants, as well as domestic policy makers, have had considerable leeway in interpreting the institutional manifestation of the European principles. On the one hand, this flexibility has been praised by policy-makers, as it provides conditions for the context-sensitive application of the European principles of administration. On the other hand, it has undermined the clarity and consistency of the European guidelines for civil service reform. Moreover, the lack of clarity has made it difficult to monitor reform progress.

The negative consequences of a lack of clarity have become increasingly evident over the last few years. The European principles have continuously been re-interpreted and adapted, leading to a situation in which even the de-regulation of civil service tenure rules in the former Yugoslav Republic of Macedonia is regarded as compatible by domestic policy-makers. Similarly, the renewed attempt of the government of $\mathrm{FBiH}$ to turn top senior civil service positions into political appointments by means of changing the Civil

20

The analytical framework of this report (Part 2) seeks to further specify and operationalise the European principles of administration insofar as civil service management is concerned. 
Service Law has created difficulties for European Commission officials and international consultants to provide clear feedback and guidelines for the revision of legal drafts.

Under these conditions, the European Commission might want to review, update and above all clarify the content of the European principles of administration. Thirteen years after the formulation of the principles for a European Administrative Space, there is scope for an update that takes into account lessons from fifteen years of international engagement in public administration reform in pre-accession states and recent international trends, in order to regain a status as a set of modern reform principles. Moreover, there is plenty of evidence that supports the benefits of an impartial, professional and depoliticised civil service in transition and pre-accession states and hence to renew the message in favour of the European principles of administration for the Western Balkan governments.

Any clarification of the European principles will require closer attention to their institutional manifestation in order to provide clearer guidelines for Western Balkan governments and to facilitate the oversight of reform and implementation. Indeed, the timing for a rejuvenation of the European principles as an initiative for better governance in the EU and its neighbourhood could not be better. The crisis of the European currency has directed attention back to the quality of public administration, even amongst the old member states. 